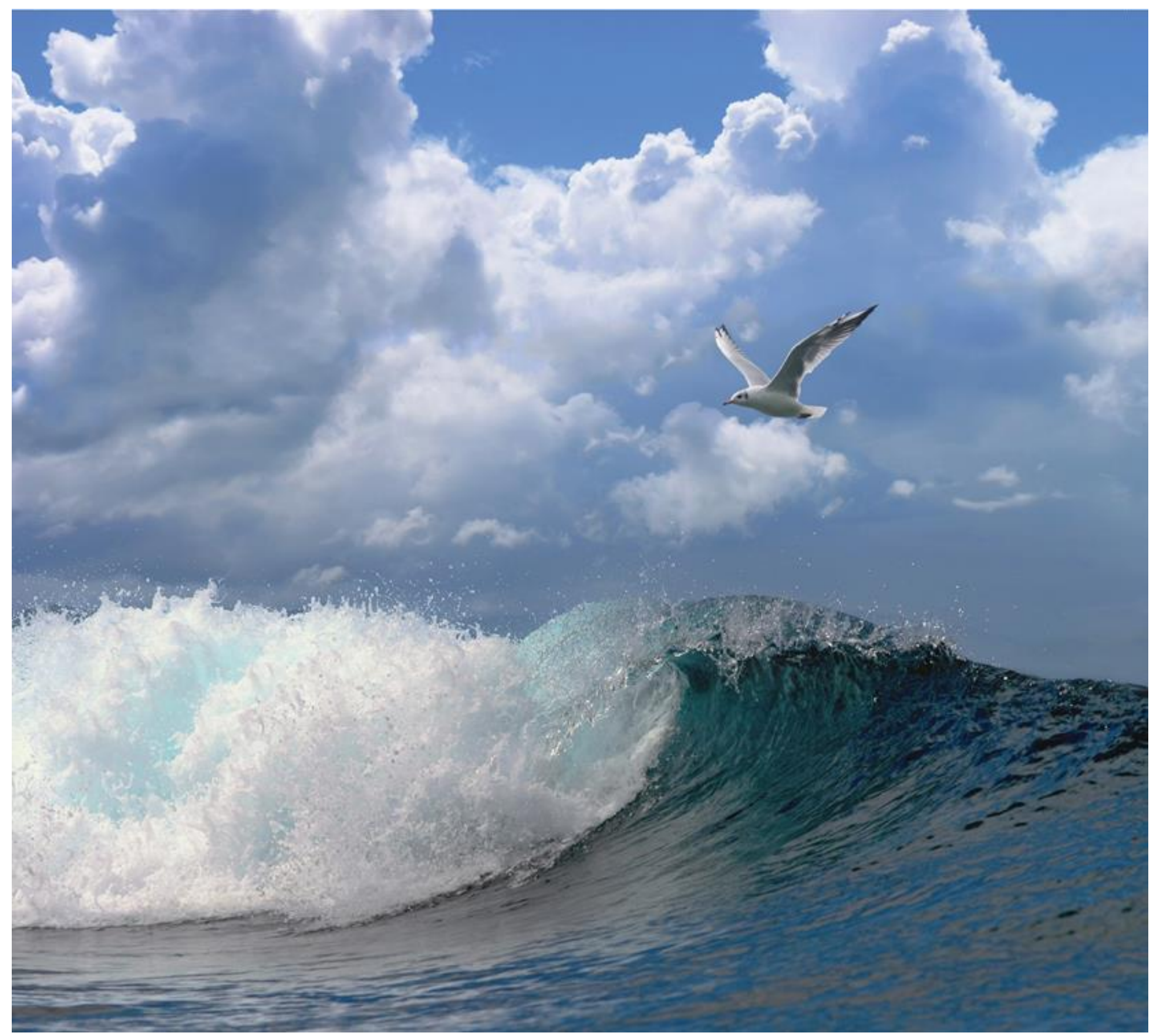

\title{
Cumulative impacts of wind farms on the North Sea ecosystem
}




\section{Cumulative impacts of wind farms on the North Sea ecosystem}

Authors: Piet G.J., Tamis J.E., van der Wal J.T., Jongbloed R.H 
Keywords: Cumulative effects assessment, ecosystem based approach, offshore wind farm, energy transition, future scenarios, vulnerability, carrying capacity, marine spatial planning

Client: $\quad$ WWF-NL

Attn.: Jonna van Ulzen

PO Box 7

3700 AA, Zeist

The Netherlands

This report can be downloaded for free from https://doi.org/10.18174/556024

Wageningen Marine Research provides no printed copies of reports

Wageningen Marine Research is ISO 9001:2015 certified.

\section{(C) Wageningen Marine Research}

Wageningen Marine Research, an institute within the legal entity Stichting Wageningen Research (a foundation under Dutch private law) represented by

Drs.ir. M.T. van Manen, Director Operations

KvK nr. 09098104,

WMR BTW nr. NL 8113.83.696.B16.

Code BIC/SWIFT address: RABONL2U

IBAN code: NL 73 RABO 0373599285
Wageningen Marine Research accepts no liability for consequential damage, nor for damage resulting from applications of the results of work or other data obtained from Wageningen Marine Research. Client indemnifies Wageningen Marine Research from claims of third parties in connection with this application.

All rights reserved. No part of this publication may be reproduced and / or published, photocopied or used in any other way without the written permission of the publisher or author.

A_4_3_2 V31 (2021) 


\section{Contents}

1 Introduction

$\begin{array}{llr}1.1 & \text { Background } & 8\end{array}$

1.2 Objectives $\quad 8$

$\begin{array}{llr}1.3 \text { Scope } & 9\end{array}$

$\begin{array}{lll}\text { 1.3.1 Study area } & 9\end{array}$

$\begin{array}{lll}1.3 .2 & \text { Scenarios } & 9\end{array}$

$\begin{array}{lll}1.3 .3 & \text { Reading guide } & 9\end{array}$

$2 \quad$ North Sea spatial data inventory $\quad 11$

2.1 Human activities $\quad 11$

$\begin{array}{lll}2.2 & \text { Ecosystem components } & 13\end{array}$

$\begin{array}{llr}3 & \text { Impact assessment future scenarios } & 18\end{array}$

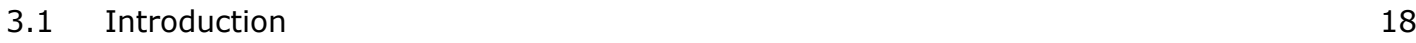

3.2 Scenarios $\quad 18$

$\begin{array}{ll}3.3 \text { Method } & 20\end{array}$

3.4 Pressures caused by offshore wind farms on the North Sea ecosystem 22

$\begin{array}{lll}3.5 & \text { Impacts of human activities on the North Sea ecosystem } & 25\end{array}$

$\begin{array}{lll}3.5 .1 & \text { Relative contribution of activities } & 25\end{array}$

3.5.2 Relative vulnerability of ecosystem components $\quad 27$

3.5.3 Relative impact of Marine Protected Area (MPA) measures 28

$\begin{array}{lll}3.6 & \text { Relevance for policy } & 31\end{array}$

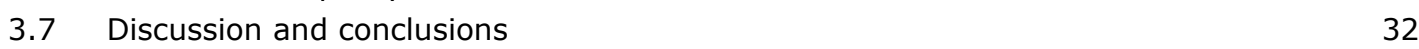

$\begin{array}{lll}3.7 .1 & \text { Methodology } & 32\end{array}$

$\begin{array}{lll}3.7 .2 & \text { Results } & 34\end{array}$

$4 \quad$ Future implications $\quad 35$

$\begin{array}{lll}4.1 & \text { Introduction } & 35\end{array}$

4.2 Carrying capacity of the North Sea ecosystem $\quad 35$

4.2.1 Concept of carrying capacity $\quad 35$

4.2.2 Policy and management $\quad 36$

4.2.3 Carrying capacity: Top-down perspective $\quad 37$

4.2.4 Carrying capacity: Bottom-up perspective 38

4.2.5 Recommendations and the way forward 41

4.3 Ecosystem-based approach to maritime spatial planning 42

$5 \quad$ Conclusions and recommendations $\quad 46$

$\begin{array}{llr}6 & \text { Quality Assurance } & 48\end{array}$

$\begin{array}{lr}\text { References } & 49\end{array}$

$\begin{array}{lr}\text { Justification } & \mathbf{5 2}\end{array}$ 
Annex 1 Spatial information and maps for human activities and protected nature areas in the North Sea

Annex 2 Spatial information and maps for habitats and species in the North Sea

Annex $3 \quad$ Impact risk criteria

66

Annex $4 \quad$ Knowledge on cause-effect relationships

67

Annex 5 Introduction to maritime spatial planning (MSP) and the ecosystem based approach (EBA)

71 


\section{Executive summary}

\section{STUDY OBJECTIVES}

Several human activities at the North Sea are expected to change in the coming thirty years, with a fast upscaling of offshore wind energy. The objectives of this study are to evaluate for the North Sea marine ecosystem the knowledge base to assess the cumulative impacts of all the main human activities under various planning scenarios. The aim is also to assess specific scenarios (until 2030 and 2050) supposed to accommodate this offshore wind upscaling process. To that end a Cumulative Impact Assessment (CIA) is applied and the outcomes are interpreted in relation to the achievement of (EU) biodiversity targets, and the concept of carrying capacity for the North Sea ecosystem. In addition we discuss the possibilities to apply CIA in the context of an ecosystem-based approach to marine spatial planning aimed at achieving existing environmental marine policy goals.

\section{RESULTS: MAIN OUTCOMES}

This report provides an overview of the state-of-the-art knowledge to assess current and future cumulative impacts of all the main human activities on the North Sea ecosystem. It consists of the description of a robust risk-based approach (explained in the methods section), where its application in the North Sea context identified many knowledge gaps in terms of quantitative data (e.g. spatial distributions) or understanding of various relationships (e.g. pressure on ecosystem component). As such, much of the knowledge is still mostly expert judgement-based but now with the advantage of having a formalised methodology that can guide further scientific research to, in time, provide the information required and (further) improve the quality of such Cumulative Impact Assessments (CIAs).

\section{RESULTS: SCENARIOS AND MAPS}

In order to compose the future scenarios for application in the CIA, an overview is compiled of the expected developments of wind energy and other main human activities across the North Sea until 2030 and planned for 2050. In doing this assumptions had to be made due to lacking information for some of the activities in several of the national EEZ's of the North Sea. For the sake of transparency all the information is available and access is provided to a set of maps of the North Sea showing current and anticipated spatial plans for wind farms, other human activities, N2000 areas. In addition we provide maps of the spatial distributions of the main ecological system components (seabed habitats including their benthic communities, fish, birds, marine mammals) based on state-of-the-art information.

\section{RESULTS: CUMULATIVE IMPACTS}

The results of this study have identified for the North Sea ecosystem the main threats caused by human activities and their pressures as well as the vulnerability of its main components, i.e. species, species groups or habitats (consisting of both a biotic and abiotic part), now and in the future. It should be noted that this CIA only includes direct effects from anthropogenic pressures on the ecosystem components, this implies that any indirect or secondary effects on other components such as through the food web are not included.

From this North Sea scale analysis bottom trawl fisheries still emerge as the human activity that poses the biggest threat to the ecosystem. In comparison the potential threat caused by the offshore wind developments are relatively small. However, several considerations apply here. Firstly, offshore wind may have significant local impacts that do not show up at a North Sea scale CIA. The potential threat caused by any emerging activity like offshore wind (or aquaculture as part of multi-use initiatives) occur in addition to those already present. This implies that without reduction of the activities already present the overall threat will only increase and hence the likelihood that environmental goals are achieved will decrease. Moreover, any emerging activity has consequences for the space available for other activities such as fisheries. Therefore any environmental impact assessment should always apply an integrated perspective which includes all activities. Planning of future scenarios for new or emerging activities should not occur in isolation. 
The most vulnerable ecosystem components are the seafloor habitat with its benthic community as well as the fish community. This is mostly caused by the widespread extent of the fishing activities. Although vulnerability is expected to decrease for both ecosystem components (as well as for the water column) under future scenarios, our assessment shows that they remain the two most vulnerable ecosystem components of the North Sea. In contrast, other habitats, birds and mammals show a slight increase in their vulnerability by 2050 . The plans for offshore wind (both installation and operation) are primarily expected to affect marine mammals and fish.

Future designation of MPAs are expected to mostly reduce the impact caused by benthic fisheries and can therefore be instrumental in offsetting (part of) any additional threat caused by the emerging activities.

\section{RELATIONSHIP WITH BIODIVERSITY STATUS INDICATORS}

There is no one-to-one relationship between the result of this (or any other) CIA and the state of the North Sea in terms of the requirement of the MSFD to achieve Good Environmental Status (GES). The reason for this is that the current state of the ecosystem (e.g. in terms of biodiversity) is caused by the historic and ongoing activities and their pressures while its future state will depend on the future scenarios of those activities in combination with the effects of exogenous drivers (such as climate). Understanding cumulative impacts in a changing context is a major knowledge gap.

The results of this CIA can be used to assess the likelihood of achieving environmental goals through the direction of the change in impact risk. With increasing impact risk, the likelihood to achieve these goals will decrease. Considering that currently most of the objectives for GES are not achieved only a decrease in overall impact risk may succeed in achieving these objectives. What specific level of change is required or how long it would take before these objectives could be achieved cannot be predicted.

\section{GEOGRAPHICAL SCALE}

This CIA is applied in a regional context, i.e. at the scale of the North Sea. Therefore the results only reveal the main threats at this regional scale whereas a smaller local scale focus might reveal other threats more relevant in the national context or for specific MPA or MSP initiatives. While the CIA methodology is suited to provide local-scale information this comes with considerable demands in terms of the spatial distribution of activities, their pressures and the ecosystem components (often species) that may be impacted. That information is now mostly lacking, certainly at a scale required to inform specific MSP initiatives like the ones now taking place in several North Sea countries. With additional information made available a (more) spatially-explicit CIA can be used to guide such MSP processes. The current CIA can direct science to the main information gaps.

\section{LEVEL OF DETAIL AND AGGREGATION}

Currently the CIA applies fairly crude groupings of whole sectors and broad ecosystem components. More detail may add realism to the analysis or improve the relevance for specific stakeholders. For example specific sectors can be split up in increasingly smaller sub-groups (e.g. benthic fisheries into specific metiers like bottom trawl, dredge or beamtrawl or fish into demersal and pelagic fish or even specific species). This, however, requires considerable effort (and thus expenses) to collect the information. Moreover, adding more detail without adequate data will probably only compromise the ability of the CIA to provide guidance as the increased level of detail comes with increased uncertainty. A stakeholder involvement process should inform what is an appropriate level of detail.

\section{CARRYING CAPACITY}

Cumulative impacts are sometimes considered in relation to the concept of carrying capacity but without any clear definition. Based on a literature review of ecological carrying capacity we distinguished two perspectives on the concept:

- A bottom-up perspective where the abundance of each ecosystem component is primarily limited by the availability of resources.

- A top-down perspective where the abundance of each ecosystem component is determined by the cumulative impact caused by all human activities acting on the ecosystem.

The current CIA primarily applies the top-down perspective as this is considered most relevant in the context of environmental impact assessments. Thus carrying capacity is defined as the maximum 
amount of human activities (and their cumulative pressures) the ecosystem can support without leading to significant deterioration of ecological processes, species, populations, communities, or biodiversity in the environment. As there is, as yet, no scientific basis for what constitutes "significant deterioration" we only assess impact as the change in ecosystem state without any indication if this is acceptable, also in relation to carrying capacity, or not. By definition, a significant deterioration would imply that environmental goals (e.g. GES) are not achieved.

\section{ECOSYTEM BASED APPROACH FOR MARINE SPATIAL PLANNING}

Maritime or marine spatial planning (MSP) and ecosystem-based approaches (EBA) are now widely seen as the means to "promote the sustainable growth of maritime economies, the sustainable development of marine areas and the sustainable use of marine resources with the aim of ensuring that the collective pressure of all activities is kept within levels compatible with the achievement of good environmental status and that the capacity of marine ecosystems to respond to human-induced changes is not compromised" (From EU MSP Directive).

This report provides an introduction to EBA and MSP mostly based on a recently published practical approach to MSP: Study on Integrating an Ecosystem-based Approach into Maritime Spatial Planning (EBA-MSP) commissioned by the European Commission. This showed CIA to be among the key tools to apply as part of EBA-MSP and thus any planning of offshore wind farms or MPAs. In the context of providing guidance of the type of EBA-MSP initiatives that come with the rollout of offshore wind, the role of CIA should be to provide strategic advice, i.e. high-level, cross-sectoral and ecosystem-wide. This should then focus further scientific efforts and more elaborate modelling towards the mitigation of those activities/pressures that provide the biggest threat to (specific parts of) the ecosystem. These more detailed, often sector-specific, models can then be applied to operationalise this guidance for the regulatory process informing sectoral management. EBA-MSP requires the combination of a fully integrated perspective as provided by e.g. CIA with additional more detailed analysis and models that focus on one or more subsets of the ecological (or better social-ecological) system. 


\section{Introduction}

\subsection{Background}

One of the biggest changes in the North Sea ecosystem in the coming thirty years is the upscaling of offshore wind energy (including energy hubs, connectors, cables, jacket structures, islands, etc.). WWF would like to have an overview of how many wind farms will be built across the entire North Sea basin in the next ten years (until 2030), get an approximation of the cumulative impact this upscaling is expected to have on the marine ecosystem of the North Sea in its current state and relate these effects to the achievement of (EU) biodiversity targets (including reaching good environmental status MSFD; Natura 2000 network of marine protected areas). WWF approached Wageningen Marine Research (WMR) to conduct a study in order to provide such a regional overview. This report is the result of that study.

\subsection{Objectives}

The study is aimed at the following objectives:

The first main objective requires 3 layers/maps that can be viewed separately and together (in an overlaying manner):

1. map showing the current and anticipated wind farm projects until 2030/50;

2. map showing all Natura 2000 areas (also current and by 2030/50);

3. wildlife and habitat sensitivity maps, showing the distribution of all ecosystem components, being seabed habitats, water column habitats, plankton, benthic invertebrates, fish, birds and marine mammals (including bats).

The second main objective focuses on the evaluation of cumulative impacts of all human activities (taking account of their location, and if relevant distinguishing construction, operation and decommission) on the North Sea marine ecosystem until 2030 and recommendations on the further development of approaches for cumulative impacts (assessments) based on the results:

1. List cumulative impacts in a table(and indicating whether they can/will be additive $(1+1=2)$, antagonistic $(1+1<2)$ or synergistic $(1+1>2)$;

2. Cumulative Effect Assessment (CIA) of existing and planned windfarms (size and implications) in relation to impact of all existing offshore activities;

3. Relation between expected (cumulative) effects/impacts and the (EU) biodiversity targets (N2000 and MSFD).

The third main objective is addressing the question "What are the implications of further upscaling offshore wind energy after 2030 for the North Sea ecosystem considering the identified cumulative impacts?". More specifically, the discussion should consider:

- $\quad$ The concept of carrying capacity in relation to the North Sea ecosystem.

- An ecosystem-based approach to marine spatial planning of offshore wind and other marine activities aimed at achieving existing environmental marine policy goals.

With the results of this study WWF intends to advise industry and governments on how to deal with these effects in a responsible manner that ensures a sustainable use of the North Sea. 


\subsection{Scope}

\subsubsection{Study area}

This study aims to cover the Greater North Sea as defined in the Marine Strategy Framework Directive (MSFD) but for practical reasons has excluded the most northern part (part of the Exclusive Economic Zones (EEZ) of Great Britain and Norway) and the Kattegat (between Denmark and Sweden).

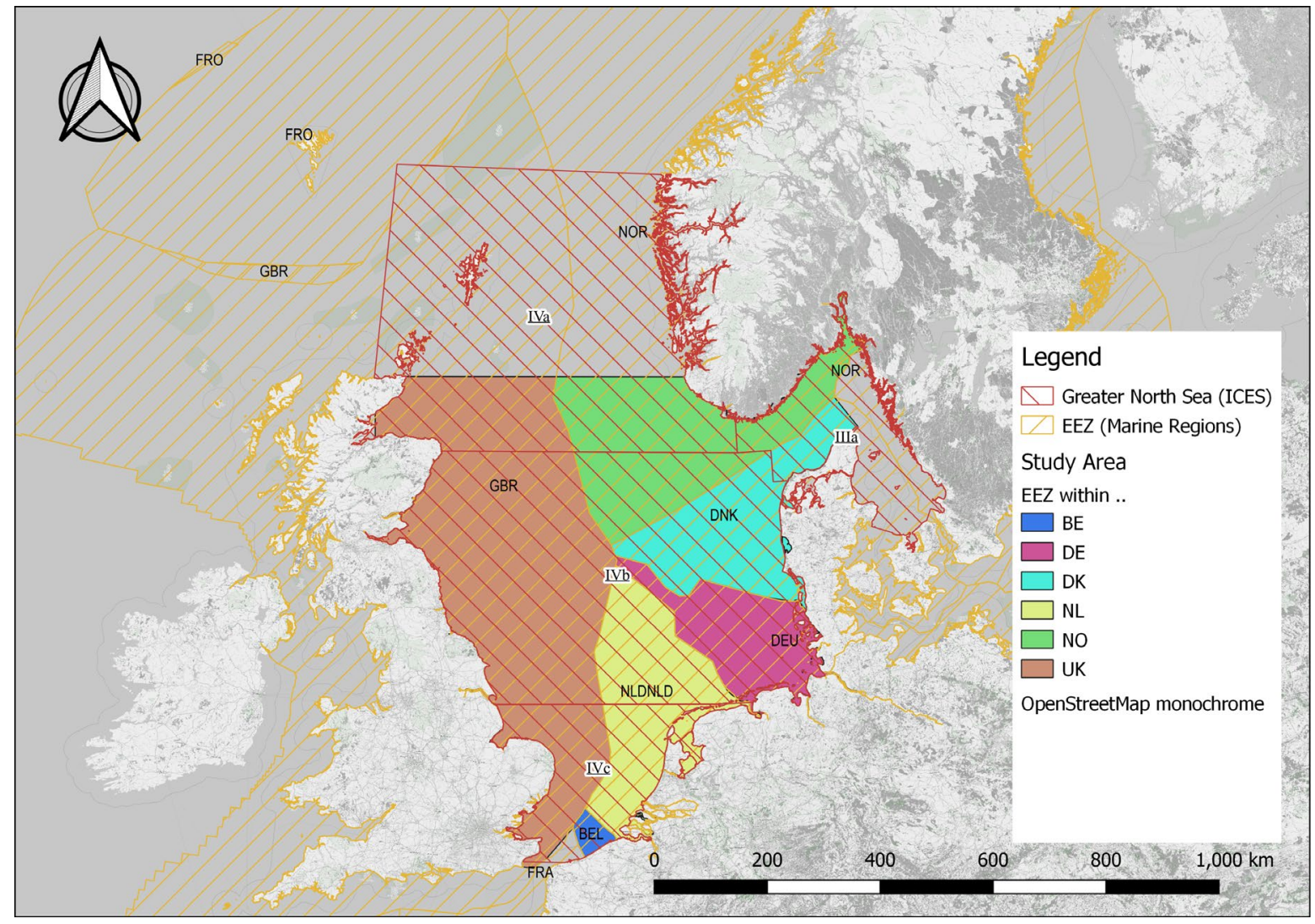

Figure 1 Study area

The selected study area has relatively good data availability (certainly compared to other EU marine regions), which weakens going further north into the ICES-area IVa. This area also has increasingly deep waters and for the past decade and the first upcoming decade limited development of (floating) offshore wind parks is foreseen. By opting to not include small patches of EEZ from further countries (e.g. France, Sweden) the burden of collecting information on renewable energy-development, rules and legislation is reduced. The Danish part of area IIIa, i.e. Kattegat, was not included because this is part of what within Denmark is considered 'inner waters' and as such has more interest and eagerness in country for development.

\subsubsection{Scenarios}

Information for the baseline and the future scenarios for human activities on the North Sea is required for the CIA. The description of the baseline situation (around the year 2017) is part of this study and thus its information requirements are covered by WMR. The information for the future scenarios (2030 and 2050) is collected for each country separately and compiled by the WWF representatives from various WWF offices. The human activities of interest are: Wind farms; Oil \& Gas; Cables \& Pipelines; Protected nature areas; Fishery; Aquaculture; Sand extraction; and Shipping (shipping routes). This study only includes these activities, all other activities on the North Sea are disregarded.

\subsubsection{Reading guide}

The table below (Table 1 ) shows the main objectives (see previous section 1.2 ) for this study and how these are addressed in the report. 
Table 1 Study objectives included in this report

\begin{tabular}{|c|c|c|}
\hline Study objective & Chapter & Report content \\
\hline 1: Maps & 2 & $\begin{array}{l}\text { Inventory of the available spatial } \\
\text { information, i.e. maps, of the North Sea, } \\
\text { showing: } \\
\text { - Wind farms (current and anticipated } \\
\text { until 2030/50); } \\
\text { N2000 areas (current and } \\
\text { anticipated); } \\
\text { Distribution of the main ecosystem } \\
\text { components: seabed habitats } \\
\text { including their benthic communities, } \\
\text { fish, birds, marine mammals, and } \\
\text { bats. }\end{array}$ \\
\hline \multirow{4}{*}{ 2: CIA } & 3.4 & $\begin{array}{l}\text { A table listing all relevant pressure - } \\
\text { ecosystem component relationships } \\
\text { caused by offshore windfarms. }\end{array}$ \\
\hline & 3.5 & $\begin{array}{l}\text { A CIA of existing and planned windfarms } \\
\text { (size) in relation to impact of all existing } \\
\text { offshore activities. The output of the CIA } \\
\text { will be presented as bar charts. }\end{array}$ \\
\hline & 3.6 & $\begin{array}{l}\text { An overview of the links between the } \\
\text { ecosystem components and pressures } \\
\text { included in the CIA and the EU policy } \\
\text { objectives of Natura } 2000 \text { (N2000) and } \\
\text { the Marine Strategy Framework Directive } \\
\text { (MSFD, i.e. Good Environmental Status } \\
\text { (GES) Descriptors). This will provide an } \\
\text { indication of the relation between } \\
\text { expected (cumulative) effects and the } \\
\text { (EU) biodiversity targets (N2000 and } \\
\text { MSFD). }\end{array}$ \\
\hline & 3.7 & $\begin{array}{l}\text { Recommendations, gaps in knowledge } \\
\text { and limitations of assessing and } \\
\text { managing cumulative impacts/effects } \\
\text { (priority) }\end{array}$ \\
\hline 3: Future implications & 4 & $\begin{array}{l}\text { Elaboration on the following topics: } \\
\text { - The concept of carrying capacity and } \\
\text { how to assess the maximal carrying } \\
\text { capacity of the North Sea } \\
\text { ecosystem; } \\
\text { - An ecosystem-based approach to } \\
\text { marine spatial planning of offshore } \\
\text { wind and other marine activities } \\
\text { aimed at achieving existing } \\
\text { environmental marine policy goals. }\end{array}$ \\
\hline
\end{tabular}




\section{North Sea spatial data inventory}

The risk-based approach applied in this report systematically disentangles risk into its exposure and effect components. Exposure is estimated as the level of spatial overlap between on the one hand the human activities and their pressures and on the other hand all the ecosystem components that together make up marine biodiversity. This may be based on actual data if information on the spatial distribution of pressures or species is available, otherwise this will be based on the perceived overlap based on expert judgement. Below we present the available information on the spatial distributions of human activities and their pressures as well as the spatial distributions of the ecosystem components. Note that availability of appropriate and accurate information (spatial distributions or otherwise) is a major issue that determines the accuracy of this assessment method. Therefore we always provide information on the source of the information that is applied in the method. This may not always reflect the latest changes or current state but, ideally, should be the most reliable source and up-to-date source. If better alternatives exist and can be made available they can be easily included in the method to replace outdated or less reliable information. This is an ongoing process part of the adaptive development of the assessment method.

\subsection{Human activities}

A selection was made of the main human activities taking place in the North Sea. This selection was based on the findings in publications about the relative contribution of a broad range of many human activities to the cumulative impacts on nature values of the North Sea (Knights et al., 2015; Borgwardt et al., 2019). These selected human activities are included in the CIA developed and applied in the present study which is elaborated in chapter 3. The selection was discussed and agreed with WWF in the preparation phase of this study.

For that CIA it was necessary to assess the spatial extent at a North Sea scale and therefore an inventory was carried out on the available spatial information, i.e. maps, for the selected human activities and marine protected areas (MPAs) on the North Sea for the baseline situation as well as anticipated until 2030/2050. An overview of the results of this inventory can be found in Annex 1 . In this paragraph we also show a map for baseline and planned offshore wind farm areas (Figure 2), a map of trawling intensity (Figure 3 ) and a map for the MPAs (Figure 4). 


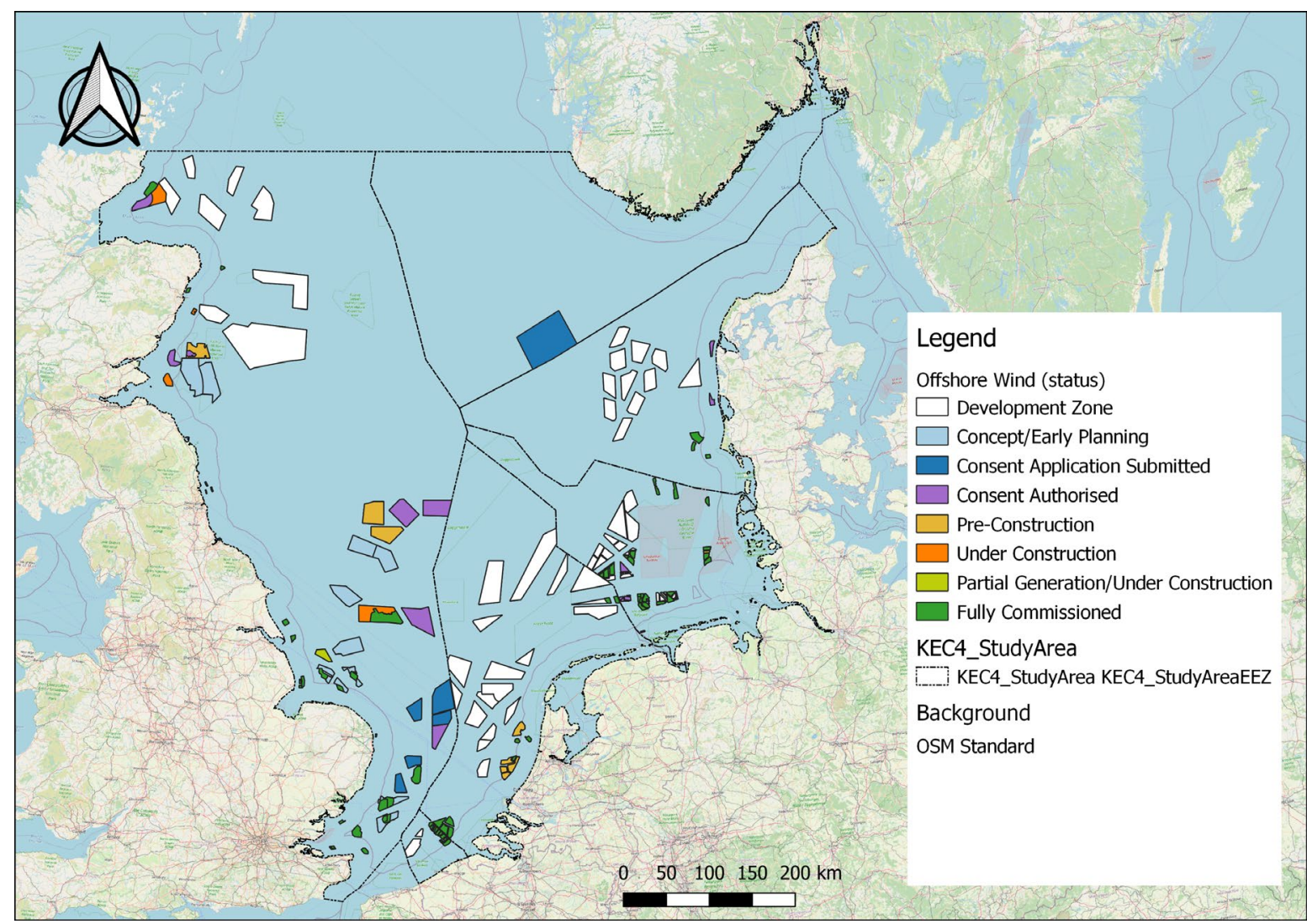

Figure 2 Offshore wind farms, by status. Development zone, mostly past 2030, Concept/Early Planning ca. 2025-2030.

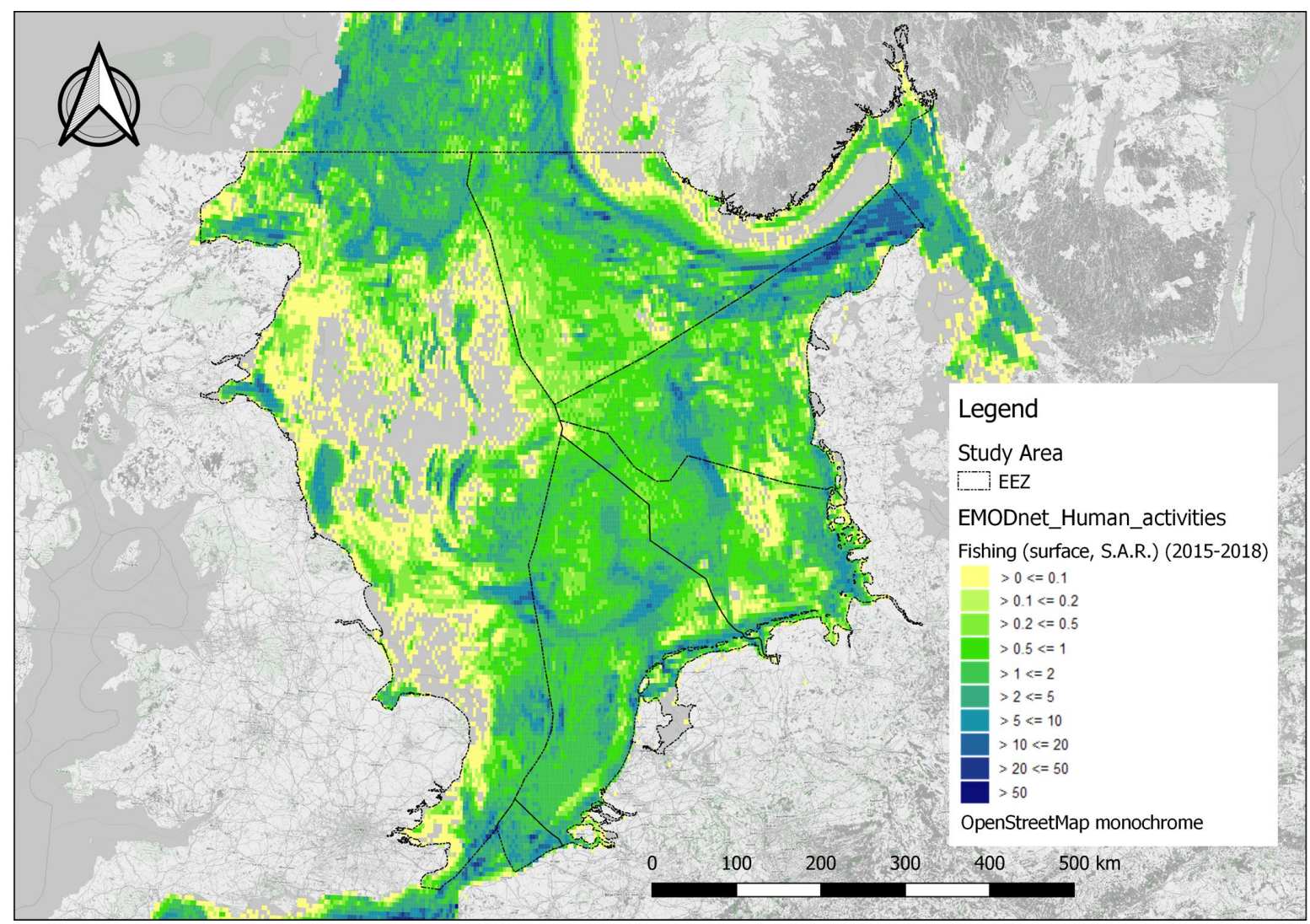

Figure 3 Spatial distribution of trawling intensity (annual swept area ratio, SAR) in the North Sea study area (based on data from EMODnet). 


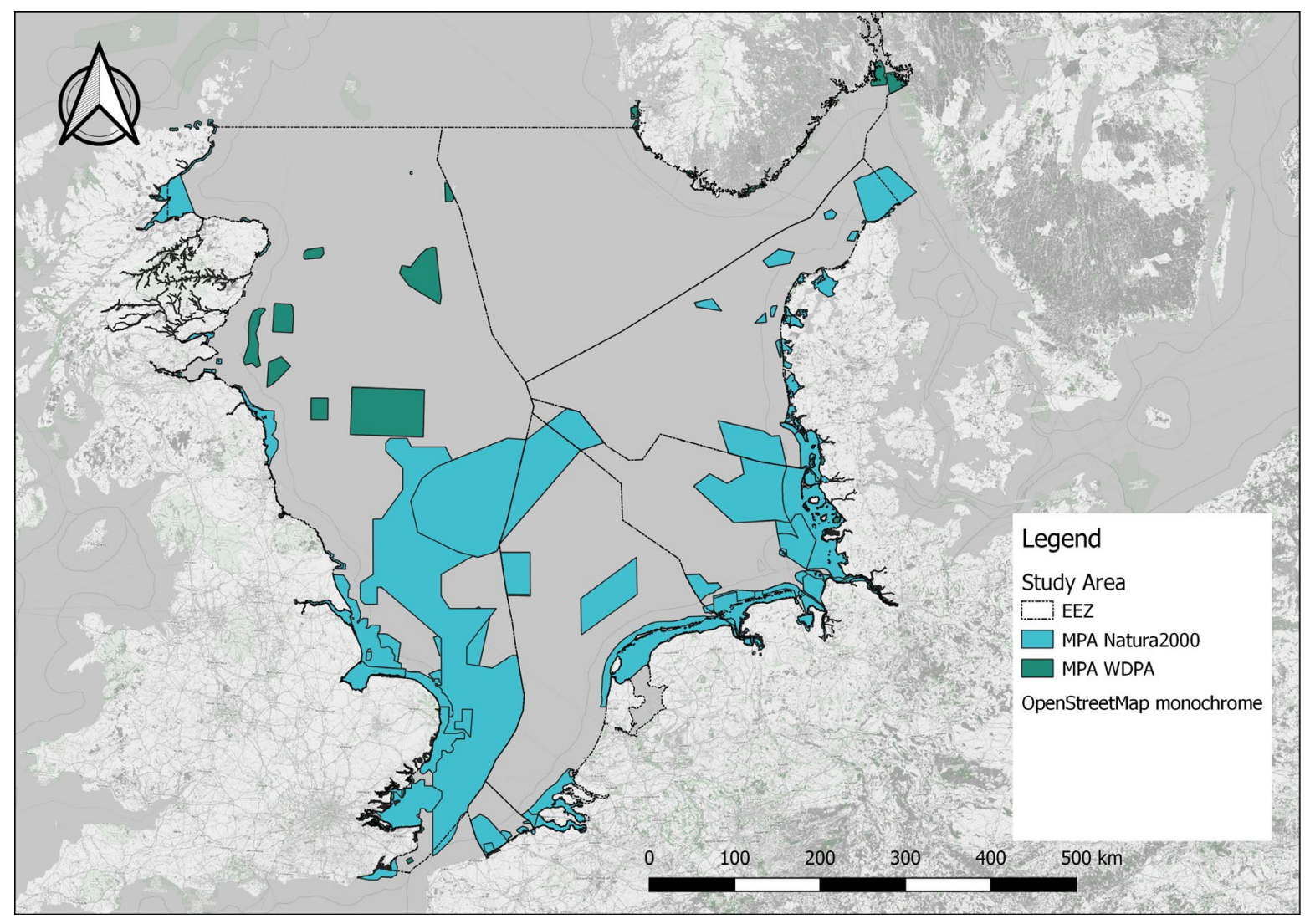

Figure 4 Marine Protected Areas (nature conservation areas), as recorded by the EEA (2019) or the WDPA (World Database of Protected Areas) (2016). Note that this reflects the status of 2019 thus recently designated areas are not included. Annex 1 shows the MPA designated up to March 2021 in the Netherlands.

\subsection{Ecosystem components}

An overview of the information on the spatial distribution of the main ecosystem components in the North Sea can be found in Annex 2: This comprises the major habitats, fish and seabirds, as well as some species of marine mammals. In this section maps are shown for a selection, namely seabed habitats Figure 5), sea birds (Figure 6), harbour porpoise (Phocoena phocoena) (Figure 7), and fish (Figure 8). Other available maps can be found in Annex 2.

It should be realised that the spatial coverage and quality of spatial distribution maps often differs highly among species and species groups but may be improved in the future by the availability of new monitoring data. For instance the map for the seabirds shown here (Figure 6) is a wind turbine sensitivity index (WSI) map. The wind turbine sensitivity is an integration of the spatial distribution density of approximately 30 sea bird species and their sensitivity towards wind turbines. However, this map only covers the southern North Sea. Spatial coverage could be improved in future because seabird density values are available for the entire North Sea (Van der Wal et al., 2011), although data quality differs between subregions within the North Sea. In 2018 updated seabird density maps have been made in $\mathrm{KEC}^{1}$ (Gyimesi et al., 2018; van der Wal et al., 2018) and in 2021 in KEC4 studies commissioned by the Dutch government). However, integration of the updated seabird density maps into a revised WSI-map was outside the scope of the KEC study.

\footnotetext{
${ }^{1}$ KEC: Kader Ecologie en Cumulatie (in English "The Framework for Assessing Ecological and Cumulative effects", see https://www.noordzeeloket.nl/en/functions-and-use/offshore-wind-energy/ecology/accumulation-ecological-effects/frameworkassessing-ecological-cumulative-effects/)
} 


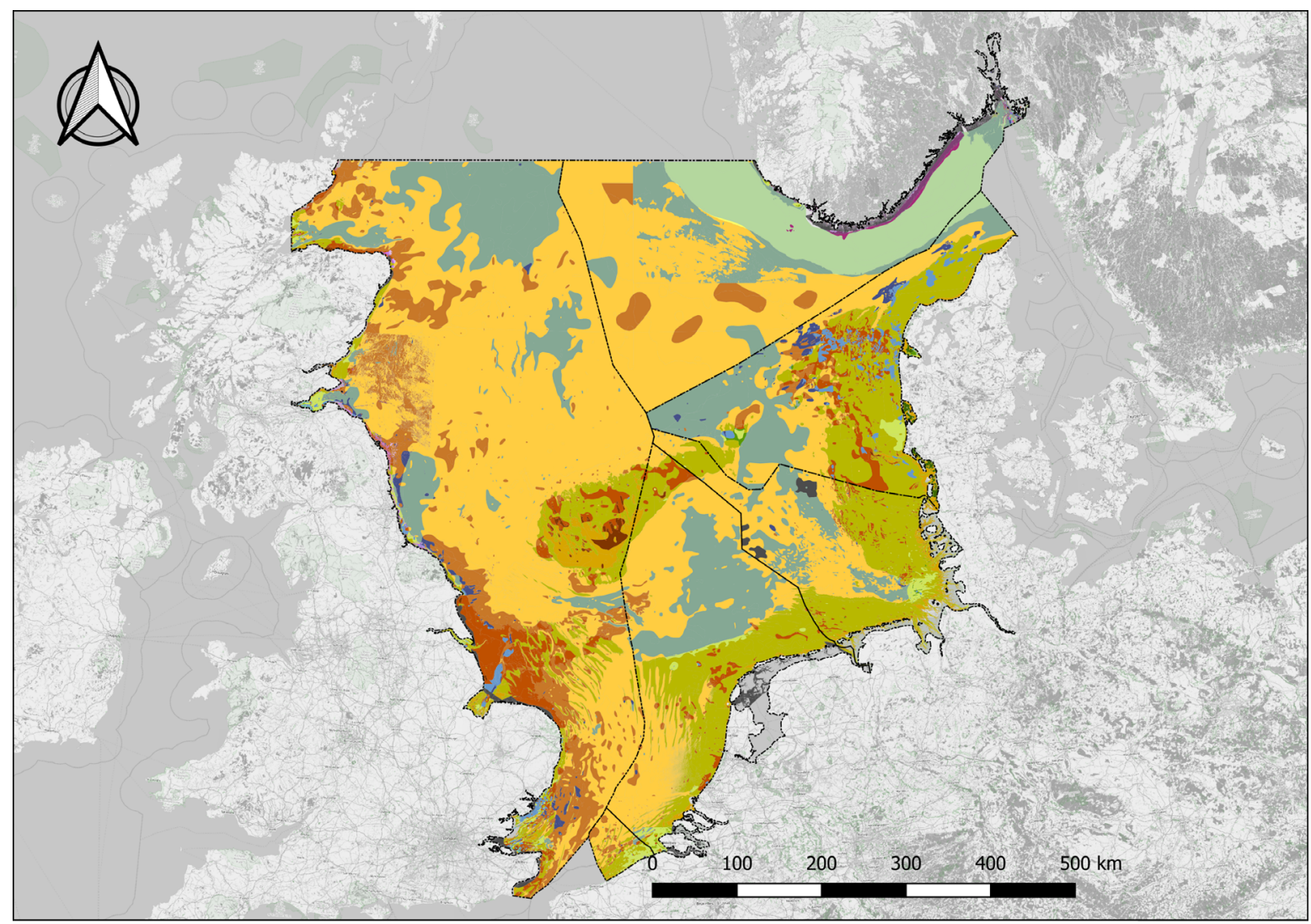

Legend

Study Area

S..... EEZ

\section{EMODnet_SeaMap2019_GNS}

EMODnet_SeaMap2019_GNS_fixedGeom_dipped

A3: Infralittoral rock and other hard substrata

A3.1: Atlantic and Mediterranean high energy infralittoral rock

A3.2: Atlantic and Mediterranean moderate energy infralittoral rock

A3.3: Atlantic and Mediterranean low energy infralittoral rock

A4: Circalittoral rock and other hard substrata

A4.1: Atlantic and Mediterranean high energy circalittoral rock

A4.12 or A4.27 or A4.33: Sponge comm. on deep circalittoral rock etc.

A4.2: Atlantic and Mediterranean moderate energy circalittoral rock

A4.27: Faunal communities on deep low energy circalittoral rock

A4.3: Atlantic and Mediterranean low energy circalittoral rock

A4.33: Faunal communities on deep low energy circalittoral rock

A5: Sublittoral sediment

A5.13: Infralittoral coarse sediment

A5.14: Circalittoral coarse sediment

A5.15: Deep circalittoral coarse sediment

A5.23 or A5.24: Infralittoral fine sand or muddy sand

A5.25 or A5.26: Circalittoral fine sand or muddy sand
A5.27: Deep circalittoral sand

A5.33: Infralittoral sandy mud

A5.33 or A5.34: Infralittoral sandy mud or fine mud

A5.34: Infralittoral fine mud

A5.35: circalittoral sandy mud

A5.35 or A5.36: Circalittoral sandy mud or fine mud

A5.36: Circalittoral fine mud

A5.37: Deep circalittoral mud

A5.43: Infralittoral mixed sediments

A5.44: Circalittoral mixed sediments

A5.45: Deep circalittoral mixed sediments

A6: Deep-sea seabed

A6.11: Deep-sea rock

A6.2: Deep-sea mixed substrata

A6.3 or A6.4: Deeps-sea sand or muddy sand

A6.5: Deep-sea mud

Non-valid habitat

OpenStreetMap monochrome

Figure 5 Seabed habitats in the North Sea study area (based on data from EMODnet). 


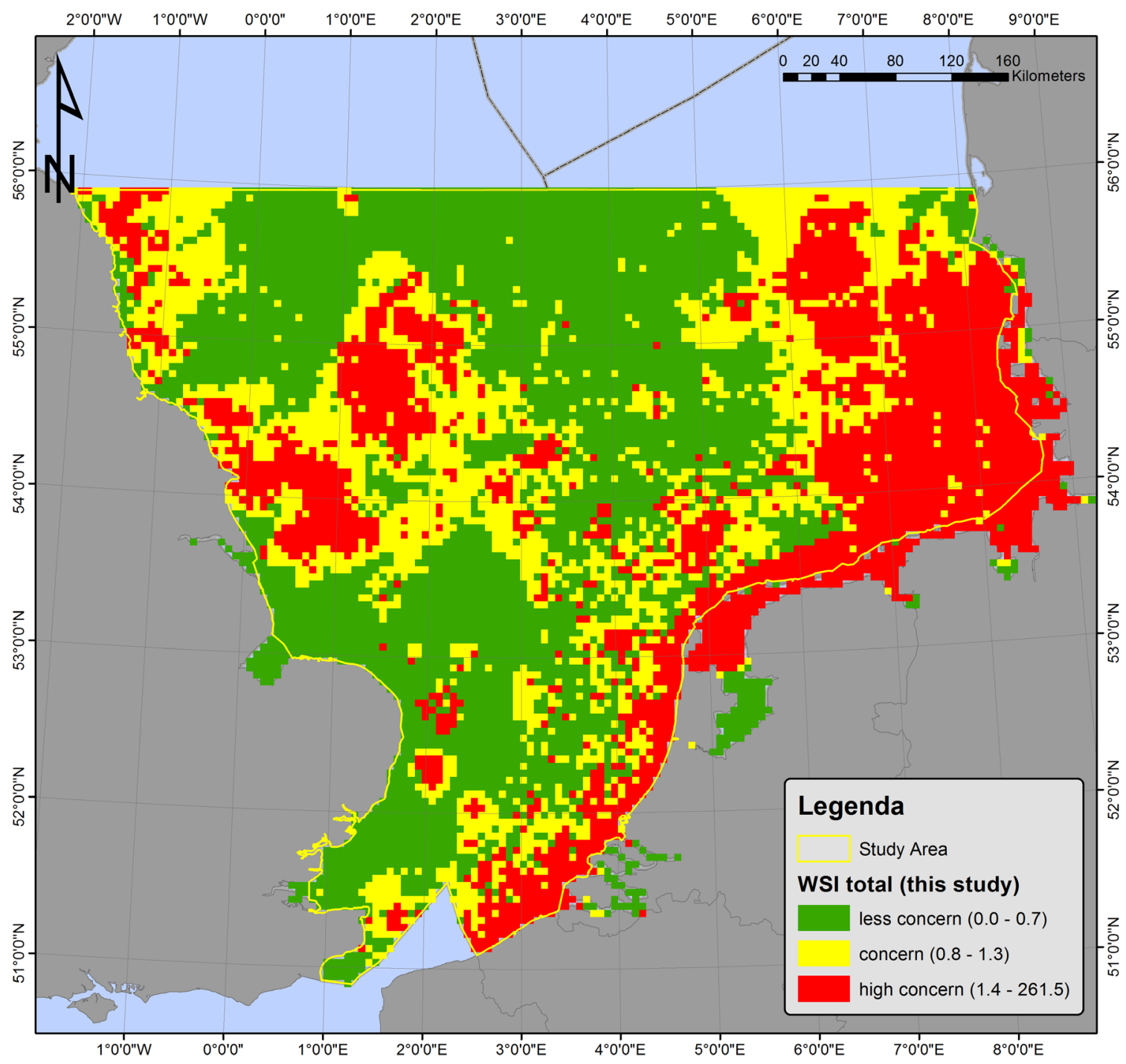

Figure 6 Windturbine Sensitivity Index (WSI) map for birds in the southern North Sea (Leopold et al., 2014). 


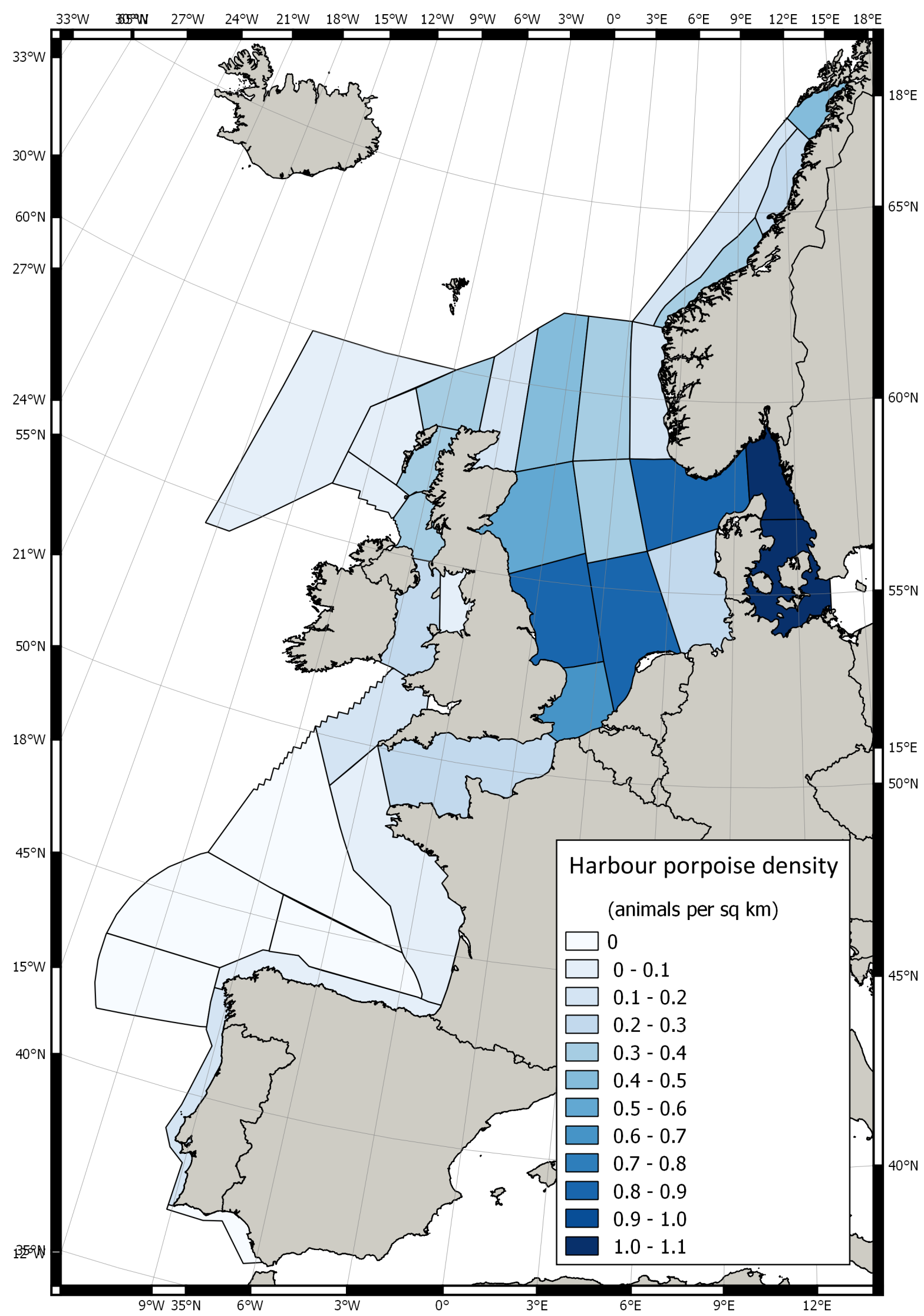

Figure 7 Distribution of Harbour porpoise (Phocoena phocoena) in the North Sea and adjacent areas (SCAN-III) (Hammond et al., 2018). 


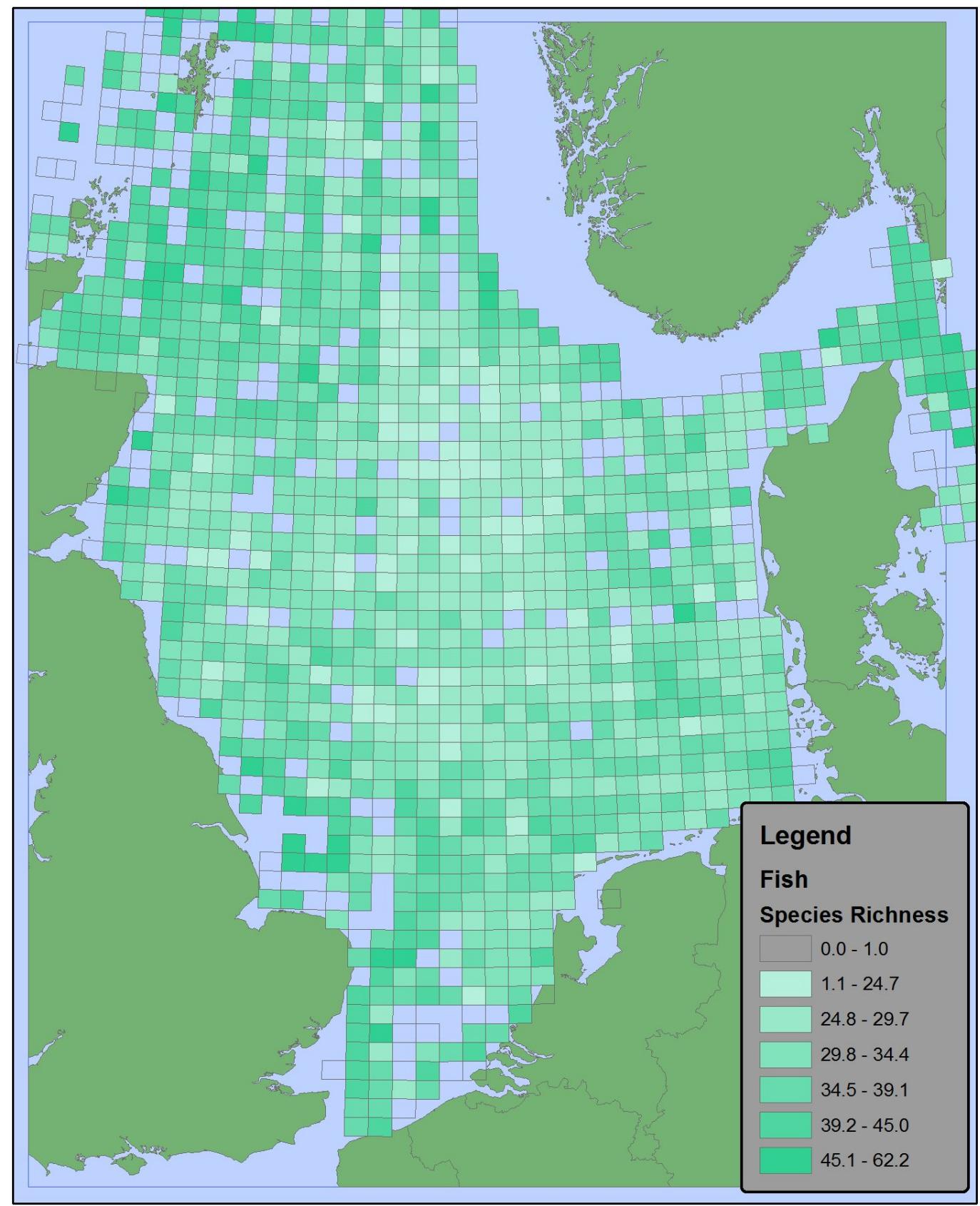

Figure 8 Species richness for fish (number of fish species) (van der Wal and Quirijns, 2011). Based on the International Bottom Trawl Survey (IBTS). This represents the whole fish community, not only commercial species. 


\section{Impact assessment future scenarios}

\subsection{Introduction}

This chapter provides an overview of the expected developments of wind energy and other activities across the North Sea until 2030 and planned for 2050. The future scenarios are described in section 3.2. They are the basis for the cumulative impact assessment of these developments on the future North Sea ecosystem compared to its baseline state. First, the method applied for the impact assessment is described (section 3.3). Next, the pressures caused by offshore wind farms are described (section 3.4) and included in the impact assessment. Results of the impact assessment are described in section 3.5.

To provide an indication of the relationship between expected (cumulative) impacts and biodiversity targets, an overview is provided of the links between the ecosystem components and pressures included in this impact assessment and the EU policy objectives, specifically those of Natura 2000 (N2000) and the Marine Strategy Framework Directive (MSFD, i.e. Good Environmental Status (GES) Descriptors), see section 3.6.

Finally, results are discussed in section 3.7. This section also includes limitations, gaps in knowledge and recommendations.

\subsection{Scenarios}

The impact of wind energy is assessed relative to the impact of other marine activities on the North Sea. The sectoral activities (i.e. Wind farms, Oil \& Gas, Cables \& Pipelines, Fishery, Aquaculture, Sand extraction, Shipping) and management measures (i.e. Protected nature areas) of interest were identified before the start of this study (see section 1.3.2). These sectoral activities may involve multiple sub-activities (see Table 2) which are based on the North Sea activities according to (Borgwardt et al., 2019). 
Table 2 Sectoral activities and their sub-activities on the North Sea (Borgwardt et al. 2019) as they are included in the assessment

\begin{tabular}{|c|c|c|c|}
\hline $\begin{array}{l}\text { In-situ } \\
\text { aquaculture }\end{array}$ & Aqua_In & $\begin{array}{l}\text { Fin-fish - operational (waste products, anti-fouling, predator } \\
\text { control, disease and disease control, infrastructure effects on local } \\
\text { hydrography, escapees, litter, anchoring/mooring of boats) }\end{array}$ & Operational \\
\hline
\end{tabular}

Fin-fish - set-up (atmospheric emissions for transport of brood Installation/removal stock/juveniles, interaction with seafloor during set-up of infrastructure, loss of gear)

Macro-algae - operational (waste products, anti-fouling, predator control, disease and disease control, infrastructure effects on local hydrography, litter, anchoring/mooring of boats)

Macro-algae - set-up (atmospheric emissions from boats (certain species), trampling (certain species), interaction with seafloor, removal of habitat-structuring species, loss of gear)

Shellfish - operational (waste products, anti-fouling, predator control, disease and disease control, infrastructure effects on local hydrography, litter, anchoring/mooring of boats)

Shellfish - setup (atmospheric emissions from boats, interaction with seafloor when dredging for brood stock, loss of gear, litter)

Telecom and

Electricity

Cable

Fishing: bentic trawling

Fish_Bent

Fishing: Nets

Fish_Net

Fishing:

Pelagic trawls

Fish_Pel

Mining

extraction of Mine

materials

Oil and Gas

Oil_Gas

Shipping

Ship

Wind farms
Telecoms and Electricity: Communication and electric cables active operational (localised electro-magnetic changes)

Telecoms and Electricity: Communication and electric cables laying cables (localised habitat change and smothering, interaction with seafloor, atmospheric emissions from ships laying cables)

Benthic trawls and dredges - general (anti-fouling, ballast water, litter, lost gear)

Benthic trawls and dredges - mooring/anchoring (interaction with seafloor)

Benthic trawls and dredges - operations (interaction with seafloor, catch, bycatch, waste products)

Benthic trawls and dredges - steaming (atmospheric emissions, collisions)

Nets (fixed/set/gillnets/other nets/lines) - general (litter, lost gear, Operational antifoulants)

Nets (fixed/set/gillnets/other nets/lines) - operational (catch, bycatch, waste products)

Nets (fixed/set/gillnets/other nets/lines) - set up/recovery

(interaction with seafloor, atmospheric emissions)

Pelagic trawls - general (anti-fouling, ballast water, litter, lost gear)

Pelagic trawls - mooring/anchoring (interaction with seafloor)

Pelagic trawls - operations (catch, bycatch, waste products)

Pelagic trawls - steaming (atmospheric emissions, collisions)

Sand/gravel aggregates - extraction of substrate (habitat change interaction with seafloor, contaminant release)

Sand/gravel aggregates - spoil/waste disposal (habitat change, smothering)

Oil and Gas - construction (drilling, anchoring, construction of wellheads, laying pipelines, oil spills)

Oil and Gas - decommissioning (anchoring, oil spills, removal of infrastructure where relevant)

Oil and Gas - exploration (seismic surveys, exploratory drilling and anchoring, oil spills)

Oil and Gas - operational (waste fluids and particulates to seafloor, Operational surface litter and wastewater, oil spills)

Shipping: General (anti-fouling, ballast water exchange, litter)

Shipping: Mooring/anchoring/beaching/launching (interaction with seafloor)

Shipping: Steaming (atmospheric emissions, collisions)

Wind farms - construction (installation of turbines on seafloor

includes interaction with seafloor, habitat change and sealing,

laying cables)

Wind farms - operational (active cables on seafloor -

electromagnetic changes, moving turbines - collisions, boats

servicing and maintaining farms)
Operational

Installation/remova

Operational

Installation/remova

Operationa

Installation/remova

Operational

Operational

Operational

Operational

Operational

Operational

Operational

Operational

Operational

Operational

Operational

Operational

Installation/removal

Installation/removal

Operational

Operational

Operational

Operational

Installation/removal

Operational 
Information for the baseline and the future scenarios for human activities on the North Sea, as required for the impact assessment (section 3.5), is presented in Table 3. The future scenarios are based on information provided by WWF representatives from the North Sea countries. At the time of the final assessment information from three countries (i.e. Germany, Denmark and the Netherlands) was available. The future scenarios of human activities in the North Sea could therefore only be based on limited information and on the assumption that that these countries are sufficiently representative for the whole study area. For each activity, the average of the three countries (weighted on the basis of spatial ratio of the North Sea) was taken. The relative change (ratio) to the baseline for these countries was applied for the whole North Sea to assess the impact of the future scenarios.

Table 3 Scenarios per sectoral activity on the North Sea based on country-specific scenarios.

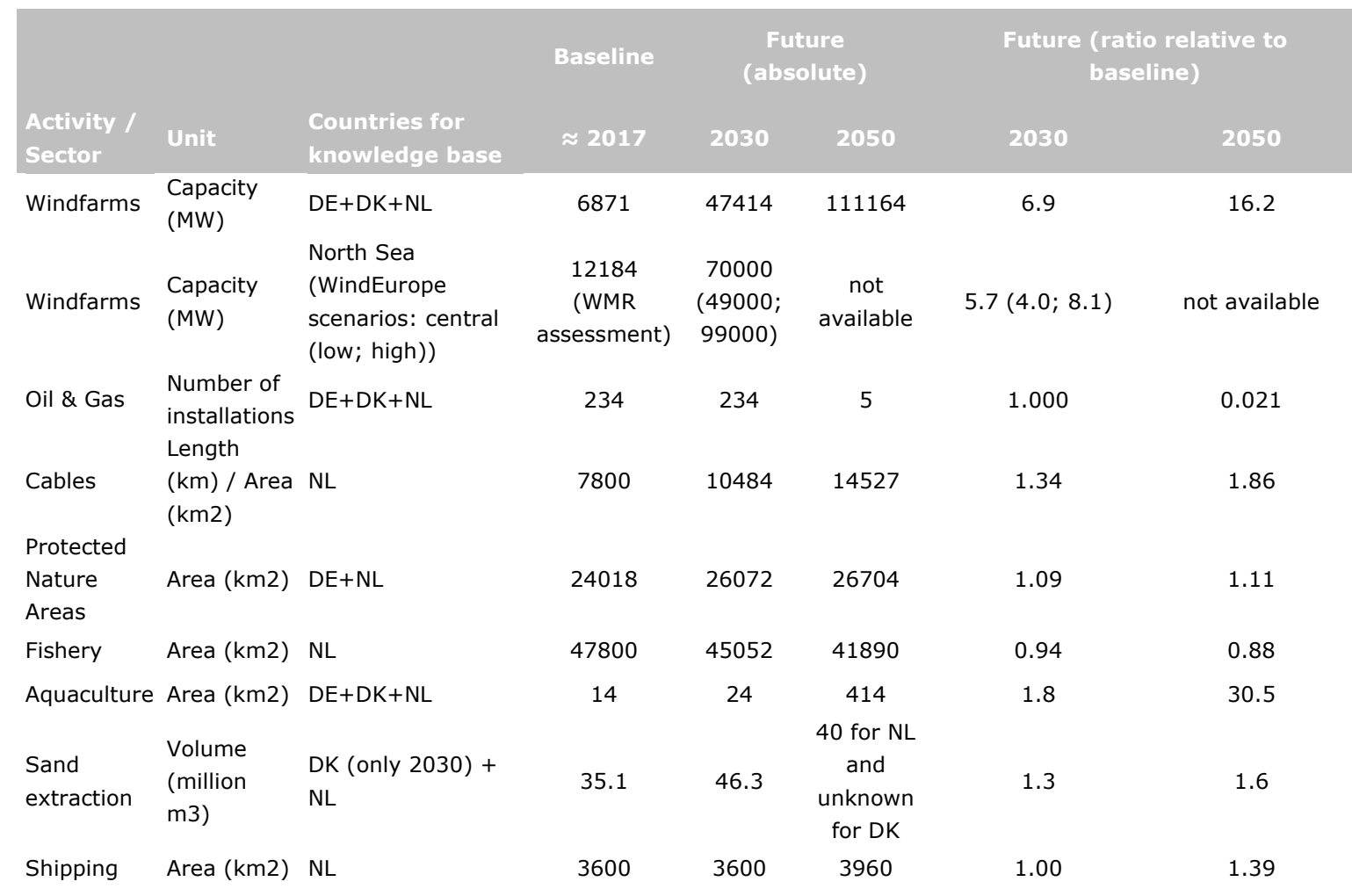

\subsection{Method}

Unless stated otherwise, the method used for this study is based on peer-reviewed studies conducted in international collaborations. The study of Borgwardt et al. (2019), including the accompanying database, was derived from the EU-funded project AQUACROSS (Knowledge, Assessment, and Management for AQUAtic Biodiversity and Ecosystem Services aCROSS EU policies; http://aquacross.eu), which built on previous work from the EU-funded project ODEMM (Options for Delivering Ecosystem-Based Marine Management; https://odemm.com), e.g. Knights et al. (2013, 2015). The database of Borgwardt et al. (2019) contains 7771 causal impact chains for the North Sea, which were all semi-quantitatively assessed using (scientific) knowledge from literature supplemented by expert judgement by a large team of international experts. This assessment was based on five AQUACROSS criteria: (i) extent, (ii) dispersal, (iii) frequency, (iv) persistence, and (v) severity (Borgwardt et al., 2019) and two additional criteria: (vi) resilience (Knights et al., 2015) and (vii) pressure load (Pload) developed as part of the ICES WGCEAM (Working Group on the use of Cumulative Impact Assessments for Management) and soon to be submitted for publication in a scientific journal (Piet et al., in prep). The criteria with their categories are provided in Annex 3 and introduced in the text box below. 
The extent, or overlap of each activity with each ecosystem component, was evaluated by considering the spatial distribution of human activities and ecosystem component in the study area, and how much spatial overlap in these there is (Borgwardt et al., 2019). The area of overlap is relative to the area occupied by the ecosystem component in question within the study area. The actual location of pressures and their impact pathways was considered when assigning spatial extent (e.g. accounting for the fact that not all pressures are introduced across the whole operating area of an activity; for example, abrasion is only introduced where fishing vessels are trawling or anchoring, while noise is introduced while also steaming). For this study, the extent scores as applied by Borgwardt et al. (2019) were adjusted according to the spatial data gathered in Chapter 2, if relevant (i.e. only for the selected activities and ecosystem components). Dispersal evaluated the potential of an activity-pressure impact to spread and increase its spatial overlap with an ecosystem component beyond that of the area of extent where the pressure and ecosystem component overlap initially (Borgwardt et al., 2019). Frequency of interactions described the most likely number of times the activity interacts with an average square kilometre of an ecosystem component in an average year, where they overlap in space (Borgwardt et al., 2019). Moreover, it is important to consider the length of time it would actually take for the pressure associated with a particular activity to disappear after cessation of any further activities causing the particular pressure. This temporal component was described by persistence. For example, while habitat loss is persistent, organic enrichment is not. Severity described the generic severity of an interaction in terms of its effects on the ecosystem component (Borgwardt et al., 2019). The type of response of the ecosystem component to the pressure was categorised as either 'Acute', 'Chronic' or 'Low'. More details on the five Aquacross criteria and the classifications are given in Annex 3. The weighting of each impact chain was carried out by regional experts and co- ordinated by a core expert team that ensured consistency in the approach. Categorical weights were converted to numerical scores based on the justifications in Annex 3 (Borgwardt et al., 2019). The criteria Resilience (Knights et al., 2015) was reintroduced for this study. The resilience represents the recovery time of the ecological characteristic to return to pre-impact conditions. Recovery times for species assessments were based on turnover times (e.g. generation times). For predominant habitat assessments, recovery time was the time taken for a habitat to recover its characteristic species of features given prevailing conditions. Furthermore, an additional criterion was added for this study, Pressure Load (Pload), which has been developed within the ICES WGCEAM (Working Group on the use of Cumulative Impact Assessments for Management). Pload was introduced because the pressure intensity was not explicitly considered in the Aquacross North Sea "Impact Risk" database. Therefore an estimated (expert judgement) activity-specific contribution to the pressure load was introduced. Together all activities add up to 1 (or $100 \%$ ) for each pressure.

Impact Risk is calculated through a risk assessment of the potential impact on nature as the combination of two aspects of risk, i.e. exposure and potential effect, where:

- The exposure is based on:

- The area of the activity (Extent);

- Potential spreading of the related pressures (Dispersion);

- Relative contribution of the activity to the related pressures (Pload).

- The potential effect is based on:

- The sensitivity of the ecosystem component to the pressures (Severity);

- The number of times the activity interacts with an ecosystem component (Frequency);

- The recovery time of the ecosystem component (Resilience);

- The length of time it would take for the pressure to disappear after cessation of the activity(s) causing the particular pressure (Persistence).

Exposure reflects the proportion (\%) of the ecosystem component that is potentially perturbed by the pressure. In case of quantitative information on a spatial grid this can be estimated in terms of the Overlap, Likelihood of encounter, the Magnitude or the Severity of Exposure (Piet et al., 2021) depending on the information available. Because this study does not include a full quantitative assessment, the exposure is semi-quantitative: based on a quantified extent and categoric scores for dispersion and Pload.

The potential effect represents the proportion (\%) of the ecosystem component that is actually perturbed to a level where its contribution to ecosystem integrity and functioning is compromised. For each grid cell where both the ecosystem component and pressure occur this is the equilibrium \% abundance (numbers, biomass) of that ecosystem component relative to undisturbed. The potential 
effect is completely based on categoric scores as already included in the Aquacross database (see Annex 3).

Impact Risk is calculated for each impact chain as the product of exposure and the potential effect and is expressed as the proportional (\%) change in the abundance of a particular ecosystem component due to a particular activity-pressure combination. The CIA then aggregates across impact chains to show for example the (1) vulnerability of each ecosystem (component) to the aggregated activity/activities or (2) the threat caused by each activity or activity-pressure combination to overall biodiversity, i.e. aggregated across ecosystem components. Vulnerability represents the likelihood that the state of the overall ecosystem and/or any of its components is reduced by a certain proportion (\%) compared to a specific undisturbed or reference period and hence the likelihood that environmental policy objectives are not achieved. A value bigger than $100 \%$ implies (local) extinction. Threat represents the relative contribution of activities and their pressures to this likelihood.

\subsection{Pressures caused by offshore wind farms on the North Sea ecosystem}

Pressures are considered as 'the mechanism through which an activity has an effect on any ecosystem component' (Knights et al., 2013). A human activity may be the source of multiple pressures and any single pressure may be caused by more than one activity (Knights et al., 2013). Borgwardt et al.

(2019) established a typology of human activities, a typology of pressures those activities introduce to aquatic ecosystems and a typology of aquatic ecosystem components impacted by those pressures. A total of 45 human activities were linked through 31 pressures to 82 ecosystem components, resulting in a linkage framework of $>22,000$ activity-pressure-ecosystem component interactions across seven European case studies, of which one involves the North Sea (Borgwardt et al., 2019). The linear interaction between a sector, pressure, and ecological component is referred to as an "impact chain" (Knights et al., 2015). Although it is recognized that indirect effects can play an important role in the functioning of an ecosystem, only direct effects of sector-pressures on ecological components are considered (Knights et al., 2015). Because knowledge on the interaction mechanisms of multiple stressors (additivity, synergy, antagonism) is lacking, first assumption is that they will act in an additive fashion (following e.g. Judd et al., 2015).

The identified pressures are categorised in broad pressure types, see Table 4 (Borgwardt et al., 2019):

- biological (e.g., Introduction of Microbial Pathogens) and;

- chemical (e.g., Introduction of Synthetic Compounds);

- $\quad$ physical (e.g., Abrasion);

- $\quad$ energy (e.g. Thermal Changes).

\section{Table 4 Pressure definitions (Borgwardt et al., 2019)}

\begin{tabular}{|c|c|c|}
\hline No & Pressure & Definition \\
\hline & Biological Disturbance & \\
\hline 1 & $\begin{array}{l}\text { Introduction of Microbial } \\
\text { Pathogens }\end{array}$ & Introduction of microbial pathogens into aquatic ecosystems by human activities \\
\hline 2 & $\begin{array}{l}\text { Introduction of Non- } \\
\text { Indigenous Species }\end{array}$ & $\begin{array}{l}\text { Introduction of non-indigenous species by the activities of a particular sector (e.g. through } \\
\text { exchange of ballast waters by shipping, or from release of individuals from the aquaria } \\
\text { trade or aquaculture). This specifically refers to the introduction of a new species to the } \\
\text { area. }\end{array}$ \\
\hline 3 & $\begin{array}{l}\text { Translocations of species } \\
\text { (native or non-native) }\end{array}$ & $\begin{array}{l}\text { Movement from one location to another of individuals from a species by the activities of a } \\
\text { particular sector (e.g. through exchange of ballast waters by shipping or from release of } \\
\text { individuals from aquaculture). Does not include new additions of non-native species (see } \\
\text { pressure } 2 \text { ). Does not include additions of microbial pathogens which are dealt with } \\
\text { separately (see pressure 1) }\end{array}$ \\
\hline 4 & $\begin{array}{l}\text { Extraction of flora and/or } \\
\text { fauna }\end{array}$ & $\begin{array}{l}\text { Extraction (and subsequent mortality) of any aquatic fauna (vertebrate or invertebrate) } \\
\text { and/or flora (plants and algae) from their natural habitat, including incidental non-target } \\
\text { catch (e.g. by commercial fishing, recreational angling and collecting/harvesting). Note that } \\
\text { extraction of cultivated fauna is not considered here. }\end{array}$ \\
\hline 5 & $\begin{array}{l}\text { Introduction of genetically } \\
\text { modified species }\end{array}$ & $\begin{array}{l}\text { Release of genetically modified species through the activities of a particular sector. A } \\
\text { specific example includes through the release of individuals of genetically modified fish or } \\
\text { shellfish species from aquaculture. }\end{array}$ \\
\hline
\end{tabular}




\begin{tabular}{|c|c|c|}
\hline No & Pressure & Definition \\
\hline & Chemical & \\
\hline 6 & $\mathrm{pH}$ changes & $\begin{array}{l}\text { Change in } \mathrm{pH} \text { (average, range or variability) e.g. due to run off from land-based industry } \\
\text { (localised, not climate change, see } 36 \text { ) }\end{array}$ \\
\hline 7 & Salinity changes & $\begin{array}{l}\text { Change in salinity (average, range or variability), e.g. due to outfalls from industrial plants } \\
\text { or alterations in coastal structures affecting mixing (localised, not climate change, see } 38 \text { ) }\end{array}$ \\
\hline 8 & $\begin{array}{l}\text { Introduction of Non- } \\
\text { Synthetic compounds }\end{array}$ & $\begin{array}{l}\text { Introduction of heavy metals and hydrocarbons into aquatic ecosystems by human } \\
\text { activities; can include new additions and/or release of compounds previously held in } \\
\text { sediments following disturbance. }\end{array}$ \\
\hline 9 & $\begin{array}{l}\text { Introduction of } \\
\text { Radionuclides }\end{array}$ & $\begin{array}{l}\text { Introduction of radionuclides into aquatic ecosystems by human activities; can include new } \\
\text { additions and/or release of compounds previously held in sediments following disturbance }\end{array}$ \\
\hline 10 & $\begin{array}{l}\text { Introduction of Synthetic } \\
\text { compounds }\end{array}$ & $\begin{array}{l}\text { Introduction of man-made compounds (e.g. pharmaceuticals, industrial compounds, etc.) } \\
\text { into aquatic ecosystems by human activities; can include new additions and/or release of } \\
\text { compounds previously held in sediments following disturbance }\end{array}$ \\
\hline 11 & Litter & $\begin{array}{l}\text { Litter originating from numerous sources but entering aquatic ecosystems and consisting of } \\
\text { different materials including: plastics, metal, glass, rubber, wood and cloth }\end{array}$ \\
\hline 12 & N\&P Enrichment & $\begin{array}{l}\text { Input of fertilisers, and other Nitrogen and Phosphorous rich substances, elevated above } \\
\text { the background levels, including any subsequent associated deoxygenation }\end{array}$ \\
\hline \multirow[t]{2}{*}{13} & $\begin{array}{l}\text { Change in input of Organic } \\
\text { Matter }\end{array}$ & $\begin{array}{l}\text { Organic enrichment and any subsequent deoxygenation, e.g. from industrial and sewage } \\
\text { effluent into aquatic ecosystems, or from the waste from aquaculture or from fishing } \\
\text { discards. Changes in organic input may also come from changes to riparian vegetation and } \\
\text { loss of allochthonous input into rivers and lakes. }\end{array}$ \\
\hline & Physical & \\
\hline 14 & Water abstraction & $\begin{array}{l}\text { Removal of freshwater or seawater for e.g. drinking water, irrigation, cooling industrial } \\
\text { plants or for desalination, directly reducing the availability of habitats and causing } \\
\text { hydrological changes. }\end{array}$ \\
\hline 15 & Water flow rate change & $\begin{array}{l}\text { Change in currents (speed, direction or variability) due to barrages or other manmade } \\
\text { structures such as coastal defences or hydropower structures (localised, not climate } \\
\text { change, see } 35 \text { ) }\end{array}$ \\
\hline 16 & $\begin{array}{l}\text { Death or Injury by } \\
\text { Collision }\end{array}$ & $\begin{array}{l}\text { Death or injury of fauna due to impact with moving parts of a human activity, e.g. marine } \\
\text { mammals with ships/jet skis, seabirds with wind turbines, fish in hydroelectric turbines, } \\
\text { etc. }\end{array}$ \\
\hline 17 & $\begin{array}{l}\text { Emergence Regime } \\
\text { changes }\end{array}$ & $\begin{array}{l}\text { Change to natural sea level regime (average, range or variability) of natural shore areas } \\
\text { due to barrages or other manmade structures such as coastal defences, or changes to the } \\
\text { regime of emergence (e.g. timing, extent) of lakes, rivers or floodplains due to human } \\
\text { activities such as alteration of water levels for hydropower (localised, not climate change, } \\
\text { see } 32 \text { ) }\end{array}$ \\
\hline 18 & Abrasion/Damage & $\begin{array}{l}\text { Physical interaction of human activities with the seafloor, riverbed or lake bottom, } \\
\text { riparian/coastal terrestrial/wetland habitats and with the benthic fauna/flora causing } \\
\text { physical damage and/or mortality (e.g. from trawling, dredging, or anchoring). }\end{array}$ \\
\hline 19 & $\begin{array}{l}\text { Barrier to species } \\
\text { movement }\end{array}$ & $\begin{array}{l}\text { Preventing the natural movement of motile fauna along a key route of travel (e.g. a } \\
\text { migration route) due to dams, barrages, causeways, wind turbines, and other manmade } \\
\text { structures. This can take place laterally across a flood plain due to e.g. flood defences. }\end{array}$ \\
\hline 20 & Changes in wave exposure & $\begin{array}{l}\text { Change in the size, number, distribution, and/or periodicity of waves along a coast due to } \\
\text { installation of coastal structures (localised, not climate change, see } 33 \text { ); change in wave } \\
\text { exposure along a shoreline due to shipping/boating activity }\end{array}$ \\
\hline 21 & Changes in Siltation & $\begin{array}{l}\text { Change in the concentration and/or distribution of suspended sediments in the water } \\
\text { column from runoff, dredging etc. }\end{array}$ \\
\hline 22 & $\begin{array}{l}\text { Total habitat loss } \\
\text { (physical) }\end{array}$ & $\begin{array}{l}\text { Loss of natural habitat from sealing by permanent manmade construction (e.g. Coastal } \\
\text { defences, wind turbines, bridges, river walls) or due to land conversion (e.g. } \\
\text { intertidal/littoral habitats lost through land claim). Can include change in habitat type at } \\
\text { Eunis Level } 3 \text { or above (e.g. Littoral mixed sediments to Littoral sand, or Broadleaf } \\
\text { deciduous woodland to Arable land). }\end{array}$ \\
\hline 23 & $\begin{array}{l}\text { Selective Extraction of } \\
\text { non-living resources: } \\
\text { substrate }\end{array}$ & $\begin{array}{l}\text { Includes sand and gravel (aggregates) extraction, removal of surface substrates for } \\
\text { exploration of seabed, river bed, lake bottom, and subsoil. This pressure involves reducing } \\
\text { the amount of physical habitat. }\end{array}$ \\
\hline 24 & Smothering & $\begin{array}{l}\text { Cover habitat surface with materials falling to the seafloor, riverbed or lake bottom or other } \\
\text { relevant aquatic habitats from activities in the water column (e.g. waste substances from } \\
\text { aquaculture cages), on land (e.g. in runoff or effluent), or around activities (e.g. around } \\
\text { trawling gear), or from disposal of materials (e.g. disposal of materials from dredging onto } \\
\text { the seafloor). Smothering may lead to reduced functioning (e.g. feeding) or mortality of } \\
\text { benthic animals living on, or in, the seafloor, river bed or lake bottom. }\end{array}$ \\
\hline 25 & $\begin{array}{l}\text { Disturbance (visual) of } \\
\text { species }\end{array}$ & Physical structures, which may affect the behaviour of fauna, e.g. wind farms and seabirds. \\
\hline 26 & Artificialisation of habitat & $\begin{array}{l}\text { The addition of artificial habitat or manmade structures to an aquatic environment e.g. } \\
\text { artificial reefs, wind turbines. This could provide stepping stones for invasive species. }\end{array}$ \\
\hline \multirow[t]{2}{*}{27} & $\begin{array}{l}\text { Change of habitat } \\
\text { structure/morphology }\end{array}$ & $\begin{array}{l}\text { Change of benthic habitat or substrate without total habitat loss (22) e.g. alteration of river } \\
\text { channels, loss of habitat complexity such as leaves, dead wood. Broad habitat type remains } \\
\text { the same but quality/structure changes. }\end{array}$ \\
\hline & Energy & \\
\hline 28 & Electromagnetic changes & $\begin{array}{l}\text { Change in the amount and/or distribution and/or periodicity of electromagnetic energy } \\
\text { emitted in a marine or freshwater area (e.g. from electrical sources such as underwater } \\
\text { cables) }\end{array}$ \\
\hline 29 & Thermal changes & $\begin{array}{l}\text { Change in temperature of the water (average, range or variability) e.g. due to outfalls from } \\
\text { industrial plants (localised, not climate change, see } 34 \text { ) }\end{array}$ \\
\hline 30 & $\begin{array}{l}\text { Noise (underwater and } \\
\text { other) }\end{array}$ & $\begin{array}{l}\text { Introduction of underwater noise that is outside normal background levels, and originates } \\
\text { from activities such as shipping, acoustic surveys, pile driving during construction etc. } \\
\text { Other noise can refer to noise elsewhere in the environment that could affect aquatic } \\
\text { species such as birds. }\end{array}$ \\
\hline 31 & Input of light & Addition of light from artificial sources e.g. due to urbanisation around a littoral area \\
\hline
\end{tabular}


For wind farm activities, Borgwardt et al. (2019) identified 18 pressures (Table 5). In selecting the relevant pressures, a distinction is made between construction- and operational sub-activities. Construction involves installation of turbines on the seafloor and laying of cables causing e.g. interaction with seafloor, habitat change and sealing (i.e. habitat loss). Operational activities include: active cables on seafloor causing electromagnetic changes; moving turbine blades causing collisions, boats servicing and maintaining farms causing various forms of disturbance (e.g. visual or noise). Each cell in the impact-chain matrix (Table 5) is a qualitative and deterministic assessment of the presence $(x)$ or absence (blank cell) of a link, which was assessed using a combination of published literature and expert judgment (Borgwardt et al., 2019). The presence of a link (i.e. the ' $x$ ' in Table 5) describes the risk for a potential impact on an ecological component by the corresponding pressure. The impact of a pressure on an ecological characteristic is not specified but could range from changes in biomass, demography, or abundance (for biotic characteristics) to ones that cause a change in the salinity or temperature profile (for abiotic, i.e. physical and chemical features).

Table 5 Pressures identified for offshore wind farm activities, differentiating in construction- and/or operational activities (based on the linkage framework derived by Borgwardt et al. (2019)). Each ' $x$ ' in the matrix describes the potential for impact on an ecological component by the corresponding pressure.

\begin{tabular}{|c|c|c|c|c|c|c|c|c|c|}
\hline Pressures & 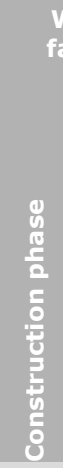 & 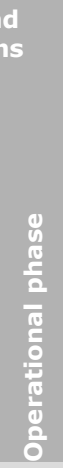 & 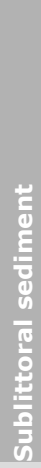 & 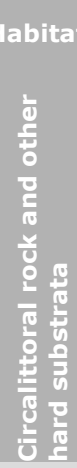 & 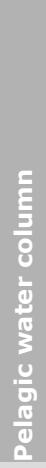 & $\begin{array}{l}\frac{n}{8} \\
\frac{0}{0} \\
\frac{0}{10} \\
\frac{\pi}{0} \\
\frac{0}{3} \\
\infty \\
\frac{5}{0} \\
\frac{5}{11}\end{array}$ & $\frac{\frac{n}{10}}{\frac{10}{10}}$ & $\frac{n}{\frac{n}{8}}$ & $\frac{0}{\frac{0}{2}}$ \\
\hline \multicolumn{10}{|l|}{ Biological Disturbance } \\
\hline Introduction of Microbial pathogens & No & Yes & $x$ & $x$ & $x$ & $x$ & $x$ & $x$ & $x$ \\
\hline \multicolumn{10}{|l|}{ Chemical } \\
\hline Introduction of Non-synthetic compounds & Yes & Yes & $x$ & $x$ & $x$ & $x$ & $x$ & $x$ & $x$ \\
\hline Introduction of Radionuclides & Yes & No & $x$ & $x$ & $x$ & $x$ & $x$ & $x$ & $x$ \\
\hline Introduction of Synthetic compounds & Yes & Yes & $x$ & $x$ & $x$ & $x$ & $x$ & & $x$ \\
\hline N\&P Enrichment & Yes & No & $x$ & $x$ & $x$ & $x$ & & & \\
\hline Changes in input of organic matter & No & Yes & $x$ & $x$ & $x$ & $x$ & & & \\
\hline \multicolumn{10}{|l|}{ Physical } \\
\hline Water flow rate changes & No & Yes & $x$ & $x$ & $x$ & $x$ & $x$ & $x$ & $x$ \\
\hline Death or Injury by Collision & Yes & Yes & & & & $x$ & $x$ & $x$ & $x$ \\
\hline Abrasion/Damage & Yes & No & $x$ & $x$ & & & & & \\
\hline Barrier to species movement & No & Yes & & & & $x$ & $x$ & $\mathrm{x}$ & $x$ \\
\hline Changes in Siltation & Yes & No & $x$ & $x$ & $x$ & $x$ & $x$ & $\mathrm{x}$ & $x$ \\
\hline Total Habitat Loss & Yes & No & $x$ & $x$ & $x$ & $x$ & $x$ & $x$ & $x$ \\
\hline Smothering & Yes & No & $\mathrm{x}$ & $x$ & & & & & \\
\hline Disturbance (visual) of species & Yes & Yes & & & & $x$ & $x$ & $\mathrm{x}$ & $x$ \\
\hline Artificialisation of habitat & No & Yes & $x$ & $x$ & $x$ & $x$ & $x$ & $x$ & $x$ \\
\hline Change of habitat structure/morphology & Yes & No & $x$ & $x$ & & $x$ & & & \\
\hline \multicolumn{10}{|l|}{ Energy } \\
\hline Electromagnetic changes & No & Yes & & & & $x$ & $x$ & & $x$ \\
\hline Noise (Underwater and Other) & Yes & Yes & & & & $x$ & $x$ & $x$ & $x$ \\
\hline
\end{tabular}




\subsection{Impacts of human activities on the North Sea ecosystem}

\subsubsection{Relative contribution of activities}

This section shows the result of the assessment in terms of the relative contribution of the sectoral activities to the impact risk on the North Sea ecosystem, also distinguishing different phases of (wind farm) sub-activities.

The impact risk on the North Sea ecosystem is assessed for the operational activities at present (baseline) and for the future scenarios (see section 3.2 for the selection of activities and scenarios and section 3.3 for the methodology). Based on the aggregation of impact risk across causal chains, benthic fisheries result in the highest impact on the North Sea ecosystem (Figure 9). Although the impact risk of benthic fisheries is expected to decrease in the future, it is still expected to remain the main cause of impact risk, both in 2030 and 2050. Second highest contributor to impact risk under future scenario's is aquaculture. The number of impact chains per sectoral activity is also shown to reflect the diversity through which the sectoral activity may impact the ecosystem and as such can be considered an indication of the information requirements. Note that the number of impact chains is only shown for the baseline situation, as it is not expected to change for the future scenarios. Wind energy itself did not contribute much (relatively) to impact risk. In the ranked order (high to low) of aggregated impact risk, wind energy is ranked 8 out of the 9 activities in the baseline situation. In 2030 wind energy is ranked 6 and in 2050 ranked 5 (after benthic fisheries, aquaculture, shipping and gillnet fisheries). It appears that, similar to on land, food production is likely to be the main threat to biodiversity.

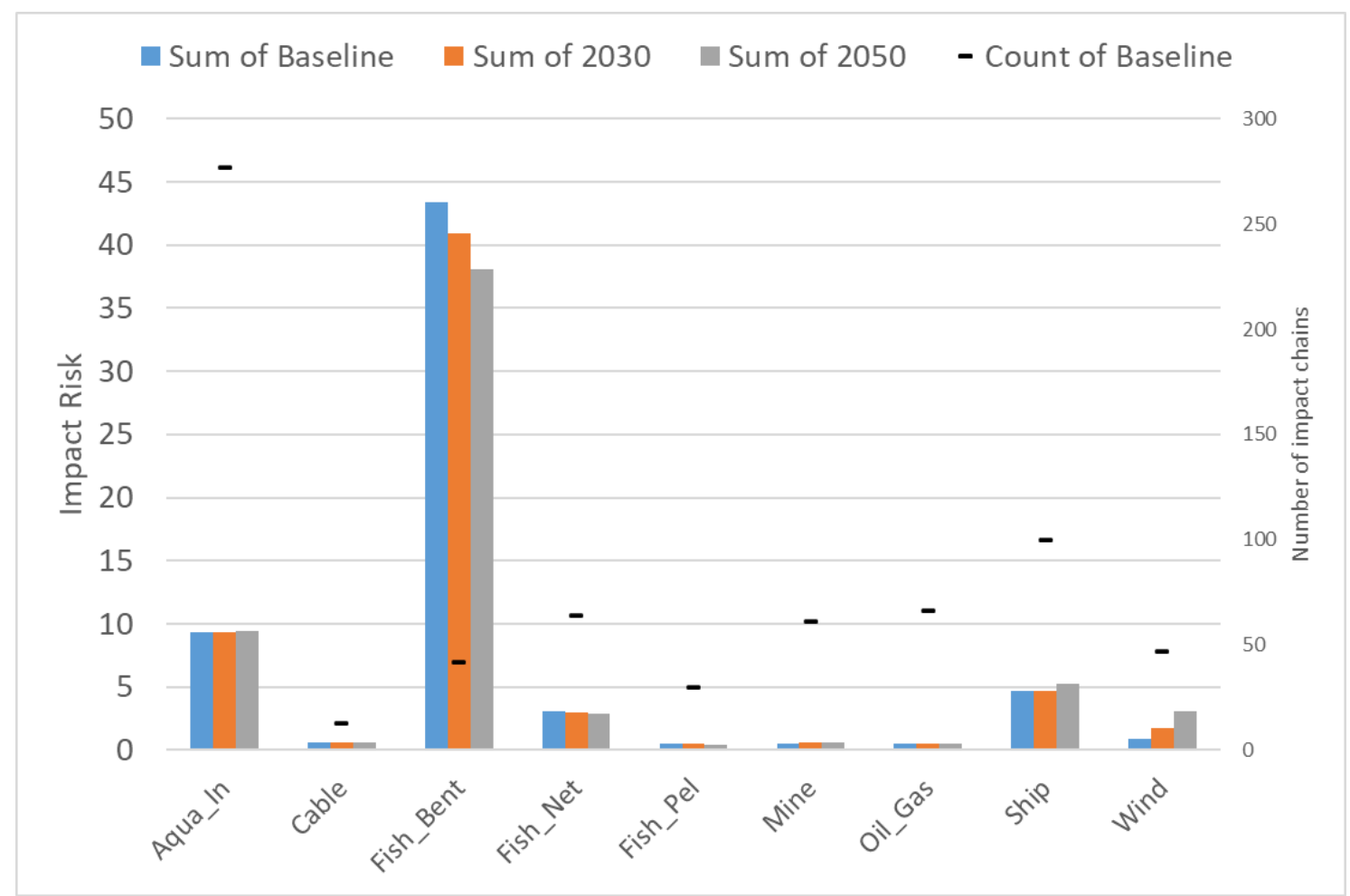

Figure 9 Cumulative (additive) impact on the North Sea ecosystem caused by the selected operational activities (see Table 2), assessed for the baseline (blue bars), scenario 2030 (orange bars) and scenario 2050 (grey bars). The number of impact chains related to the activities are indicated on the secondary $y$-axis (on the right) and marked by the dashes. 
The sectoral activities presented above are in fact an aggregation of specific sub-activities in the operational phase, as shown in Table 2 of section 3.2. Some sectors operate in the marine environment without the use of installed objects, such as fishing and mining. Other sectors depend on infrastructure (e.g. platforms, cables) for their operations, such as wind energy development and oil and gas development. The next figure (Figure 10) shows the aggregated impact on the North Sea ecosystem caused by these sectoral activities, distinguishing the two phases of activities (i.e. construction/removal and operation). For example for wind farms, sub-activities include construction (installation of turbines on seafloor exerts interaction with seafloor, habitat change and sealing, laying cables) and operational (active cables on seafloor - electromagnetic changes, moving turbines collisions, boats servicing and maintaining farms). See Table 2 of section 3.2 for the categorisation of all sub-activities into the 2 phases. Operational activities contribute most to the long-term total aggregated impact risk of the North Sea ecosystem, also for the future scenarios (Figure 10). For both phases and all scenarios, highest impact is caused by aquaculture. Aquaculture exerts a relatively large number of pressures of which several may disperse over larger areas. This results in many impact chains (Figure 9) with often a (potentially) large extent, adding all up to the relatively high total impact risk. Note, however, that there is considerable uncertainty on the dispersal potential of several pressures (see Discussion section on confidence). This may have considerable consequences on the outcome of the assessment, certainly with regard to the impact of aquaculture.

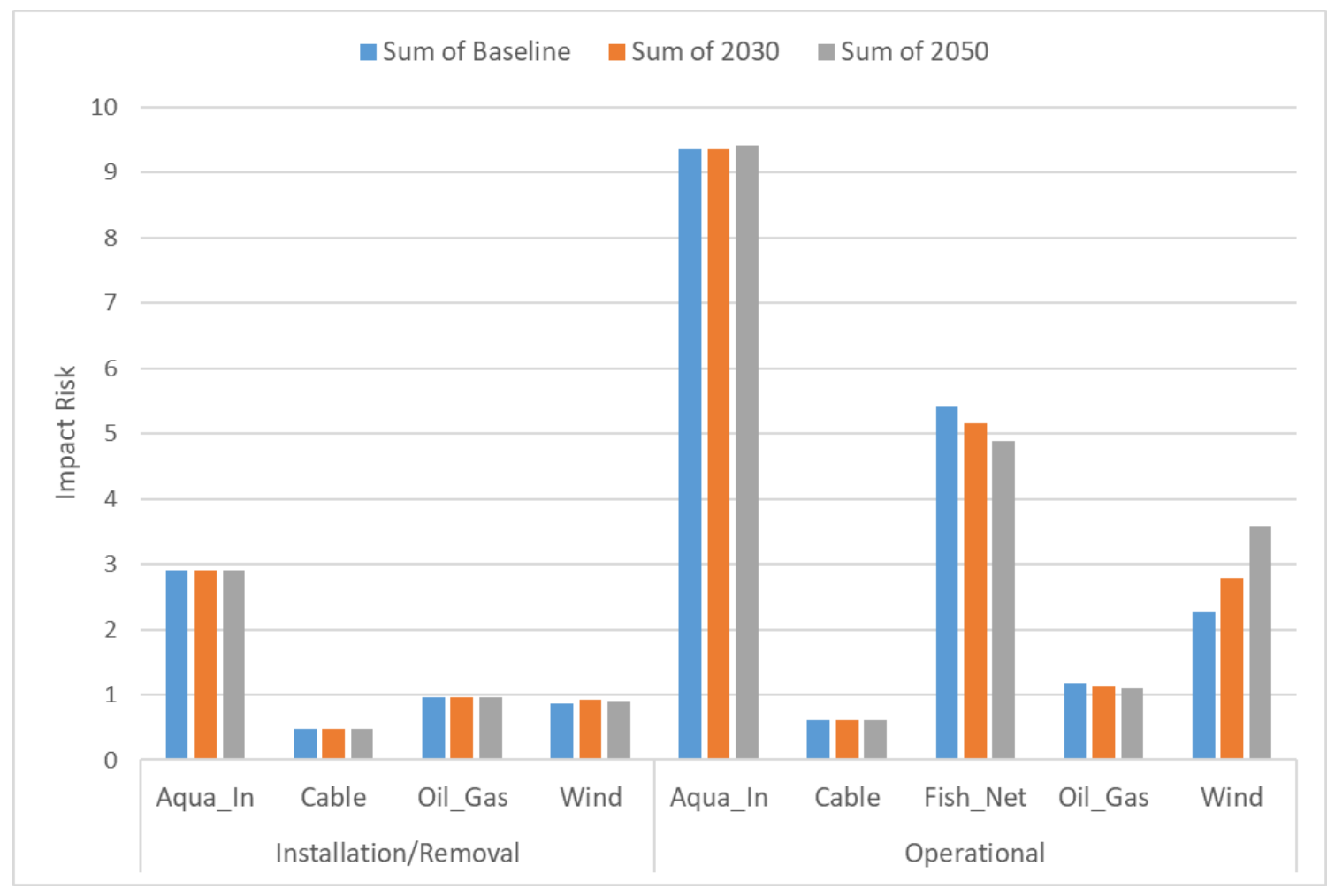

Figure 10 Cumulative (additive) impact on the ecosystem from activities involving the use of installed objects, distinguishing sub-activities for installation/removal and operational sub-activities (see Table 2 for a list of the sub-activities). The impact is assessed for the baseline (blue bars), scenario 2030 (orange bars) and scenario 2050 (grey bars). 


\subsubsection{Relative vulnerability of ecosystem components}

This section differentiates between the ecosystem components in the North Sea ecosystem, i.e. the habitats including their associated biota (pelagic water column, (sub)littoral sediment and hard substrate), birds, fish \& cephalopods and marine mammals.

\section{All activities}

Results show that highest impact risk is posed for the sublittoral sediment, including benthic communities (Figure 11). Fish have second highest vulnerability. Although impact risk is expected to decrease for both ecosystem components (as well as for the water column) under future scenarios, our estimations show that they remain the two most vulnerable ecosystem components of the North Sea. In contrast, other habitats, birds and mammals show a slight increase in impact risk by 2050 (Figure 11).

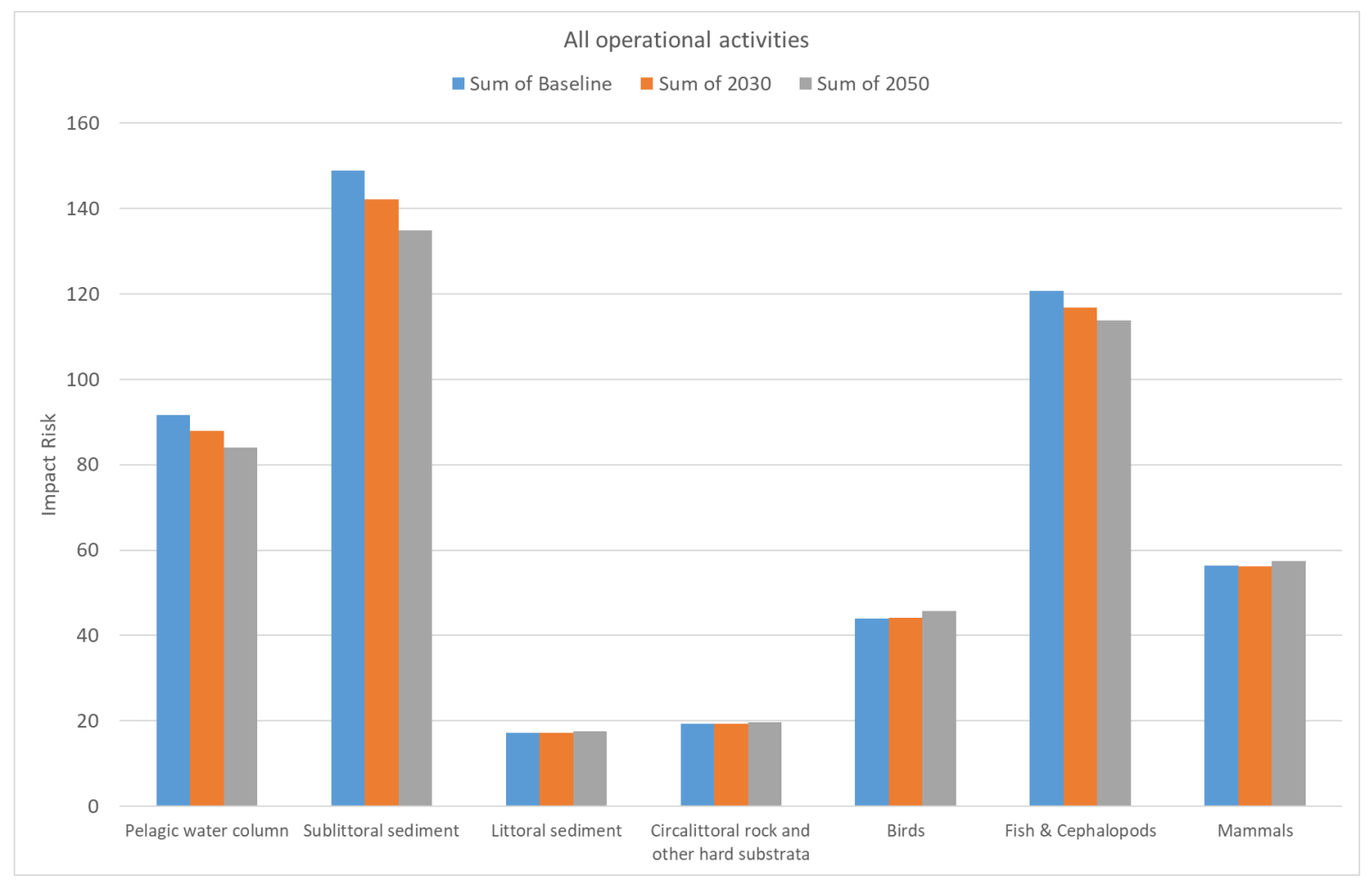

Figure 11 Cumulative (additive) impact from the operational phase of all selected activities (see Table 2) on ecosystem components. Three scenarios are shown: Baseline (blue bars); Scenario 2030 (orange bars); Scenario 2050 (grey bars).

\section{Possible threats caused by wind farms}

Looking only at the contribution of wind farms to the impact risk of the North Sea ecosystem components (Figure 12), it shows that all components, including the species groups are expected to increase in vulnerability for the future scenarios. It is expected that the habitat type circalittoral rock and other hard substrata, will not be affected under the future scenarios. This is because there are no wind energy developments expected to overlap with these habitat types (but note that possible indirect effects are not considered in this assessment). For both the wind farm installation phase as well as the operational phase marine mammals and fish are expected to be the most vulnerable ecosystem component (Figure 12). The results show that future scenarios mostly affect the impact from operational wind farms on species groups. 


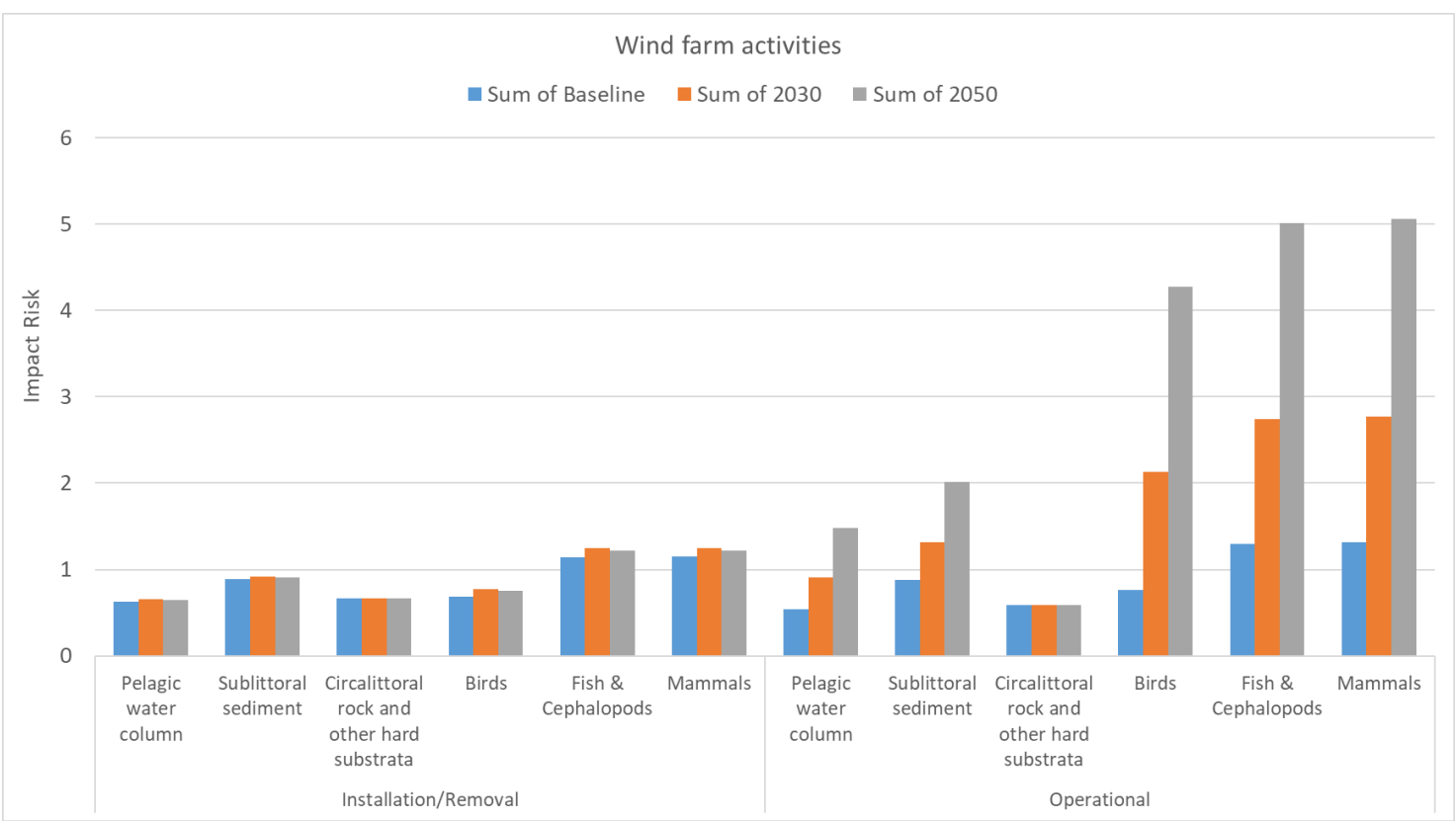

Figure 12 Cumulative (additive) impact from installation and operational wind farms activities (see Table 2) on ecosystem components of the North Sea. Three scenarios are shown: Baseline (blue bars); Scenario 2030 (orange bars); Scenario 2050 (grey bars).

\subsubsection{Relative impact of Marine Protected Area (MPA) measures}

The impact risks of human activities on the North Sea ecosystem as presented above reflect the aggregated impact resulting from the direct effects from activities according to the present situation (baseline) and activities expected for future scenarios (2030 and 2050). The present and future designation of Marine Protected Areas (MPAs) are disregarded in these scenarios. Here, the possible influence of MPAs on the impact risks is estimated by use of the following assumptions:

- MPAs affect the North Sea ecosystem by reducing the spatial extent of human activities (assuming no reallocation) and hence Impact Risk. This is proportional to the relative extent of the MPAs

- Three different MPA scenarios are applied:

- Bottom trawling is prohibited in all MPAs

- All fishing activities are prohibited in all MPAs

- Bottom trawling is prohibited in $50 \%$ of the MPAs and all fishing activities are prohibited in $10 \%$ of the MPAs

Following these scenarios for 2030 and 2050, the MPAs are expected to mostly affect the impact caused by benthic fisheries (Figure 13) which is obvious as benthic fisheries have already been identified as the main threat to the North Sea ecosystem (Figure 9). Note that offshore wind farms are included in this figure to indicate the relative impact expected from these activities, although its impact is not affected by choices involving MPAs. Also to be expected is that MPAs show most impact reduction for sublittoral sediment, i.e. the main seabed habitat in the North Sea, and fish (Figure 14). Only minor differences are observed between the scenario where bottom trawling is prohibited and the scenario where all fisheries are prohibited. This because bottom trawling has by far the biggest impact on the ecosystem. 


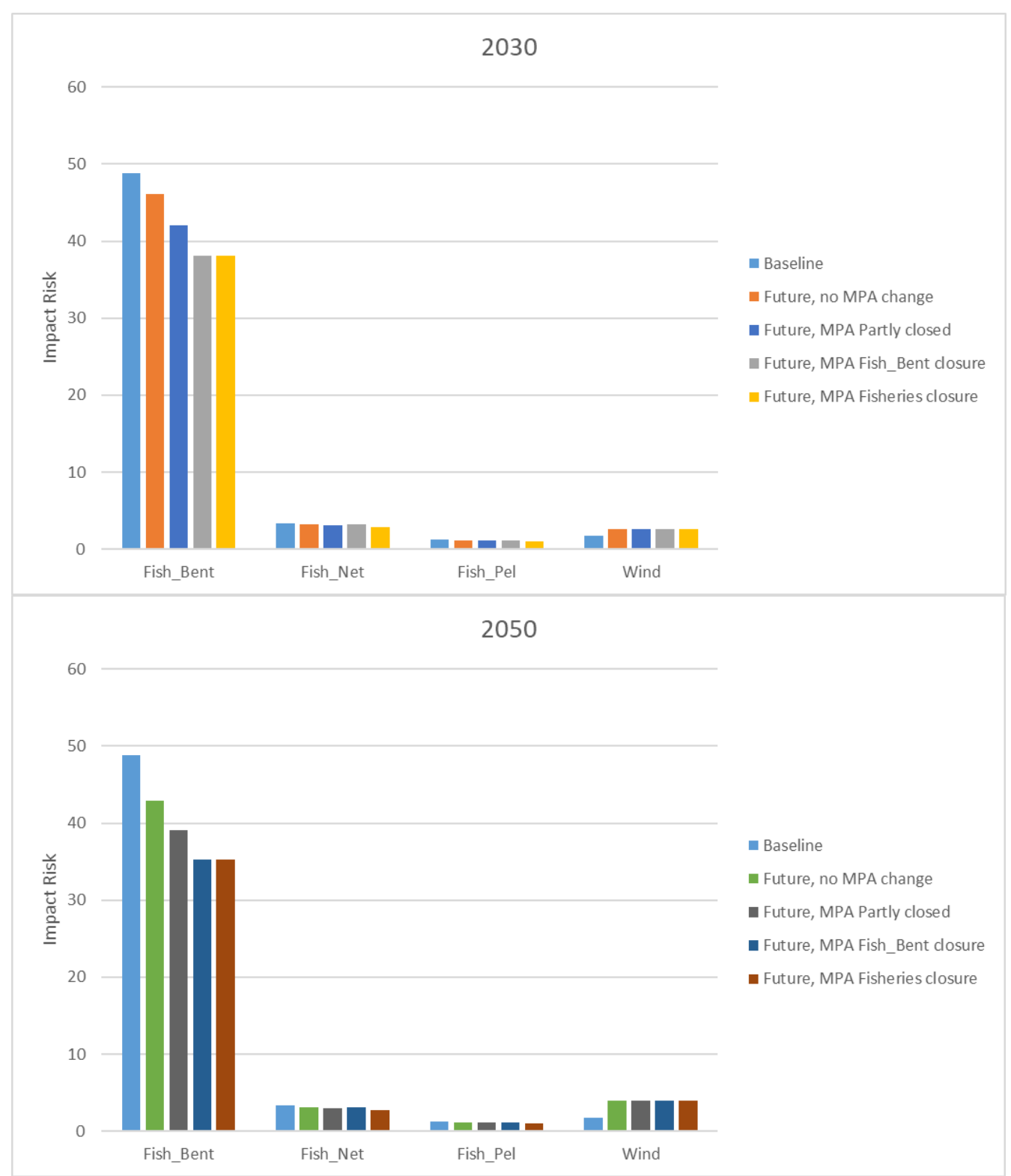

Figure 13 Cumulative (additive) impact from fishing and wind farms activities (see Table 2) on ecosystem components of the North Sea for the baseline and future scenarios 2030 (top chart) and 2050 (bottom chart). Four different future scenarios are shown: no MPA change (assuming no effect of MPA measures); MPA Fish_Bent closure (assuming all MPAs are closed for bottom trawling); MPA Fisheries closure (assuming all MPAs are closed for all fishing activities); MPA Partly closed (assuming $50 \%$ of the MPAs are closed for bottom trawling and $10 \%$ of the MPAs are fully closed for fishing activities). 


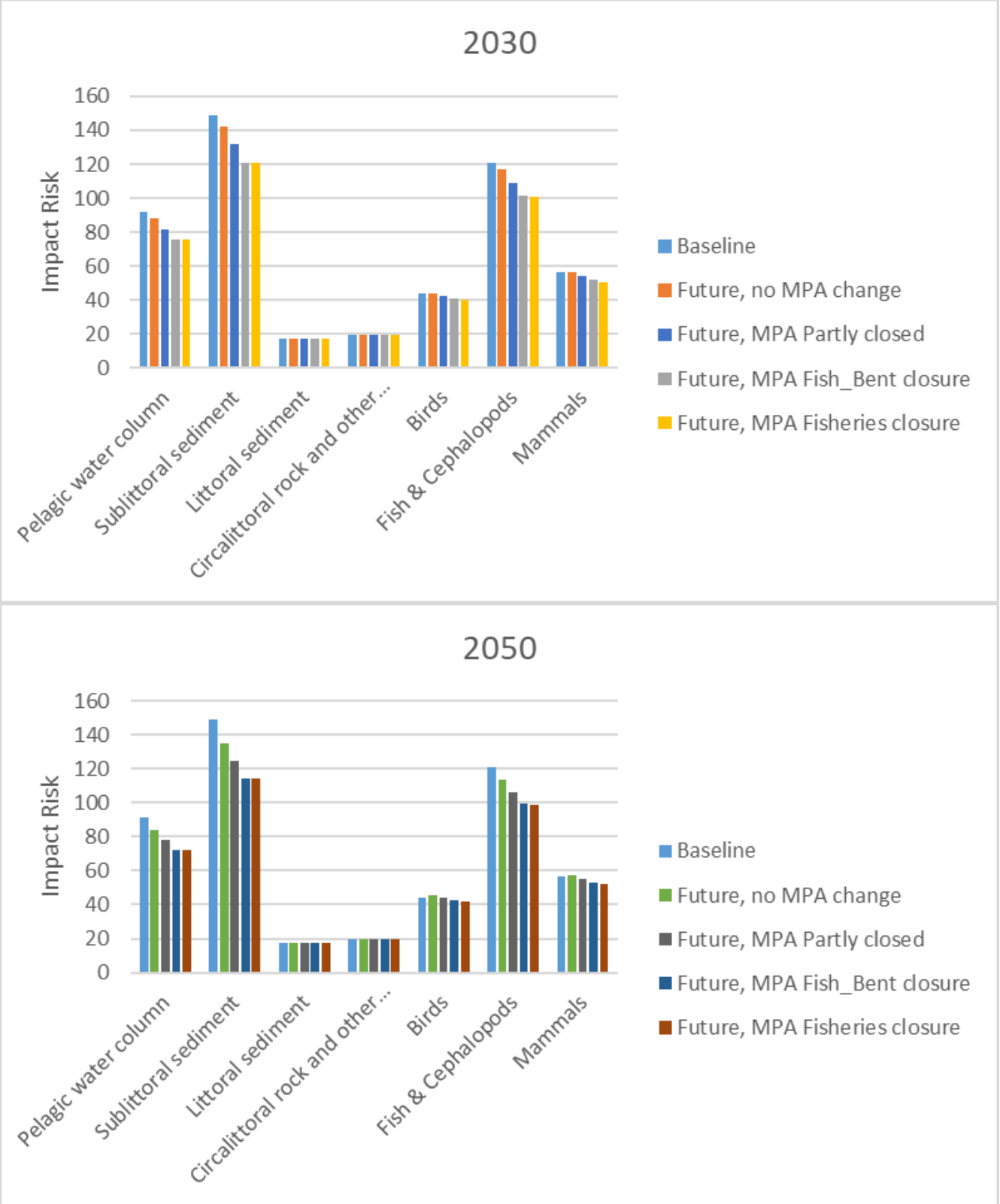

Figure 14 Cumulative (additive) impact from all operational activities (see Table 2) on ecosystem components of the North Sea for the baseline and future scenarios 2030 (top chart) and 2050 (bottom chart). Four different future scenarios are shown: no MPA change (assuming no effect of MPA measures); MPA Fish_Bent closure (assuming all MPAs are closed for bottom trawling); MPA Fisheries closure (assuming all MPAs are closed for all fishing activities); MPA Partly closed (assuming 50\% of the MPAs are closed for bottom trawling and $10 \%$ of the MPAs are fully closed for fishing activities). 


\subsection{Relevance for policy}

For this section we focus on two of the main EU policy directives concerned with biodiversity, i.e. the Marine Strategy Framework Directive (MSFD) and the Birds \& Habitats Directives, the latter specifically in relation to the Natura 2000 (N2000) requirements.

The MSFD (EU, 2008) aims to reach good environmental status (GES), which is described on the basis of eleven descriptors (MSFD Annex I, see Table 6). It comes with the requirement to make an initial assessment of the marine waters consisting of

a) an analysis of the essential features and characteristics, and current environmental status of those waters, covering the physical and chemical features, the habitat types, the biological features and the hydro-morphology;

b) an analysis of the predominant pressures and impacts, including human activity, on the environmental status of those waters which covers the main cumulative and synergetic effects.

This initial assessment should then drive the implementation of marine strategies that "apply an ecosystem-based approach to the management of human activities, ensuring that the collective pressure of such activities is kept within levels compatible with the achievement of good environmental status and that the capacity of marine ecosystems to respond to human-induced changes is not compromised, while enabling the sustainable use of marine goods and services by present and future generations". Ecosystem health, an ecosystem-based approach to management and sustainability are thus at the core of this directive.

The CIA that is applied in this study clearly addresses the assessment of cumulative effects and impacts caused by pressures from human activities. To that end it applies ecosystem components covering the main biological features which can be easily linked to the MSFD descriptors (see Table 7). It was also considered to support ecosystem-based management (e.g. Piet et al., 2015, 2017, 2019).

Table 6 Qualitative descriptors for determining good environmental status in the MSFD (EU, 2008). The right column classifies the descriptors according to presence of corresponding pressure or state criteria/attributes within the descriptor (following the DPSIR framework) (Berg et al., 2015).

$\begin{array}{lcl}\text { MSFD descriptor } & \text { Short name } & \text { Classiffication } \\ \text { Biological diversity } & \text { D1 } & \text { State } \\ \text { Non-indigenous species } & \text { D2 } & \text { Pressure/state } \\ \text { Commercially exploited fish and shellfish } & \text { D3 } & \text { Pressure/state } \\ \text { Marine food webs } & \text { D4 } & \text { State } \\ \text { Human-induced eutrophication } & \text { D5 } & \text { Pressure/state } \\ \text { Sea floor integrity } & \text { D6 } & \text { Pressure/state } \\ \text { Hydrographical conditions } & \text { D7 } & \text { Pressure/state } \\ \text { Concentrations of contaminants } & \text { D8 } & \text { Pressure } \\ \text { Contaminants in fish and other seafood } & \text { D9 } & \text { Pressure } \\ \text { Marine litter } & \text { D10 } & \text { Pressure } \\ \text { Energy, including underwater noise } & \text { D11 } & \text { Pressure }\end{array}$


Table 7 The components of the North Sea ecosystem (as included within the impact assessment) and the corresponding MSFD criteria. Translated from (Tamis et al., 2019). The MSFD criteria are related to the MSFD descriptors (D), see Table 6. For more information on MSFD criteria see European Commission (2017)

\begin{tabular}{|c|c|c|}
\hline \multicolumn{2}{|r|}{ North Sea Ecosystem } & MSFD Criteria \\
\hline \multirow{5}{*}{$\begin{array}{l}\text { Ecosystem } \\
\text { components }\end{array}$} & Sea mammals & $\begin{array}{l}\text { D1C1, D1C2, D1C3, D1C4, } \\
\text { D1C5, D11C1 }\end{array}$ \\
\hline & Sea birds & D1C2, D1C3 \\
\hline & $\begin{array}{c}\text { Fish: Commercial species and aspects of } \\
\text { the fish community }\end{array}$ & $\begin{array}{c}\mathrm{D} 1 \mathrm{C} 2, \mathrm{D} 1 \mathrm{C} 3, \mathrm{D} 1 \mathrm{C} 4, \mathrm{D} 1 \mathrm{C} 5 \\
\mathrm{D} 3 \mathrm{C} 1, \mathrm{D} 3 \mathrm{C} 2, \mathrm{D} 4 \mathrm{C} 3\end{array}$ \\
\hline & $\begin{array}{l}\text { Seafloor habitats: Indicator species and } \\
\text { aspects of the benthic community }\end{array}$ & D4C1, D6C4, D6C5 \\
\hline & $\begin{array}{l}\text { Water column: Aspects of the zooplankton } \\
\text { and phytoplankton community }\end{array}$ & D1C6, D4C1, D4C2, D5C2 \\
\hline \multirow{8}{*}{$\begin{array}{l}\text { Human } \\
\text { activities } \\
\text { and their } \\
\text { pressures }\end{array}$} & Non-indigenous species & D2C1 \\
\hline & Fishery: catch and bycatch & D1C1, D3C1, D3C2 \\
\hline & Eutrophification & D5C1, D5C2, D5C3, D5C5 \\
\hline & Seafloor disturbance and loss & D6C1, D6C2, D6C3 \\
\hline & Hydrographical conditions & D7C1, D7C2 \\
\hline & Contaminants & $\mathrm{D} 8 \mathrm{C} 1, \mathrm{D} 8 \mathrm{C} 2, \mathrm{D} 8 \mathrm{C} 3, \mathrm{D} 9 \mathrm{C} 1$ \\
\hline & Marine litter & D10C1, D10C2, D10C3 \\
\hline & Energy and noise & $\mathrm{D} 11 \mathrm{C} 1, \mathrm{D} 11 \mathrm{C} 2$ \\
\hline
\end{tabular}

Natura 2000 targets are based on the Habitats Directive (HD, Directive 92/43/EEC) and the Birds Directive (BD, Directive 2009/147/EC) and focus on maintaining or improving the size and quality of habitats within designated areas, in some cases to maintain or improve populations of specific habitat species and/or bird species. These measures are specifically aimed at some of the ecosystem components included in the impact assessment (Table 7) with designated areas for each (group of) ecosystem component(s). For example, in the Natura 2000 area Frisian Front the Common Guillemot is a designated species under the BD. Bycatch from gillnet fisheries is considered a threat to the conservation of this species (The Netherlands, 2019). In this protected area, the ecosystem component 'Sea birds' and how this is affected through the pressure extraction of flora and/or fauna (catch and bycatch from fisheries, Table 7) are specifically relevant for the impact assessment in relation to $\mathrm{N} 2000$.

\subsection{Discussion and conclusions}

\subsubsection{Methodology}

\section{Meaning of results}

The CIA shows the vulnerability of the different ecosystem components in terms of their potential impact risk from the cumulative pressures across all human activities. An impact risk equal to 0 implies the ecosystem component is undisturbed, a value of 100 or more implies (local) extinction. The CIA can also show the relative contribution of each activity and its cumulative pressures to that vulnerability or, in other words the threat caused by that activity. It should be noted that the output of the CIA:

- Only includes direct effects, i.e. effects via food web relations and other cascading effects are not included.

- Is especially informative on relative values, i.e. the differences between the reference situation and the alternative/future/potential situation.

- Provides ranking orders of contributors to the overall threat caused by human activities.

- Can be used to provide an integrated perspective on the (change in) vulnerability of the ecosystem as a whole (in a specific study area like the Dutch part of the North Sea) as well as each of the different ecosystem components. 
- While this may be relevant for (future trends of) specific indicators (e.g. MSFD), it cannot be used to predict the actual values of those indicators.

- Has currently only limited value in providing spatially-explicit advice.

\section{Confidence}

The assessment is based on categorized risk criteria. Scores are assigned to the qualitative categories in order to reach semi-quantitative estimates of impact risk (see Annex 3). These categories and scores are rather course and the scores may be arbitrary. Although the extent was improved as compared to Borgwardt et al. (2019) by application of actual data (\% total surface area) instead of expert judgement-based categorical scores, this has only slightly improved the accuracy of the exposure estimate. The extent of the activity is used together with the assumed dispersal of the exerted pressures to estimate the exposure of the ecosystem components to the pressure. This dispersal was estimated using course and often arbitrary categorical scores. The actual dispersal of these pressures is unknown thus introducing considerable uncertainty. Certainly for pressures with (assumed) highest dispersal (e.g. litter, introduction of synthetic and non-synthetic compounds, genetically modified organisms, non-indigenous species) the pressure extent and hence impact risk is mostly determined by dispersal. In case of activities with a small extent (e.g. aquaculture) this overrides any effect of future scenarios or MPAs. Uncertainty is therefore huge for all activity-pressure combinations with low extent of the activity but high pressure dispersal and should hence be a priority topic to improve CIA.

In general the criteria, their scores and estimated impact risks come with considerable uncertainty. To illustrate this uncertainty, the impact risk of two different impact chains has been assessed using not only the applied scores for this study (as presented in Annex 3 ) but also including minimum and maximum categorical scores (Figure 15). This example illustrates that based on their applied "best" scores the aquaculture chain could be considered to contribute about twice as much to the overall threat as the wind farms chain which because of the known limitations of the method is presented as being more important. However, given their uncertainties they probably should be considered equally important while it could even be possible that in some occurrences the aquaculture chain contributes less to the threat. The assumption is that the aggregation across large numbers of chains as occurs in the results presented alleviates the effect of such exceptions. Thus when interpreting the CIA outcome we assume the ranked order, e.g. sector $A$ causes a bigger threat than sector $B$, is accurate but the relative impact, e.g. ecosystem component $C$ is twice as vulnerable as component $D$, is not. A fully quantitative assessment such as applied by Piet et al., (2021) would reduce these uncertainties considerably but requires substantial quantitative information.

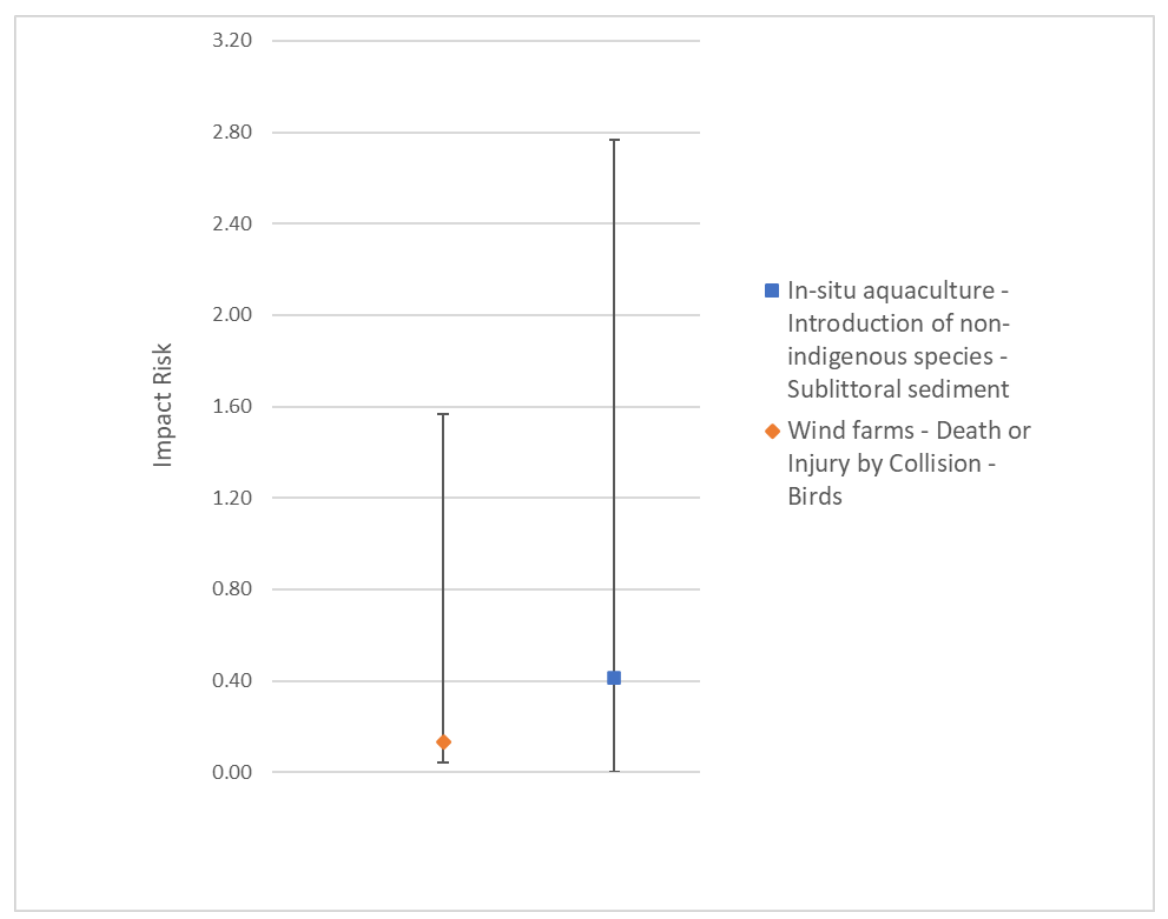

Figure 15 Impact risk of two different impact chains. The estimated risk is indicated by the markers, and the error bars show the uncertainty caused by the use of categories and scores. 


\subsubsection{Results}

The upscaling of wind energy and other future plans is expected to increase the threat to the North Sea ecosystem caused by offshore wind energy, both in an absolute sense as well as compared to that of other activities. This, however, need not result in an increase in the overall threat, i.e. all activities together, as these plans coincide and/or have consequences for several other activities. For example, the upscaling of wind energy is likely to coincide with a decrease in fishing impact as most/all of the fisheries applying mobile gear (e.g. trawling) are assumed to be banned within the windfarm areas. If this is not the case this assessment will give a very different outcome.

In order to meet the increasing demands for marine food production and compensate for the decreasing fisheries yields, the increase of windfarm areas is expected to be accompanied by (multiuse) aquaculture developments. The choice of aquaculture and design of the installations will have huge consequences on their impact on the ecosystem.

This study shows that the two activities causing most impact, i.e. benthic fisheries and aquaculture, are likely to continue to do so in future scenarios.

Aggregated impact risk caused by upscaling wind energy is expected to increase in future scenarios, for all relevant habitats and species groups. However, when considering all North Sea activities, the threat to habitats is expected to decrease in 2030 and 2050. Overall, the species groups show no major changes in the future scenarios, although in 2050 the vulnerability of birds is expected to have increased. It should be noted that within an ecosystem component there may be considerable differences among specific species. This depends on the species-specific sensitivity to OWF as compared to the sensitivity to other human activities like benthic fishery and aquaculture. Some species may benefit more from a decrease in the extent and intensity of a certain human activity as compared to other species and that effect may be higher than the added negative impact of an extension of OWF. Therefore attention should be given to study the consequences for key species, for instance "worst case" bird species with highest sensitivity to collision and habitat loss caused by OWF. Certain gull species, gannets and divers are seen as key bird species (Leopold et al., 2015; Fijn et al. 2019?; KEC 4 project) and have been selected for further studies in WOZEP. In addition harbour porpoise and seal species are key species among the marine mammals and as such require additional research. It makes sense to distinguish between harbour porpoises and seals when representing the marine mammals in the impact assessments as they have very different behaviour and population dynamics. 


\section{$4 \quad$ Future implications}

\subsection{Introduction}

This chapter addresses the implications of further upscaling offshore wind energy after 2030 for the North Sea ecosystem considering the identified cumulative impacts (i.e. the third main objective of this study, see chapter 1.2). More specifically, this includes the following topics:

- $\quad$ The concept of carrying capacity in relation to the North Sea ecosystem (4.2).

- An ecosystem-based approach to marine spatial planning of offshore wind and other marine activities aimed at achieving existing environmental marine policy goals (4.3).

For each topic a brief literature search was conducted by use of the SCOPUS search engine (www.scopus.com). Relevant studies were made available by the Wageningen University \& Research Library. The knowledge generated by this brief literature study was used together with expert opinion of the authors of this report to elaborate on these topics also in context of renewable (wind) energy developments.

\subsection{Carrying capacity of the North Sea ecosystem}

\subsubsection{Concept of carrying capacity}

Carrying capacity can have both natural and social science connotations and four different types of carrying capacities can be distinguished: physical, production, ecological and social (Byron and CostaPierce, 2013). Within the scope of this study, the term "carrying capacity" is intended to refer to the ecological carrying capacity.

Carrying capacity is typically defined as the maximum population size that can be supported indefinitely by a given environment, but there are at least 10 different specific definitions used in basic and applied ecology (Hixon, 2008). These include (1) the equilibrium population size or density where the birth rate equals the death rate, (2) a long-term average population size that is stable through time (regardless of varying demographic rates), and (3) population size constrained by whatever resource is in the shortest supply, in accordance with the law of the minimum. In this study we refer to these as part of the bottom-up perspective on carrying capacity where each ecosystem component occurs at a specific level limited by the resource in the shortest supply where each ecosystem component occurs at a specific level limited by the resource is in the shortest supply which effectively determines environmental capacity.

From reviewing the literature on carrying capacity in relation to food production Byron and CostaPierce (2013) found that, with few exceptions, carrying capacity is defined as the maximum sustainable yield (MSY) that can be produced within an area. Working from the premise that in this food production context where the removed biomass represents the pressure, carrying capacity is in fact the maximum allowable pressure exerted on the ecosystem. For an integrated multi-sectoral approach like CIA we expanded this to the maximum amount of pressure from any human activity acting on the ecosystem to acknowledge that food production is but one of the activities operating in the ecosystem. In this study we refer to this as the top-down perspective where each ecosystem component occurs at a specific level determined by the maximum amount of impact caused by the cumulative pressures from all human activities acting on the ecosystem. 
For this study we acknowledge the relevance of the bottom-up perspective but primarily apply the topdown perspective as this is most relevant in the context of impact assessments. Thus carrying capacity is defined as the maximum amount of human activities (and their cumulative pressures) the ecosystem can support without leading to significant deterioration of ecological processes, species, populations, or communities in the environment (adapted from Byron and Costa-Pierce, 2013). As there is, as yet, no scientific basis for what constitutes "significant deterioration" we only assess impact as the change in ecosystem state.

\subsubsection{Policy and management}

Carrying capacity is an important concept for ecosystem-based management (EBM, see section 4.3) as it may help define the upper limits of human activities and ecological limits (i.e. without causing "unacceptable change" to both natural ecosystem and social functions and structures) (Byron and Costa-Pierce, 2013), and hence the social acceptability of human activities which drives EBM. It is often used in the food production context to regulate sustainable aquaculture (Byron et al., 2011; Byron and Costa-Pierce, 2013) and fisheries (Akpalu and Bitew, 2014; Earle, 2021). However, since many more human activities occur in the North Sea, the carrying capacity concept needs to be expanded such that it encompasses all those activities and their pressures and considers all ecosystem components, not only those providing services such as (sea) food.

The concept is important in the Dutch North Sea Agreement (OFL, 2020), see text box below. This agreement also involves research on how to assess the anthropogenic impacts on carrying capacity and where to set a limit in order to maintain a healthy ecosystem. As, at present, there are no science-based thresholds that could be used as guidance for policy to set such limits, no indication can be given of what constitutes a minimum carrying capacity of the North Sea ecosystem (Figure 16).

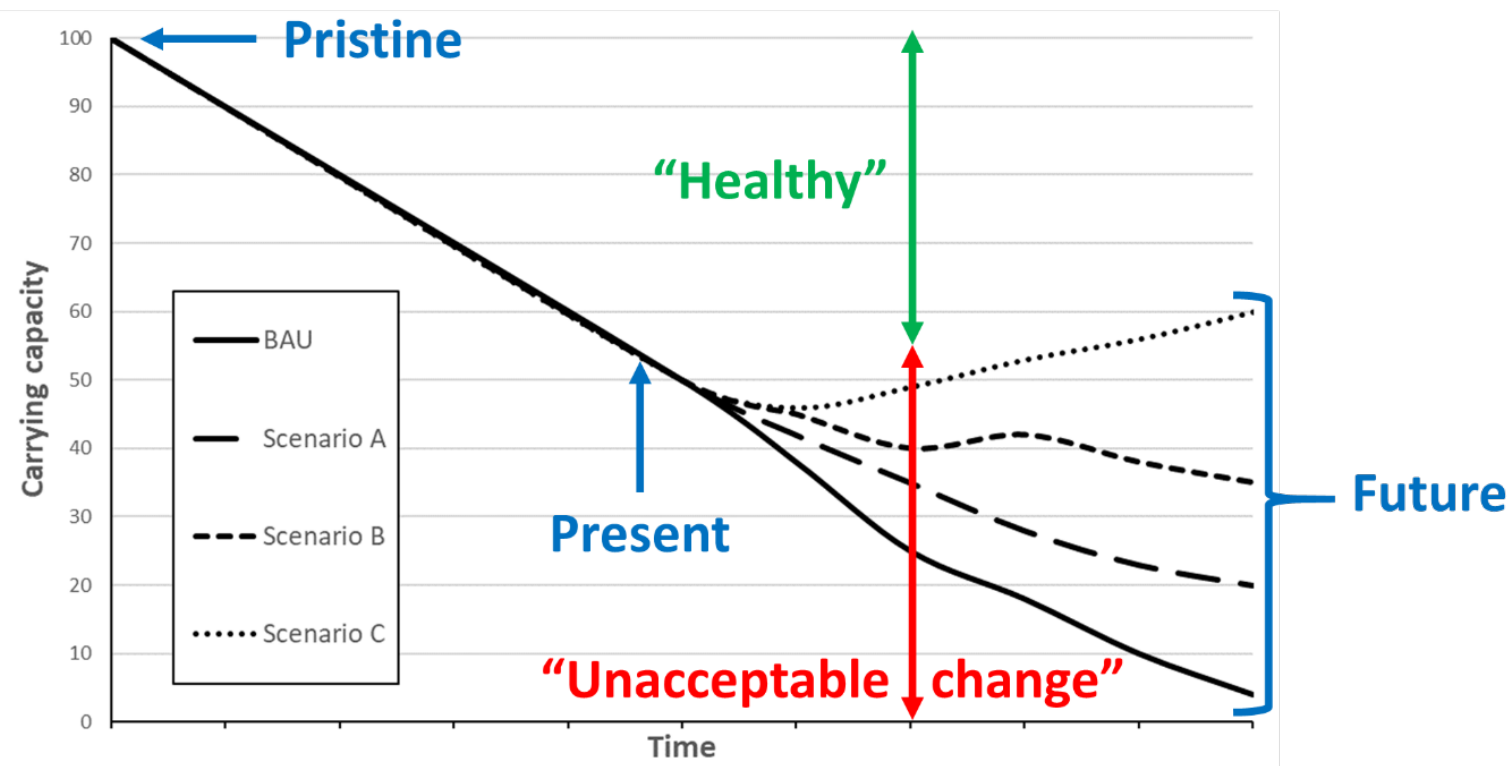

Figure 16 Schematic to explain the different terms related to carrying capacity. Other than "Pristine" none of them represent actual values. Also the scenarios are fictional. BAU stands for "Business as usual" representing a continuation of current practices. The shown threshold between "Healthy" and "Unacceptable change" is for demonstration purposes only and does not reflect any existing threshold. 


\section{North Sea Agreement (OFL, 2020)}

The Paris Climate Agreement calls for a fundamental shift in our way of life and production. It has been recognised that a new equilibrium needs to be achieved, taking the health of the North Sea as a whole into account. Specifically given the increasing pressure on the North Sea, additional efforts will be demanded in preserving and improving the quality of the ecosystem (including biodiversity). The North Sea Agreement (OFL, 2020) describes the agreements between the Dutch government and stakeholders through to 2030 with a future vision on the development of wind energy in the long term. It has been agreed to go extra miles for a healthy North Sea, both in area protection and in the protecting of species and supplementary measures for mitigating the negative effects on nature.

Ecological carrying capacity is a precondition for the individual and cumulative use of the North Sea by the various functions. The 'New Economy' on the North Sea calls for space for (the upscaling of) robust pilots and a uniform policy with clear underlying principles for licensing and choice of locations. This relates to mariculture (the farming of marine fish, shellfish and crustaceans, algae and seaweeds) and to alternative forms of marine energy generation. These activities must also be demonstrably appropriate for the ecological carrying capacity of the North Sea, for example in terms of the nutrients present and guaranteed safety. Within the North Sea Consultation, discussions aimed at achieving consensus regarding the governance and relevant principles will be organised.

In the joint assessment of the future for the North Sea, it became clear that with regard to certain matters, knowledge about the functioning of the ecosystem and the possible effects of the transitions that are set to take place is still lacking. The parties have reached agreements on the large-scale intensification of monitoring and scientific research on the North Sea. This could form the basis for future choices and further agreements (OFL, 2020).

\subsubsection{Carrying capacity: Top-down perspective}

The concept of carrying capacity from a top-down perspective is at the core of this impact assessment which estimates the change in all the relevant ecosystem components caused by the cumulative pressures from all human activities.

The assessment method works from the assumption that in an undisturbed situation all ecosystem components are at a specific (in this case pristine) equilibrium carrying capacity level but without specifying the actual population numbers or biomass. Similarly we can assume that the ecosystem components were at a (mostly lower than pristine) equilibrium carrying capacity level in any reference period where there were already specific levels of human activity. The impact assessment then calculates how the (further) change in human activities and their pressures results in a (further) change in equilibrium ecosystem state (=impact). This change is calculated from the effect the changes in human-induced pressures have on the two processes that determine this equilibrium, reproduction (i.e. number of births) and mortality (i.e. number of deaths).

Thus:

- The effect of a pressure on an ecosystem component results in an impact (=change in state) expressed as a proportional change in abundance (0-100\%)

- The cumulative impacts then reflect the overall footprint of the human activities on the ecosystem. This is the summation of all the impacts per ecosystem component and then aggregated into an ecosystem assessment as the averaged across the components (thus assuming equal importance).

Carrying capacity can be interpreted as the capacity of the ecosystem to sustain populations at a specific level through its productivity with primary production as its main driver and mortalities at natural levels determined by foodweb relationships. However, accepting humans as part of the ecosystem (and its carrying capacity) can also be interpreted to represent some acceptable level (e.g. sustainable, or "Good Environmental Status") of ecosystem state (and hence carrying capacity), i.e. population level of humans and their pressures. This level is determined by both the direct and indirect effects of human-induced pressures. The direct effects can occur by reducing the reproductive capacity of specific components (e.g. through contaminants) or through additional mortality (e.g. as caused by fishing) or both (e.g. habitat loss). The indirect effects constitute the effects on abiotic resources 
and/or the abundance or productivity of lower trophic level biota that have knock-on consequences on the higher levels (e.g. through the foodweb).

This approach thus circumvents the issue of having to establish what equilibrium carrying capacity levels (pristine or otherwise) are in terms of the actual population numbers or biomass. Something for which, certainly in the North Sea but just about any sea with a history of exploitation, information usually does not exist, e.g. for lack of time-series that go back far enough and notwithstanding that the ecosystem is likely to have changed even without human interference.

The approach also does not determine whether the baseline or future levels of human activity result in a "significant deterioration" of carrying capacity for lack of any scientific basis or accepted thresholds for what constitutes "significant deterioration". If such thresholds are established this assessment can determine if the ecosystem and its carrying capacity is in a healthy (i.e. not significantly deteriorated) state. Clearly this links to the concept of Good Environmental Status (GES) as used in the MSFD where for any specific ecosystem component significant deterioration would imply that it is not in GES.

\subsubsection{Carrying capacity: Bottom-up perspective}

The bottom-up perspective on carrying capacity assumes that all ecosystem components are at levels entirely determined by the availability of resources. For primary producers these are the abiotic resources, for all other trophic levels these are both biotic (lower-trophic-level) and abiotic resources. It may well be that some higher-trophic-level ecosystem components are indirectly affected by changes in other (a)biotic resources, e.g. through foodweb effects. These indirect effects, however, are not considered in this study. Below we provide some of the main potential indirect effects of OWF. In this brief introduction, we limit these changes to the pelagic water column and benthic habitats assuming that these are mostly responsible for the indirect effects on the other ecosystem components (i.e. birds, mammals and fish).

Based on an extensive literature review, Dannheim et al. (2020) developed conceptual path diagrams of hypothesized benthic changes by renewable energy devices (Figure 17). In total, 31 cause-effect relationships (or paths) were identified. Here, we highlight the paths possibly related to OWFs and the carrying capacity of the ecosystem. The knowledge base of these relationships can be found in Annex 4 of this report (taken from the Review of current knowledge on the hypothesized cause-effect relationships (hypothesized paths), provided as supplemental material by Dannheim et al. (2020)). Some relationships were identified as priority research areas by Dannheim et al. (2020). The relevant paths possibly related to OWFs and the carrying capacity of the ecosystem associated with the benthos are listed below, including the identification as priority research area and the numbering used by Dannheim et al. (2020), see Figure 17.

- $\quad$ Altered food availability to filter-feeders (priority research area; relationship No. 2);

- Modified currents/ hydrodynamic conditions will determine settlement success and species occurrences in the surrounding natural substrates (priority research area; relationship No. 4);

- Three-dimensional artificial structures which extend through the entire water column will affect local hydrodynamic conditions such as tidal and wind induced currents (relationship No. 5);

- Turbidity caused by suspended matter reduces light penetration into the water column thereby reducing the primary production of photosynthetically active phytoplankton (priority research area; relationship No. 6);

- Suspension-feeding fouling organisms extract plankton and suspended matter from the water column and thereby decrease turbidity (relationship No. 7);

- The addition of artificial hard structures will change the morphology and the complexity of benthic habitats. Alters types and amount of habitat (relationship No. 9);

- A specific hard bottom assemblage (fouling and mobile megafauna) consisting of primary and secondary producers will colonize the new and complex artificial habitat (relationship No. 13);

- Changes in the current conditions/altered hydrodynamics resuspend fine inorganic and organic sediment fractions in the water column and cause scour effects (relationship No. 20);

- Sediment disturbance such as dredging and cable laying during the construction phase will resuspend formerly deposited organic matter from the sediment (relationship No. 29). 
(a) biodiversity

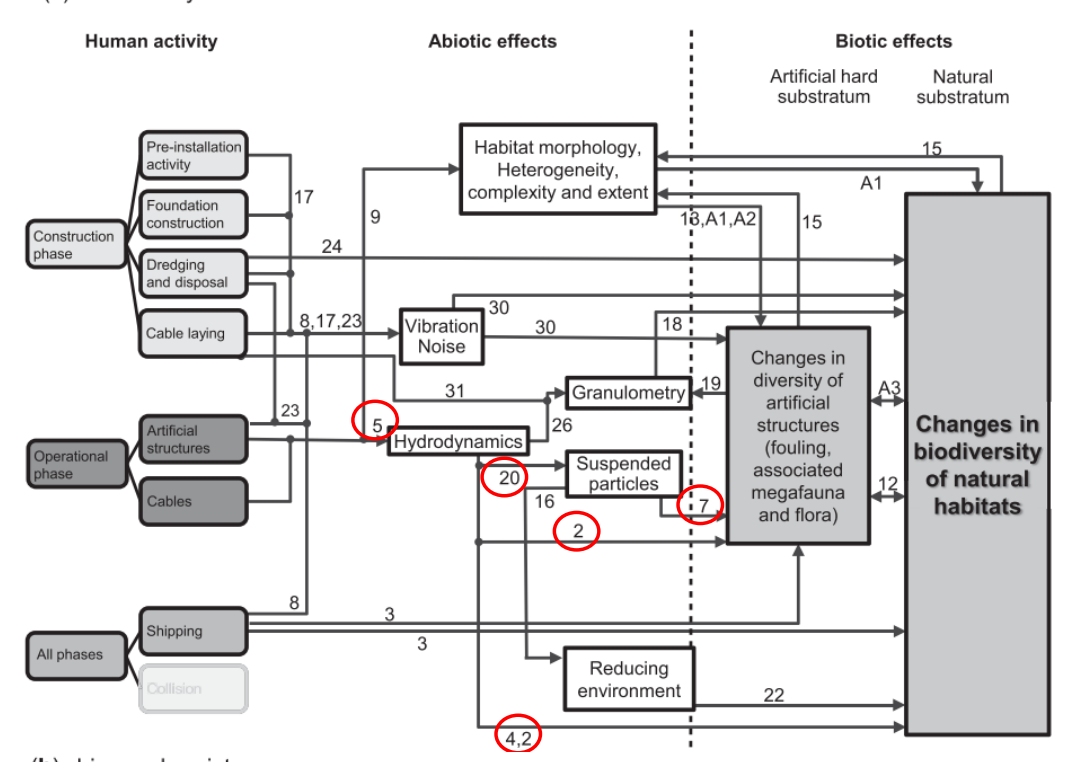

(b) biogeochemistry

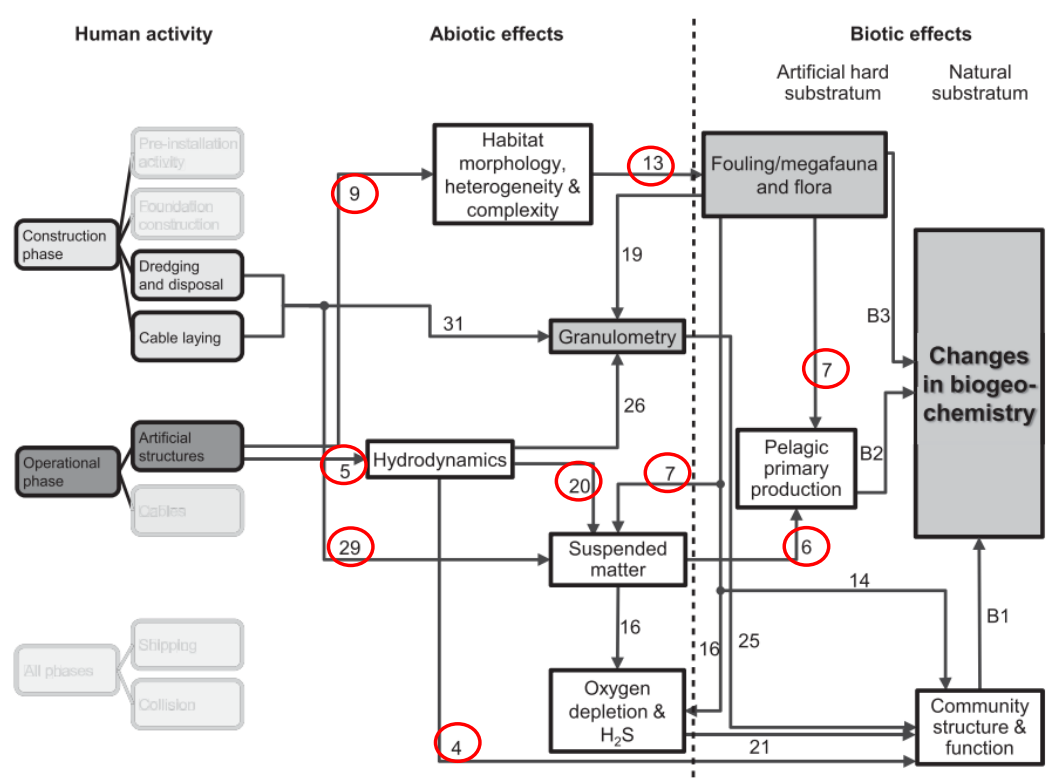

(c) food resources

Human activity

Abiotic effects

Biotic effects Artificial hard
substratum $\quad \begin{gathered}\text { Natural } \\ \text { substratum }\end{gathered}$

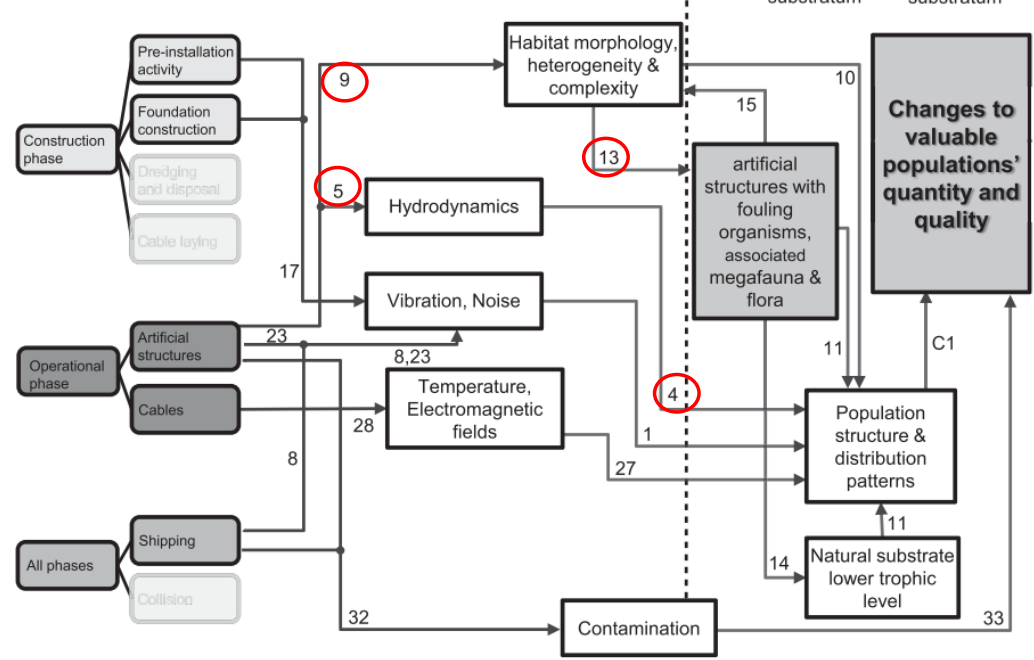

Figure 17 Conceptual path diagrams of the processes linked to a) biodiversity-, b) biogeochemicaland c) food resources-importance of the benthos (adapted from Dannheim et al., 2020). Hypothesized cause-effect relationships (paths) are numbered with red circles indicating paths related to carrying capacity, i.e. path 2, 4-7, 9, 13, 20 and 29. Dashed line divides abiotic (left) from biotic (right) effects. 
As shown in Figure 17, offshore wind farms may affect the ecological carrying capacity of the North Sea, both during the construction phase as well as during production phase. Activities during the construction phase are likely to increase the natural background levels of suspended particulate matter (SPM) in the water column (Tseng et al., 2020). Increased suspended particles may decrease light penetration and therewith decrease primary production (Tseng et al., 2020 and references therein; Dannheim et al., 2020). As construction activities are relatively short and local, the overall increase in SPM concentration is limited as opposed to the potential impacts during the operational phase of the OWF, which has a minimum duration of 20 years.

During production, the OWF foundation structures generate a turbulent wake as tidal currents move past the structures (i.e. cause higher turbulence levels), which may increase SPM. This was confirmed for wind turbines in the North Sea which induce SPM plumes with concentrations that are considerably higher than in ambient waters (Baeye and Fettweis, 2015). It is suggested that the epifaunal communities colonizing the monopile surface and the protective rock collar at the base play a key role as source of the SPM plumes. The organisms filter and trap fine SPM from the water column, resulting in predominant accumulation of SPM, including detritus and (pseudo-) faeces, at the base of the piles. When tidal currents exceed a certain velocity, fine particles in the near-bed fluff layer are resuspended and transported downstream in the wake of the piles (Baeye and Fettweis, 2015). The resuspension helps detrital organic particles disperse into the water column. This raises the detritus biomass and facilitates their opportunity of being captured by filter feeders such as zooplankton who then also increase in biomass (Wang et al., 2019 and references therein). In addition, resuspension enables the nutrient release from sub-marine sediments into water columns, and thus promotes phytoplankton growth by providing essential biogenic elements for photosynthesis (Wang et al., 2019). Thus, the biomass and production of zooplankton could be additionally enhanced, which makes it possible for other filter feeders such as shrimps, crabs, and small pelagic fish (e.g. anchovies, whose biomass significantly increased in the post-construction ecosystem) to be fed (Wang et al., 2019).

The wake generated by the turbine structures will also contribute to a mixing of the stratified water column and may significantly impact sediment transport and downstream sedimentation, which has been observed in the North Sea (Vanhellemont and Ruddick, 2014; Carpenter et al., 2016). Carpenter et al. (2016) showed that OWFs could impact the large-scale stratification, but only when they occupy extensive shelf regions. They are expected to have very little impact on large-scale stratification at the current capacity in the North Sea (a typical length of $8 \mathrm{~km}$ is used for the OWFs), but the impact could be significant in future large-scale development scenarios with a length scale of approximately $100 \mathrm{~km}$ (Carpenter et al., 2016).

An increase in phytoplankton's primary production by increased vertical mixing (reduced stratification during summer) due to OWFs, and subsequent nutrient transport throughout the water column, was recently demonstrated in the North Sea (Floeter et al., 2017). Concurrently, local hydrographic turbulences by OWFs increase particulate matter that increases the attenuation of light affecting primary production of phytoplankton.

Slavik et al. (2018) demonstrated that an increase in OWFs and the attached periphyton by mainly filter feeders in the North Sea, might lead to lower phytoplankton production. Slavik et al. (2019) investigated whether the accumulation of epifauna, dominated by the filter feeder Mytilus edulis (blue mussel), on turbine structures affects pelagic primary productivity and ecosystem functioning in the southern North Sea. M. edulis is the most abundant and ecologically important species at OWF epistructural communities in the North Sea (Slavik et al. (2019) and references therein). Simulations revealed potential changes in regional annual primary productivity of up to $8 \%$ within the OWF area, and induced maximal increases of the same magnitude in daily productivity also far from the wind farms (Slavik et al., 2019). Phytoplankton decreased throughout many parts of the Southern North Sea, albeit concentrated up to $20 \mathrm{~km}$ around the OWF. Water filtering by the epifauna might lead to changes in clearance rates of the water, i.e. reducing phytoplankton bloom and larvae affecting larval settlement success. Furthermore, these changes may have measurable effects on the composition of the benthic assemblages close to OWFs (Dannheim et al. (2020) and references therein). A strong increase of primary production was found up to $50 \mathrm{~km}$ outside the OWF area (Slavik et al., 2019). 
Tseng et al. (2020) measured average primary production and its seasonal variations in the Taiwan Strait. The authors suggest the impacts on primary production due to OWF installation to be limited during the winter and spring because vertical mixing in the Taiwan Strait was strong and water stability was already low during these seasons. However, since the highest primary production was in summer, the potential impact of OWF installation on primary production reduction may be larger during the summer than during other seasons (Tseng et al., 2020).

The impact of OWFs on the structure and energy flow of coastal ecosystems was assessed in a case study of the Rudong offshore wind farms in China (Wang et al., 2019). Ecopath models were constructed based on biological field data collected before the establishment of the OWFs in 2007 and compared with field data after establishment in 2015. The first set of the Rudong OWFs was constructed in 2010 and comprised 16 wind turbines with in total 32MW capacity. The number of turbines subsequently increased to 105 in 2014, and the capacity increased to 309.3MW (Wang et al., 2019). The most common turbine foundations in the Rudong OWFs are suction caissons which are designed to be lighter than an equivalent monopile foundation, which is a common foundation used in the North Sea. Overall, the existence of the Rudong OWFs resulted in significant changes in the trophic flow and system structure of the ecosystem. In the post-construction ecosystem phytoplankton and detritus was increased. The increased primary production and detritus resulted in the increased food supply for zooplankton, which made it possible for planktivorous species (zooplankton, anchovies) to be fed. Consequently, the biomass and production of other benthic fish also increased, which indicates a potential reef effect. However, other groups with decreased biomasses and productions may have been negatively impacted by the OWFs. Biomass decreases were observed in benthos (61.8\% decrease), shrimps (22.5\% decrease) and Gobiidae ( $12.1 \%$ decrease). This could be caused by resuspension induced by more hydrodynamics via soft-mud habitat destruction and settlement disturbance (Wang et al., 2019). All functional groups in the Rudong ecosystem had lower trophic levels in 2015 than in 2007, except zooplankton, phytoplankton, and detritus that had unchanged trophic levels. This indicates that the species composition within functional groups and the trophic relationships of the Rudong ecosystem might have changed. Indeed, detritus, zooplankton, anchovies, and other benthic fish increased in biomasses whereas other functional groups decreased in biomass with larger decreases occurring at higher trophic levels (Wang et al., 2019). The decreases in trophic levels observed in China (Wang et al., 2019) correspond to the trend observed in the North Sea (Reubens et al., 2013).

\subsubsection{Recommendations and the way forward}

Based on the literature reviewed for this study, the following major gaps and recommendations were found to further develop these integrated assessments through the consideration of both a top-down perspective and bottom-up perspective on carrying capacity.

\section{Top-down perspective}

The current assessment approaches essentially work from a top-down perspective on carrying capacity as only the direct effects of human activities on the (carrying capacity of) the ecosystem are considered. Despite this limitation the methodology is well-developed and supported widely in the scientific literature. The review of the literature reveals a trend of increasingly more sophisticated cumulative impact assessment methodologies supported by an expanding and improving knowledge base. The current assessment is a reflection of this where available quantitative information is merged into an assessment that was until very recent only based on expert judgement. This ongoing process should be continued and strengthened through the inclusion of available and newly developed quantitative information. Specifically spatial distribution maps of all the major ecosystem components and their pressures as well as robust pressure-effect relationships between those pressures and ecosystem components. The existing framework can guide this process by identifying the main knowledge gaps. 


\section{Bottom-up perspective}

This integrated assessment approach could be expanded so that it also includes the indirect effects. To that end we (1) need to strengthen the knowledge on the foodweb and its functioning and identify the main linkages (also other than through the foodweb and predator-prey relationships) through which these indirect effects may occur, and (2) increase our knowledge of the impacts of human activities on the lower-level biota and abiotic resources. Below are some findings from the literature.

- To assess OWF impact on water stratifications it is necessary to better understand the local turbulence production and induced mixing of the different OWF foundation structures so that more accurate mixing parameterisations can be developed (Carpenter et al., 2016).

- All the interactions between water stratification and turbidity within the nutrient and lightlimitation context, as well as the effect of filter-feeders on phytoplankton and larval settlement success (i.e. physical-biological interactions in OWFs) have currently not been investigated effectively (van der Molen et al., 2014; Carpenter et al., 2016; Dannheim et al., 2020).

- More information on diet composition of all ecosystem components is highly recommended (Reubens et al., 2013).

- We still miss a full understanding of the ecological processes that might change the ecological functioning, as studying biodiversity related to ecological functioning is still in its infancy (Dannheim et al., 2020). Despite the high sensitivity of the benthos to offshore wind farms, knowledge, particularly on long-term changes and large-scale effects related to artificial structures is lacking, as they are yet not sufficiently understood for us to make reliable assessments of effects or be able to predict changes. Consequently, this lack of knowledge hinders our ability to make informed decisions (Dannheim et al., 2020).

\subsection{Ecosystem-based approach to maritime spatial planning}

Maritime spatial planning (MSP) is widely seen as a tool enabling effective implementation of ecosystem-based marine management by considering and responding to our increasing understanding of the complex socio-ecological inter-relationships with the sea (Langlet and Westholm, 2019; Kidd et al., 2020). An introduction to MSP and the ecosystem based approach (EBA) is provided in Annex 5. In this section we focus on the most recent and internationally accepted practical approach to MSP by disclosing the results of the Study on Integrating an Ecosystem-based Approach into Maritime Spatial Planning. This study was contracted by the European Commission, i.e. initially the Executive Agency for Small and Medium-sized Enterprises (EASME), now the European Climate, Environment and Infrastructure Executive Agency (CINEA) together with DG Maritime Affairs and Fisheries (DGMARE) ${ }^{2}$, and awarded to a consortium led by Milieu Consulting together with, among others, Wageningen Marine Research (WMR). The study was finalized within the duration of this contract and provides a good basis to understand how the findings of this study may contribute to an Ecosystem-based approach to Maritime Spatial Planning (EBA-MSP) in the North Sea.

The practical approach that was put forward in this study was basically a merger between a suite of 15 principles that applied for ecosystem-based approaches based on a literature review and organised into three broad elements representing the main aspects of EBA specifically relevant for MSP:

1. Environmental - capturing the functioning and dynamics of marine ecosystems. The requirement to consider ecosystem aspects such as health, integrity, biodiversity and its functioning comes from the mentioning of these aspects in the various relevant policy documents (see section 3.6). The degree, to which these are incorporated, however, is determined not only by these policy documents but also by the outcome of the stakeholder process and the available knowledge. In each cycle of the MSP process, these need to be balanced but may initiate the further development of the knowledge base where clear gaps are identified. This should then allow the MSP process to become increasingly more ecosystem-based as more elaborate EBA are applied.

\footnotetext{
${ }^{2}$ Contract no. EASME/EMFF/2018/1.3.11/SI2.814068 (following call for tenders EASME/2019/OP/0002). In February 2021, EASME became part of the European Climate, Infrastructure and Environment Executive Agency (CINEA)
} 
2. Socio-economic - accounting for relevant human activities and socio-economic considerations including their interconnections with marine ecosystems. MSP always involves sectoral human activities, but the integration of EBA requires an explicit consideration of their potential ecosystem effects and the social-economic consequences. This will likely determine which activities to include but also more detail on how they may impact the ecosystem as well as the socio-economic drivers determining their allocation and operations. Ultimately EBA-MSP requires that the socio-economic drivers and their goals need to be balanced with the environmental goals for the ecosystem.

3. Governance and institutional - organising the MSP process with regard to governance and management. This involves stakeholder involvement, the use of science at the, sometimes multi-level, science-policy interface.

\section{The principles of EBA organised into three broad elements*}

\section{Capturing the integrity, functioning and dynamics of marine ecosystems}

- Consider the ecological integrity and biodiversity of marine ecosystems;

- Consider ecosystem connections and define distinct boundaries;

- Account for the dynamic nature of ecosystems;

- Give priority to sustainability as priority policy objective accounting for ecological as well as socio-economic goals and how society chooses to balance them;

- Consider appropriate spatial and temporal scales;

Incorporating human activities and their potential ecosystem effects along with their socio-economic considerations

- Make explicit human activities, their pressures and ecosystem services delivered as part of an entire Socio-Ecological System (SES);

- Take account of the cumulative impacts of human activities;

- Give priority to sustainability as priority policy objective accounting for ecological as well as socio-economic goals and how society chooses to balance them;

- Consider appropriate spatial and temporal scales;

\section{Organising the MSP process with regard to governance and management}

- Acknowledge uncertainty in assessments and decisions;

- Make best use of up-to-date scientific knowledge;

- Mobilise interdisciplinary science to address the different components of the SES;

- Support integrated management accounting for all sectors and issues;

- Support adaptive management of marine ecosystems that can respond to unexpected (climate, socio-economic) changes, including by setting relevant long-term management objectives;

- Apply the precautionary principle for issues and concerns where uncertainty is significant;

- Develop appropriate monitoring for capturing the functioning and dynamics of the SES;

- Mobilise stakeholders and support management at the lowest appropriate level.

* Note that some principles fit under more than one element

The proposed EBA-MSP process works from a five-stage MSP cycle based on the IOC-UNESCO 2009 guidance (Ehler et al., 2009) but simplified based on experience of EU Member States in notably the Baltic Sea (Schmidtbauer Crona et al., 2017). These five stages are:

1. Defining: setting the frame for the MSP, organising the MSP process and identifying its priority objectives and principles (societal goals)

2. Developing: building the knowledge base including stocktaking and analysing data and other information

3. Assessing: Assessing and balancing planning alternatives

4. Implementing: Implementing the plan

5. Follow-up: Evaluating results and performance 
Note these steps present a schematic view of MSP (see Figure 18). The actual sequence in each Regional Sea or Member State will depend on (inter)national governance and planning mechanisms.

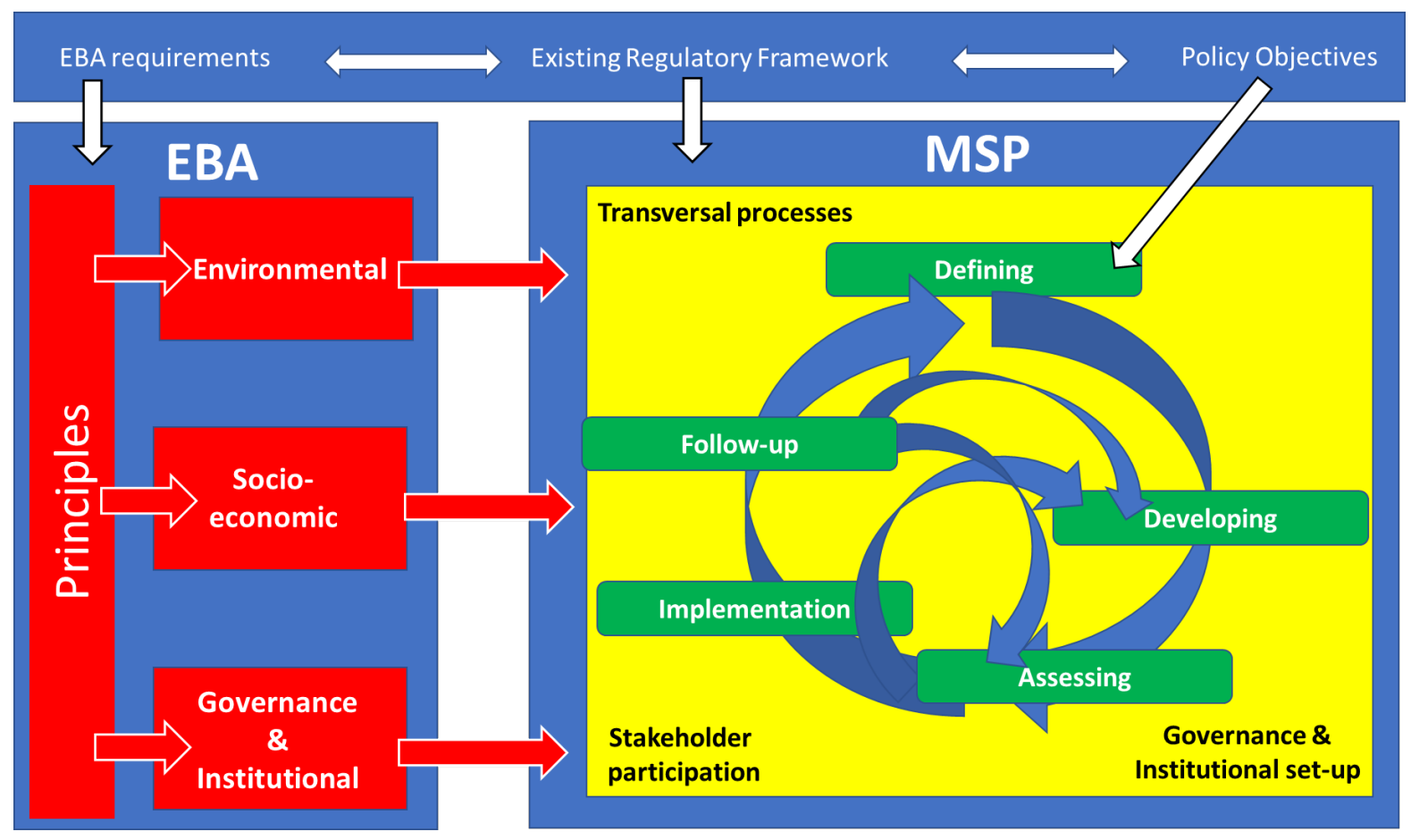

Figure 18 Various ecosystem-based approach (EBA) elements can be applied in each step of the Maritime Spatial Planning (MSP) cycle, sometime causing internal feedback loops. Both the EBA requirement, the MSP process and (part of) the societal goals come from the existing regulatory framework.

Based on a literature review conducted as part of the study on Integrating an Ecosystem-based Approach into Maritime Spatial Planning, the three main aspects of EBA specifically relevant for MSP are: (1) capturing the functioning and dynamics of marine ecosystems, (2) accounting for relevant human activities and socio-economic considerations including their interconnections with marine ecosystems, and (3) organising the MSP process with regard to governance and management.

To structure the practical approach, we adopted the five steps of the MSP cycle as the organising elements (see Figure 19). Together with this, the practical approach will present the cross-cutting elements needed when integrating EBA into MSP, much of this comes from the regulatory framework which includes key EU Directives such as the MSFD, the Nature Directives, the SEA Directive, as well as cross-cutting processes such as stakeholder engagement. In doing this it will account for known concepts such as the social-ecological system, nature-based solutions, or cumulative impacts.

The figure below (Figure 19) provides a schematic outline of our practical approach. The red arrows indicate how the outcome of the MSP steps feeds into the tools (including CIA). The black arrows indicate how the information may flow from one tool into the next. The figure shows that CIA is usually applied as part of the Assessing step where it may be combined with tools to conduct a costbenefit analysis and/or assess ecosystem services. The CIA application builds on decisions taken in the Defining step (where a Mental model may be constructed). 


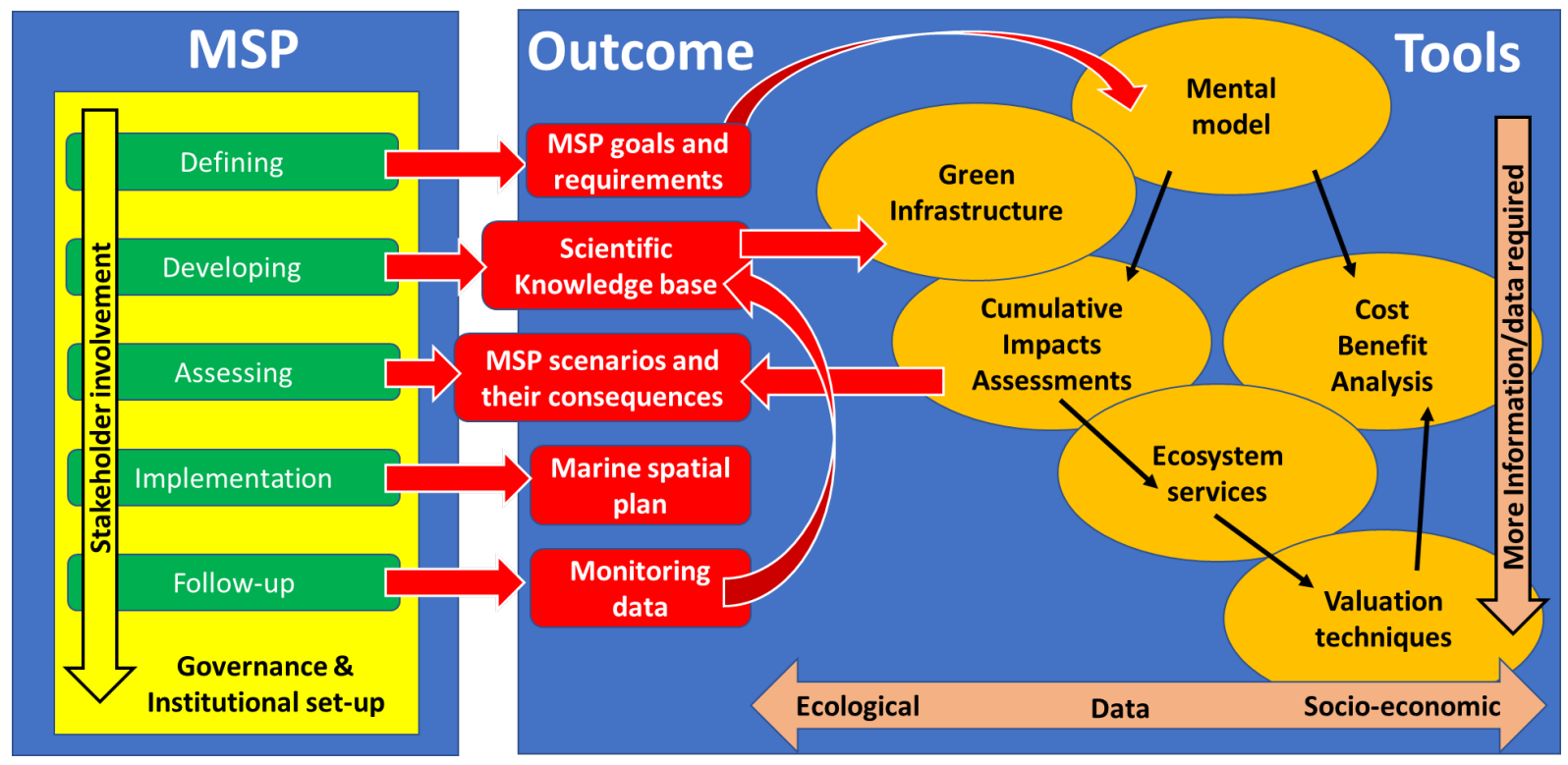

Figure 19 Outline of the practical approach in relation to the MSP process, its primary outcomes and the tools that may be applied where their positioning indicates their data requirements, how they relate to the science disciplines and sustainability dimensions and possible interrelatedness/dependency.

\section{Gaps and recommendations}

Based on the literature reviewed for this study, the following major gaps and recommendations were found regarding EBA to MSP:

- incorporating long-term change is a critical gap in MSP research (Gissi et al., 2019);

- new and intensified efforts on environmental data collection are needed to enable ecosystembased approach in MSP (Pınarbaşı et al., 2019). 


\section{$5 \quad$ Conclusions and recommendations}

This report provides an overview of the state-of-the-art knowledge to assess current and future cumulative impacts of all the main human activities on the North Sea ecosystem. This overview consists of the description of a robust risk-based methodology but its application in the North Sea context also reveals many of limitations in terms of quantitative data (e.g. spatial distributions) or understanding of various relationships (e.g. pressure on ecosystem component). As such much of the knowledge is still mostly expert judgement-based but now used in a formalised methodology that can guide further scientific studies to, in time, provide the information required and (further) improve the quality of such Cumulative Impact Assessments (CIAs).

The results of this study have identified the main threats to the North Sea ecosystem and its vulnerabilities, now and in the future. Bottom trawl fisheries still emerge as the human activity that, at a North Sea scale, poses the biggest threat to the ecosystem. The most vulnerable ecosystem components are the seafloor habitat with its benthic community as well as the fish community. This is as expected and mostly caused by the widespread extent of the fishing activities. Whereas the potential threat caused by the offshore wind developments are relatively small at a North Sea scale compared to that of fishing they may have significant local impacts that were not explicitly considered in this study. Moreover, because any emerging activity like offshore wind (or as part of multi-use initiatives aquaculture) has consequences for the space available for other activities such as fisheries, any environmental impact assessment should always consider these activities together, not in isolation.

This study has also shown that all human activities contribute to the overall (cumulative) impact on the ecosystem. This implies that the current state of the ecosystem (e.g. in terms of biodiversity) is caused by the historic and ongoing activities and their pressures while its future state will depend on the future scenarios of those activities in combination with the effects of exogenous drivers (such as climate) which are not explicitly covered in this study. Understanding cumulative impacts in a changing context is another major knowledge gap. While there is no one-to-one relationship between this (or any other) CIA and the state of the different indicators of the state of the North Sea (e.g. in terms of Good Environmental Status (GES) as required by the MSFD) the results of this CIA can be used to assess the likelihood of achieving environmental goals. For example: considering the current situation where GES is not achieved for the North Sea ecosystem as a whole, nor any of its biodiversity descriptors, it can be assumed that only if the future overall impact decreases there is a chance that GES will be achieved. Thus overall, aggregated, impact risk as assessed in the CIA can be considered a good predictor for the likelihood that GES can be achieved.

This CIA can also guide strategic, i.e. cross-sectoral, ecosystem-based management towards the mitigation of the activities/pressures that provide the biggest threat to the ecosystem as a whole or any of the specific indicators. Sector-specific models can then be applied to operationalise this guidance for the regulatory process informing sectoral management. In contrast, CIAs can never be sectoral and the consequences of such sectoral management should always be considered as part of a fully integrated perspective.

This CIA was now applied in a regional, i.e. North Sea, context. Therefore the results only reveal the main threats at a North Sea scale whereas a more local scale might reveal entirely different local threats that may be more relevant to guide national or even more local, e.g. specific MPAs or MSP initiatives. While the CIA methodology is suited to provide local-scale information it comes with considerable demands in terms of spatial distributions of activities, their pressures and the, sometimes very specific, i.e. species, ecosystem components. That information is now mostly lacking, certainly at a scale required to inform specific MSP initiatives such as are now taking place in several North Sea countries. A (more) spatially-explicit CIA can be used to guide the science to make such information available.

Another potentially relevant issue that was not touched upon in this CIA is that of the level of detail required in terms of the sectoral activities or ecosystem components. For example, for the fishing activity we distinguish between three different types of fisheries, i.e. benthic, pelagic and set nets. This because it is known that these different fisheries interact differently with the ecosystem and 
hence can be expected to contribute differently to the cumulative impacts. Due to a long history of fisheries science adequate information is available to make this distinction. Any further split into more fisheries comes with an information requirement. The same applies for offshore wind or any other activity. Together with stakeholders we need to decide what level of detail is appropriate/feasible considering the current availability of information and what needs to be made available. Similarly this CIA still applies rather crude categories of ecosystem components even though it is well known that there may be significant differences between sub-components (e.g. pelagic or demersal fish, epibenthos versus infauna) or specific species of marine mammals or seabirds. If species-specific information is available a CIA could provide species-specific assessments or for components consisting of many species, like fish or the benthic communities in the various habitats, an indication of worstcase situations where it is likely that the community risks losing its most vulnerable species even though the ecosystem component as a whole is not considered at risk.

Cumulative impacts are sometimes considered in relation to the concept of carrying capacity but mostly without any clear definition. Based on a literature review of ecological carrying capacity we distinguished two perspectives on the concept:

- A bottom-up perspective where each ecosystem component occurs at a specific level limited by the resource is in the shortest supply which effectively determines environmental capacity

- A top-down perspective where each ecosystem component occurs at a specific level determined by the maximum amount of impact caused by the cumulative pressures from all human activities acting on the ecosystem

For this study we acknowledge the relevance of the bottom-up perspective but primarily apply the topdown perspective as this is most relevant in the context of impact assessments. Thus carrying capacity is defined as the maximum amount of human activities (and their cumulative pressures) the ecosystem can support without leading to significant deterioration of ecological processes, species, populations, communities in the environment, or biodiversity. As there is, as yet, no scientific basis for what constitutes "significant deterioration" we only assess impact as the change in ecosystem state without any indication if this is acceptable, also in relation to carrying capacity, or not. By definition, a significant deterioration would imply that environmental goals (e.g. GES) are not achieved.

Ecosystem-based management and Marine Spatial Planning are now rapidly gaining attention as the means to mitigate the various human activities that may compromise the achievement of GES. A recent Study on Integrating an Ecosystem-based Approach into Maritime Spatial Planning (EBA-MSP) commissioned by the European Commission showed CIA to be among the key tools to apply as part of EBA-MSP and thus any planning of offshore wind farms or MPAs. 


\section{Quality Assurance}

Wageningen Marine Research utilises an ISO 9001:2015 certified quality management system. This certificate is valid until 15 December 2021. The organisation has been certified since 27 February 2001. The certification was issued by DNV GL. 


\section{References}

Akpalu, W., and Bitew, W. T. (2014). Optimum reserve size, fishing induced change in carrying capacity, and phenotypic diversity. J. Bioeconomics 16, 289-304. doi:10.1007/s10818-014-9178-8.

Baeye, M., and Fettweis, M. (2015). In situ observations of suspended particulate matter plumes at an offshore wind farm, southern North Sea. Geo-Marine Lett. 35, 247-255. doi:10.1007/s00367-0150404-8.

Berg, T., Fürhaupter, K., Teixeira, H., Uusitalo, L., and Zampoukas, N. (2015). The Marine Strategy Framework Directive and the ecosystem-based approach - pitfalls and solutions. Mar. Pollut. Bull. 96, 18-28. doi:10.1016/j.marpolbul.2015.04.050.

Borgwardt, F., Robinson, L., Trauner, D., Teixeira, H., Nogueira, A. J. A., Lillebø, A. I., et al. (2019). Exploring variability in environmental impact risk from human activities across aquatic ecosystems. Sci. Total Environ. 652, 1396-1408. doi:10.1016/j.scitotenv.2018.10.339.

Byron, C., Bengtson, D., Costa-Pierce, B., and Calanni, J. (2011). Integrating science into management: Ecological carrying capacity of bivalve shellfish aquaculture. Mar. Policy 35, 363-370. doi: $10.1016 / \mathrm{j}$.marpol.2010.10.016.

Byron, C. J., and Costa-Pierce, B. A. (2013). Carrying capacity tools for use in the implementation of an ecosystems approach to aquaculture. Site Sel. Carr. Capacit. Inl. Coast. Aquac., 87-101. Available at: http://ecologicalaquaculture.org/Byron\&Costa-PierceFAO(2011).pdf.

Carpenter, J. R., Merckelbach, L., Callies, U., Clark, S., Gaslikova, L., and Baschek, B. (2016). Potential impacts of offshore wind farms on North Sea stratification. PLoS One 11, 1-28. doi: $10.1371 /$ journal.pone.0160830.

Chalastani, V. I., Tsoukala, V. K., Coccossis, H., and Duarte, C. M. (2021). A bibliometric assessment of progress in marine spatial planning. Mar. Policy 127, 104329. doi:10.1016/j.marpol.2020.104329.

Dannheim, J., Bergström, L., Birchenough, S. N. R., Brzana, R., Boon, A. R., Coolen, J. W. P., et al. (2020). Benthic effects of offshore renewables: Identification of knowledge gaps and urgently needed research. ICES J. Mar. Sci. 77, 1092-1108. doi:10.1093/icesjms/fsz018.

DG Mare-IOC-UNESCO (2017). Joint Roadmap to accelerate Maritime/Marine Spatial Planning processes worldwide (MSP). 2nd Int. Conf. Mar. Spat. Plan., 5.

Earle, M. (2021). Maximum sustainable yield in the EU's Common Fisheries Policy - a political history. ICES J. Mar. Sci. doi:10.1093/icesjms/fsab037.

Ehler, Charles, Douvere, Fanny, and Ioc (2009). Marine spatial planning: a step-by-step approach toward ecosystem-based management.

EU (2008). Directive 2008/56/EC of the European Parliament and of the council of 17 June 2008 establishing a framework for community action in the field of marine environmental policy (Marine Strategy Framework Directive). 40. Available at: https://eur-lex.europa.eu/legalcontent/EN/TXT/?uri=CELEX:32008L0056.

European Commission (2017). Commission Decision (EU) 2017/848 of 17 May 2017 laying down criteria and methodological standards on good environmental status of marine waters and specifications and standardised methods for monitoring and assessment, and repealing Decision 2010/477/EU. Off. J. Eur. Union 125, 43-74. doi:http://eurlex.europa.eu/pri/en/oj/dat/2003/l_285/I_28520031101en00330037.pdf.

Floeter, J., van Beusekom, J. E. E., Auch, D., Callies, U., Carpenter, J., Dudeck, T., et al. (2017). Pelagic effects of offshore wind farm foundations in the stratified North Sea. Prog. Oceanogr. 156, 154-173. doi:10.1016/j.pocean.2017.07.003.

Frazão Santos, C., Domingos, T., Ferreira, M. A., Orbach, M., and Andrade, F. (2014). How sustainable is sustainable marine spatial planning? Part I-Linking the concepts. Mar. Policy 49, 59-65. doi:10.1016/j.marpol.2014.04.004.

Friess, B., and Grémaud-Colombier, M. (2019). Policy outlook: Recent evolutions of maritime spatial planning in the European Union. Mar. Policy, 103428. doi:10.1016/j.marpol.2019.01.017.

Garcia, S. . ed. (2003). The ecosystem approach to fisheries. Rome: FOOD AND AGRICULTURE ORGANIZATION OF THE UNITED NATIONS Available at: http://www.fao.org/3/Y4773E/y4773e00.htm\#Contents.

Gissi, E., Fraschetti, S., and Micheli, F. (2019). Incorporating change in marine spatial planning: A review. Environ. Sci. Policy 92, 191-200. doi:10.1016/j.envsci.2018.12.002.

Government of the Netherlands (2019). Joint recommendation by the Netherlands regarding fisheries management measures under Article 11 and 18 of Regulation (EU) No 1380/2013 of The European 
Parliament and of the Council of 11 December 2013 on the Common Fisheries Policy (the Basic Regulation).

Gyimesi, A., De Jong, J. W., Potiek, A., and Bravo Rebolledo, E. L. (2018). Actualisatie van KEC vogelaanvaring berekeningen volgens Routekaart 2030. Rapportnr. 18-290. Available at: https://www.noordzeeloket.nl/publish/pages/157580/actualisatie_van_kec_vogelaanvaring_berekenin gen_volgens_routekaart_2030.pdf.

Hammond, P. S., Lacey, C., Gilles, A., Viquerat, S., Börjesson, P., Herr, H., et al. (2018). Estimates of cetacean abundance in European Atlantic waters in summer 2016 from the SCANS-III aerial and shipboard surveys. Available at:

https://doi.org/10.1016/j.seares.2019.03.004\%0Ahttp://dx.doi.org/10.1016/j.marpolbul.2014.08.025 \%0Ahttps://doi.org/10.1016/j.ijppaw.2018.04.001\%0Ahttp://dx.doi.org/10.1016/j.vetpar.2011.08.00 2\%0Ahttps://doi.org/10.1016/j.ijppaw.2018.01.002\%0Ahttp://dx.doi.

Hixon, M. A. (2008). "Carrying Capacity," in Encyclopedia of Ecology, Five-Volume Set (Elsevier Inc.), 528530. doi:10.1016/B978-008045405-4.00468-7.

Kidd, S., Calado, H., Gee, K., Gilek, M., and Saunders, F. (2020). Marine Spatial Planning and sustainability: Examining the roles of integration - Scale, policies, stakeholders and knowledge. Ocean Coast. Manag. 191, 105182. doi:10.1016/j.ocecoaman.2020.105182.

Kirkfeldt, T. S. (2019). An ocean of concepts: Why choosing between ecosystem-based management, ecosystem-based approach and ecosystem approach makes a difference. Mar. Policy 106, 103541. doi:10.1016/j.marpol.2019.103541.

Knights, A. M., Koss, R. S., and Robinson, L. A. (2013). Identifying common pressure pathways from a complex network of human activities to support ecosystem-based management. Ecol. Appl. 23, 755765. doi:https://doi.org/10.1890/12-1137.1.

Knights, A. M., Piet, G. J., Jongbloed, R. H., Tamis, J. E., White, L., Akoglu, E., et al. (2015). An exposureeffect approach for evaluating ecosystem-wide risks from human activities. ICES J. Mar. Sci. 72, 11051115. Available at: https://doi.org/10.1093/icesjms/fsu245.

Langlet, D., and Westholm, A. (2019). Synthesis Report on the Ecosystem Approach to Maritime Spatial Planning.

Leopold, M. F., Boonman, M., Collier, M. P., Davaasuren, N., Fijn, R. C., Gyimesi, A., et al. (2014). A first approach to deal with cumulative effects on birds and bats of offshore wind farms and other human activities in the Southern North Sea. IMARES Report C166/14. 360.

OFL (2020). The North Sea Agreement. doi:10.1080/00139157.1974.9928424.

Piet, G., Culhane, F., Jongbloed, R., Robinson, L., Rumes, B., and Tamis, J. (2019). An integrated risk-based assessment of the North Sea to guide ecosystem-based management. Sci. Total Environ. 654, 694704. doi: $10.1016 /$ j.scitotenv.2018.11.001.

Piet, G. J., Jongbloed, R. H., Knights, A. M., Tamis, J. E., Paijmans, A. J., van der Sluis, M. T., et al. (2015). Evaluation of ecosystem-based marine management strategies based on risk assessment. Biol. Conserv. 186, 158-166. doi:10.1016/j.biocon.2015.03.011.

Piet, G. J., Knights, A. M., Jongbloed, R. H., Tamis, J. E., de Vries, P., and Robinson, L. A. (2017). Ecological risk assessments to guide decision-making: Methodology matters. Environ. Sci. Policy 68, 1-9. doi:10.1016/J.ENVSCI.2016.11.009.

Piet, G. J., Tamis, J. E., Volwater, J., de Vries, P., and van der Wal, J.T. Jongbloed, R. H. (2021). A roadmap towards quantitative cumulative impact assessments: every step of the way. Sci. Total Environ. 784, 146847. doi:10.1016/j.scitotenv.2021.146847.

Pınarbaşı, K., Galparsoro, I., and Borja, Á. (2019). End users' perspective on decision support tools in marine spatial planning. Mar. Policy 108. doi:10.1016/j.marpol.2019.103658.

Qiu, W. F., and Jones, P. J. S. (2013). The emerging policy landscape for marine spatial planning in Europe. Mar. Policy 39, 182-190. doi:10.1016/j.marpol.2012.10.010.

Reubens, J. T., Vandendriessche, S., Zenner, A. N., Degraer, S., and Vincx, M. (2013). Offshore wind farms as productive sites or ecological traps for gadoid fishes? - Impact on growth, condition index and diet composition. Mar. Environ. Res. 90, 66-74. doi:10.1016/j.marenvres.2013.05.013.

Schmidtbauer Crona, J. (Ed. ., Ruskule, A., Kopti, M., Käppeler, B., Dael, S., and Wesolowska, M. (2017). The Ecosystem Approach in Maritime Spatial Planning - A Checklist Toolbox. Available at: http://www.balticscope.eu/.

Slavik, K., Lemmen, C., Zhang, W., Kerimoglu, O., Klingbeil, K., and Wirtz, K. W. (2019). The large-scale impact of offshore wind farm structures on pelagic primary productivity in the southern North Sea. Hydrobiologia 845, 35-53. doi:10.1007/s10750-018-3653-5.

Tamis, J. E., Jongbloed, R. H., Asjes, A., and Piet, G. J. (2019). NatuurBalans Noordzee.

The Netherlands (2019). Proposal for Fisheries Management Measures to protect the Common Guillemot ( A199) in the Frisian Front Special Protection Area. Annex to the Joint Recommendation. Submission to the European Commission. The Hague.

Tseng, H. C., You, W. L., Huang, W., Chung, C. C., Tsai, A. Y., Chen, T. Y., et al. (2020). Seasonal Variations 
of Marine Environment and Primary Production in the Taiwan Strait. Front. Mar. Sci. 7, 1-13. doi:10.3389/fmars.2020.00038.

van der Molen, J., Smith, H. C. M., Lepper, P., Limpenny, S., and Rees, J. (2014). Predicting the large-scale consequences of offshore wind turbine array development on a North Sea ecosystem. Cont. Shelf Res. 85, 60-72. doi:10.1016/j.csr.2014.05.018.

van der Wal, J. T. ., van Puijenbroek, M. E. B., and Leopold, M. F. (2018). Cumulatieve effecten van offshore wind parken : habitatverlies zeevogels. Available at:

https://www.noordzeeloket.nl/publish/pages/157569/cumulatieve_effecten_van_offshore_wind_parke n_habitatverlies_zeevogels_update_voor_vijf_zeevogelsoor.pdf.

van der Wal, J. T., and Quirijns, F. J. (2011). Inventory of current and future presence of non-wind sea use functions. Den Helder, Netherlands Available at:

http://www.windspeed.eu/media/publications/Windspeed_WP3_D3.1_update_V2_final.pdf [Accessed April 25, 2014].

Vanhellemont, Q., and Ruddick, K. (2014). Turbid wakes associated with offshore wind turbines observed with Landsat 8. Remote Sens. Environ. 145, 105-115. doi:10.1016/j.rse.2014.01.009.

Wang, J., Zou, X., Yu, W., Zhang, D., and Wang, T. (2019). Effects of established offshore wind farms on energy flow of coastal ecosystems: A case study of the Rudong offshore wind farms in China. Ocean Coast. Manag. 171, 111-118. doi:10.1016/j.ocecoaman.2019.01.016.

Zaucha, J., and Gee, K. eds. (2019). Maritime Spatial Planning past, present, future. Cham, Switzerland: Springer Nature Switzerland doi:10.1007/978-3-319-98696-8_10. 


\section{Justification}

Report C081/21

Project Number: 4315100152

The scientific quality of this report has been peer reviewed by a colleague scientist and a member of the Management Team of Wageningen Marine Research

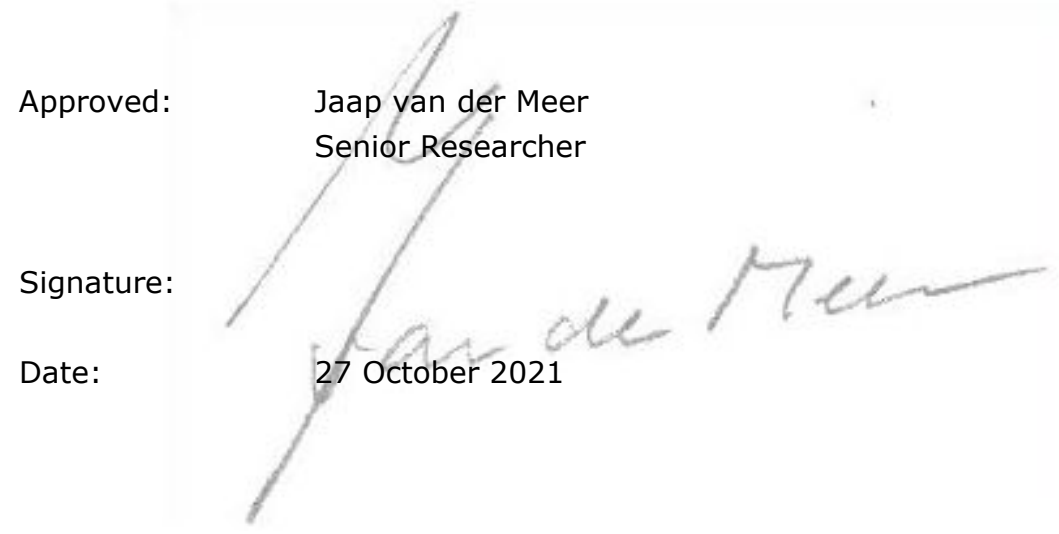

Approved:

Jakob Asjes

Manager Integration

Signature:

Date:

26 October 2021 


\section{Annex 1 Spatial information and maps for human activities and protected nature areas in the North Sea}

List of maps available for human activities and protected nature areas in the North Sea

\begin{tabular}{|c|c|c|c|c|}
\hline $\begin{array}{l}\text { Human } \\
\text { use }\end{array}$ & Source & URL & $\begin{array}{l}\text { WFS } \\
\text { availab } \\
\text { le }\end{array}$ & Format \\
\hline \multirow[t]{3}{*}{$\begin{array}{l}\text { Wind } \\
\text { farms }\end{array}$} & $\begin{array}{l}\text { EMODn } \\
\text { et HA }\end{array}$ & $\begin{array}{l}\text { Wind Farms (Polygons) | EMODnet Human Activities (emodnet- } \\
\text { humanactivities.eu): https://www.emodnet-humanactivities.eu/search- } \\
\text { results.php?dataname=Wind+Farms+\%28Polygons } \% 29\end{array}$ & Yes & \\
\hline & $\begin{array}{l}\text { EMODn } \\
\text { et HA }\end{array}$ & $\begin{array}{l}\text { Wind Farms (Points) | EMODnet Human Activities (emodnet- } \\
\text { humanactivities.eu): https://www.emodnet-humanactivities.eu/search- } \\
\text { results.php?dataname=Wind+Farms+\%28Points } \% 29\end{array}$ & Yes & \\
\hline & OSPAR & $\begin{array}{l}\text { OSPAR Offshore Renewable Energy Developments - 2017 - ODIMS: } \\
\text { https://odims.ospar.org/en/submissions/ospar_offshore_renewables_2 } \\
\text { 017_01_002/ }\end{array}$ & Possibly & $\begin{array}{l}\text { Shapefile(s } \\
\text { ) }\end{array}$ \\
\hline \multirow[t]{4}{*}{ Oil \& Gas } & OSPAR & $\begin{array}{l}\text { OSPAR Inventory of Offshore Installations - } 2017 \text { - ODIMS: } \\
\text { https://odims.ospar.org/en/submissions/ospar_offshore_installations_2 } \\
017 \_01 \_001 /\end{array}$ & Possibly & $\begin{array}{l}\text { Shapefile(s } \\
\text { ) }\end{array}$ \\
\hline & $\begin{array}{l}\text { EMODn } \\
\text { et HA }\end{array}$ & $\begin{array}{l}\text { Offshore Installations | EMODnet Human Activities (emodnet- } \\
\text { humanactivities.eu): https://www.emodnet-humanactivities.eu/search- } \\
\text { results.php?dataname=Offshore+Installations }\end{array}$ & Yes & \\
\hline & $\begin{array}{l}\text { EMODn } \\
\text { et HA }\end{array}$ & $\begin{array}{l}\text { Active Licences | EMODnet Human Activities (emodnet- } \\
\text { humanactivities.eu): https://www.emodnet-humanactivities.eu/search- } \\
\text { results.php?dataname=Active+Licences }\end{array}$ & Yes & \\
\hline & $\begin{array}{l}\text { EMODn } \\
\text { et HA }\end{array}$ & $\begin{array}{l}\text { Boreholes | EMODnet Human Activities (emodnet-humanactivities.eu): } \\
\text { https://www.emodnet-humanactivities.eu/search- } \\
\text { results.php?dataname=Boreholes }\end{array}$ & Yes & \\
\hline \multirow[t]{3}{*}{$\begin{array}{l}\text { Cables \& } \\
\text { Pipelines }\end{array}$} & $\begin{array}{l}\text { EMODn } \\
\text { et HA }\end{array}$ & $\begin{array}{l}\text { Telecommunication Cables (actual route locations) | EMODnet Human } \\
\text { Activities (emodnet-humanactivities.eu): https://www.emodnet- } \\
\text { humanactivities.eu/search- } \\
\text { results. php?dataname=Telecommunication+Cables+\%28actual+route } \\
\text { +locations } \% 29\end{array}$ & Yes & $\begin{array}{l}\text { fGDB } \\
\text { +ShapeFile } \\
\text { (s) }\end{array}$ \\
\hline & $\begin{array}{l}\text { EMODn } \\
\text { et HA }\end{array}$ & $\begin{array}{l}\text { Power Cables | EMODnet Human Activities (emodnet- } \\
\text { humanactivities.eu): https://www.emodnet-humanactivities.eu/search- } \\
\text { results.php?dataname=Power+Cables }\end{array}$ & Yes & $\begin{array}{l}\text { fGDB } \\
\text { +ShapeFile } \\
\text { (s) }\end{array}$ \\
\hline & $\begin{array}{l}\text { EMODn } \\
\text { et HA }\end{array}$ & $\begin{array}{l}\text { Pipelines | EMODnet Human Activities (emodnet-humanactivities.eu): } \\
\text { https://www.emodnet-humanactivities.eu/search- } \\
\text { results.php?dataname=Pipelines }\end{array}$ & Yes & $\begin{array}{l}\text { fGDB } \\
\text { +ShapeFile } \\
(\mathrm{s})\end{array}$ \\
\hline \multirow[t]{2}{*}{$\begin{array}{l}\text { Protected } \\
\text { nature } \\
\text { areas * }\end{array}$} & EEA & $\begin{array}{l}\text { Natura } 2000 \text { data - the European network of protected sites - } \\
\text { European Environment Agency (europa.eu): } \\
\text { https://www.eea.europa.eu/data-and-maps/data/natura-11 }\end{array}$ & $\begin{array}{l}\text { via } \\
\text { EMODn } \\
\text { et HA }\end{array}$ & GPKG \\
\hline & $\begin{array}{l}\text { EMODn } \\
\text { et HA }\end{array}$ & $\begin{array}{l}\text { Nationally Designated Areas | EMODnet Human Activities (emodnet- } \\
\text { humanactivities.eu): https://www.emodnet-humanactivities.eu/search- } \\
\text { results.php?dataname=Nationally+Designated+Areas }\end{array}$ & Yes & fGDB \\
\hline Fishery \# & $\begin{array}{l}\text { EMODn } \\
\text { et HA }\end{array}$ & $\begin{array}{l}\text { Fishing Intensity | EMODnet Human Activities (emodnet- } \\
\text { humanactivities.eu): https://www.emodnet-humanactivities.eu/search- } \\
\text { results.php?dataname=Fishing+Intensity }\end{array}$ & Yes & \\
\hline \multirow[t]{3}{*}{$\begin{array}{l}\text { Aquacultu } \\
\text { re @ }\end{array}$} & $\begin{array}{l}\text { EMODn } \\
\text { et HA }\end{array}$ & $\begin{array}{l}\text { Finfish Production | EMODnet Human Activities (emodnet- } \\
\text { humanactivities.eu): https://www.emodnet-humanactivities.eu/search- } \\
\text { results.php?dataname=Finfish+Production }\end{array}$ & Yes & $\begin{array}{l}\text { fGDB } \\
\text { +ShapeFile } \\
\text { (s) }\end{array}$ \\
\hline & $\begin{array}{l}\text { EMODn } \\
\text { et HA }\end{array}$ & $\begin{array}{l}\text { Shellfish Production | EMODnet Human Activities (emodnet- } \\
\text { humanactivities.eu): https://www.emodnet-humanactivities.eu/search- } \\
\text { results.php?dataname=Shellfish+Production }\end{array}$ & Yes & $\begin{array}{l}\text { fGDB } \\
\text { +ShapeFile } \\
\text { (s) }\end{array}$ \\
\hline & $\begin{array}{l}\text { EMODn } \\
\text { et HA }\end{array}$ & $\begin{array}{l}\text { Macroalgae (seaweeds) | EMODnet Human Activities (emodnet- } \\
\text { humanactivities.eu): https://www.emodnet-humanactivities.eu/search- } \\
\text { results.php?dataname=Macroalgae+\%28seaweeds } \% 29\end{array}$ & Yes & \\
\hline $\begin{array}{l}\text { Sand } \\
\text { extraction }\end{array}$ & $\begin{array}{l}\text { EMODn } \\
\text { et HA }\end{array}$ & $\begin{array}{l}\text { Aggregate Extraction Areas | EMODnet Human Activities (emodnet- } \\
\text { humanactivities.eu): https://www.emodnet-humanactivities.eu/search- } \\
\text { results.php?dataname=Aggregate+Extraction+Areas }\end{array}$ & Yes & \\
\hline $\begin{array}{l}\text { Shipping } \\
\text { routes }\end{array}$ & $\begin{array}{l}\text { EMODn } \\
\text { et HA }\end{array}$ & $\begin{array}{l}\text { Vessel Density | EMODnet Human Activities (emodnet- } \\
\text { humanactivities.eu): https://www.emodnet-humanactivities.eu/search- } \\
\text { results.php?dataname=Vessel+Density+ }\end{array}$ & Yes & \\
\hline
\end{tabular}

* discrimination in Level of protection (some categories to be chosen)

\# discrimination in 1. Benthic, 2. Pelagic, 3. Nets

@ discrimination in 1.Seaweed, 2. Shellfish, 3. Fish

+ (map needed to estimate area, length, count, volume etc.)

Access date was 21 March 2021 


\section{Maps of human activities and protected nature areas in the North Sea}

In this annex and this report, maps are shown for:

- Wind farms

- Protected natura areas

- Fishery

- Oil \& Gas

- $\quad$ Cables \& Pipelines

- Aquaculture

- Sand extraction

- $\quad$ Shipping routes

\section{Wind farms:}

See Figure 2 in this report

\section{Protected nature areas:}

See Figure 4 in this report

The recently assigned N2000-area Bruine Bank (Brown Ridge) and the "candidate" N2000-area Borkumse Stenen (Borkum Stones) in the Dutch EEZ of the North Sea.

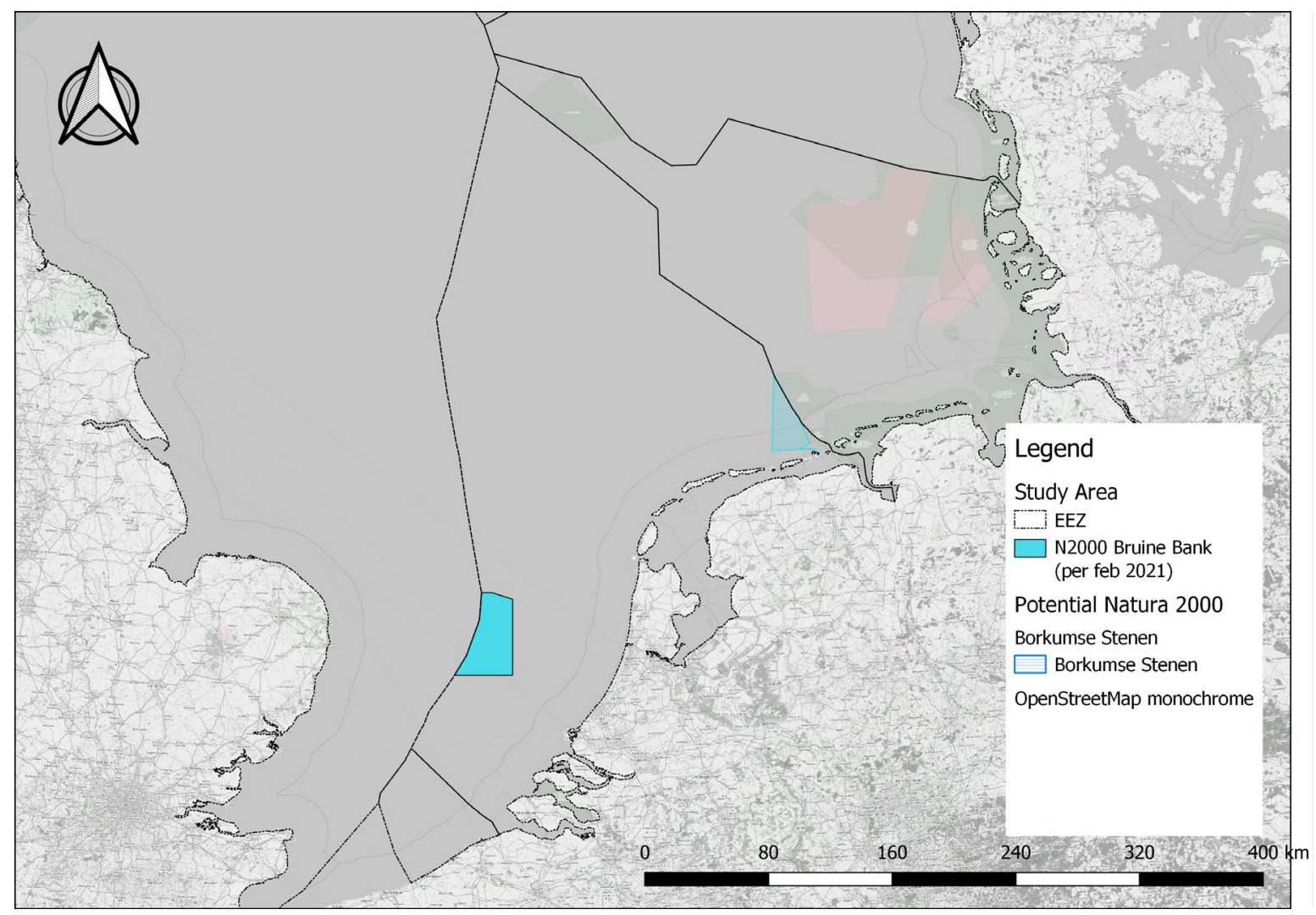

Fishery:

See Figure 3 in this report. 


\section{Oil \& Gas:}

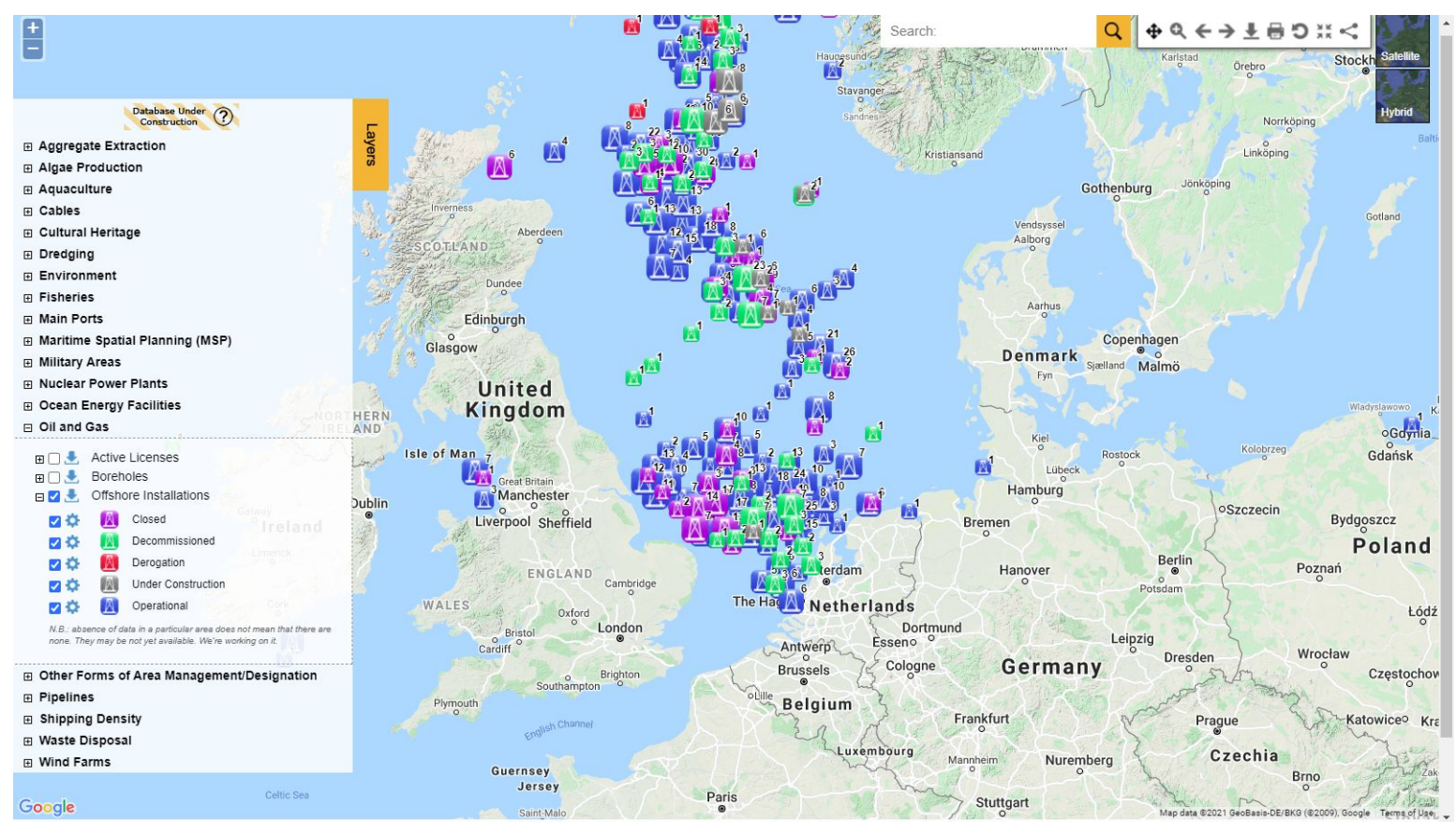

\section{Cables \& Pipelines:}

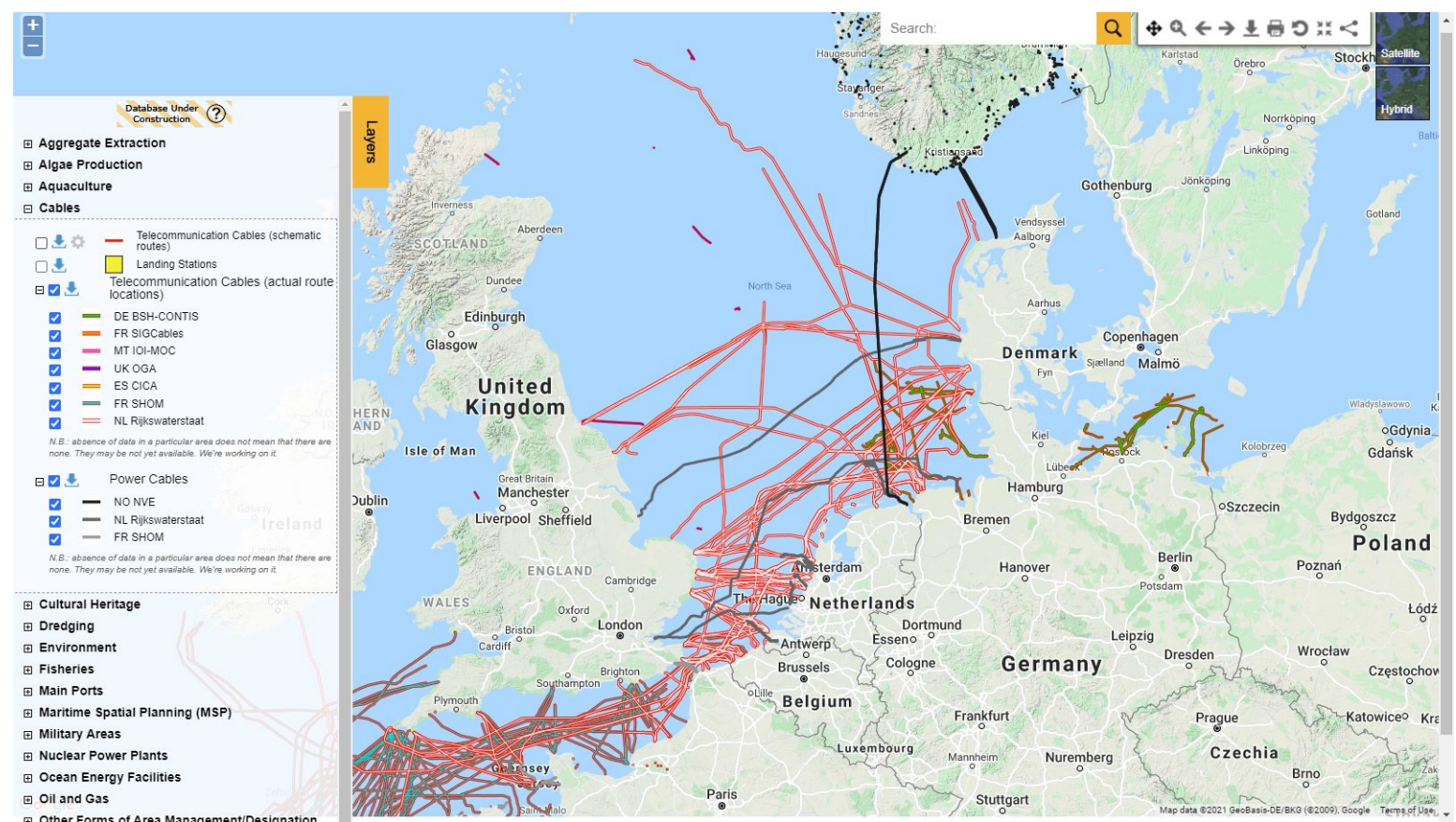




\section{Aquaculture:}

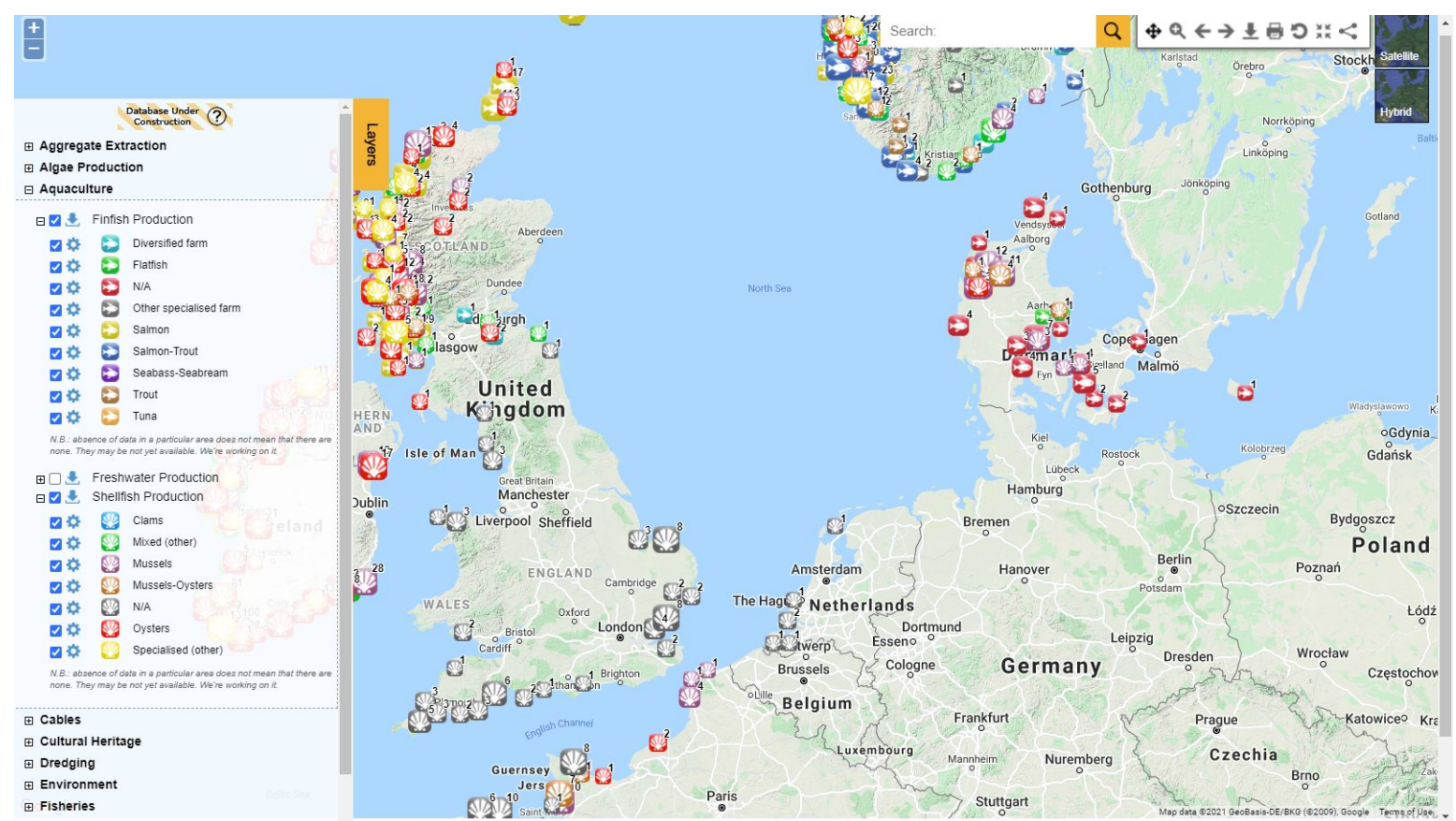

\section{Sand extraction:}

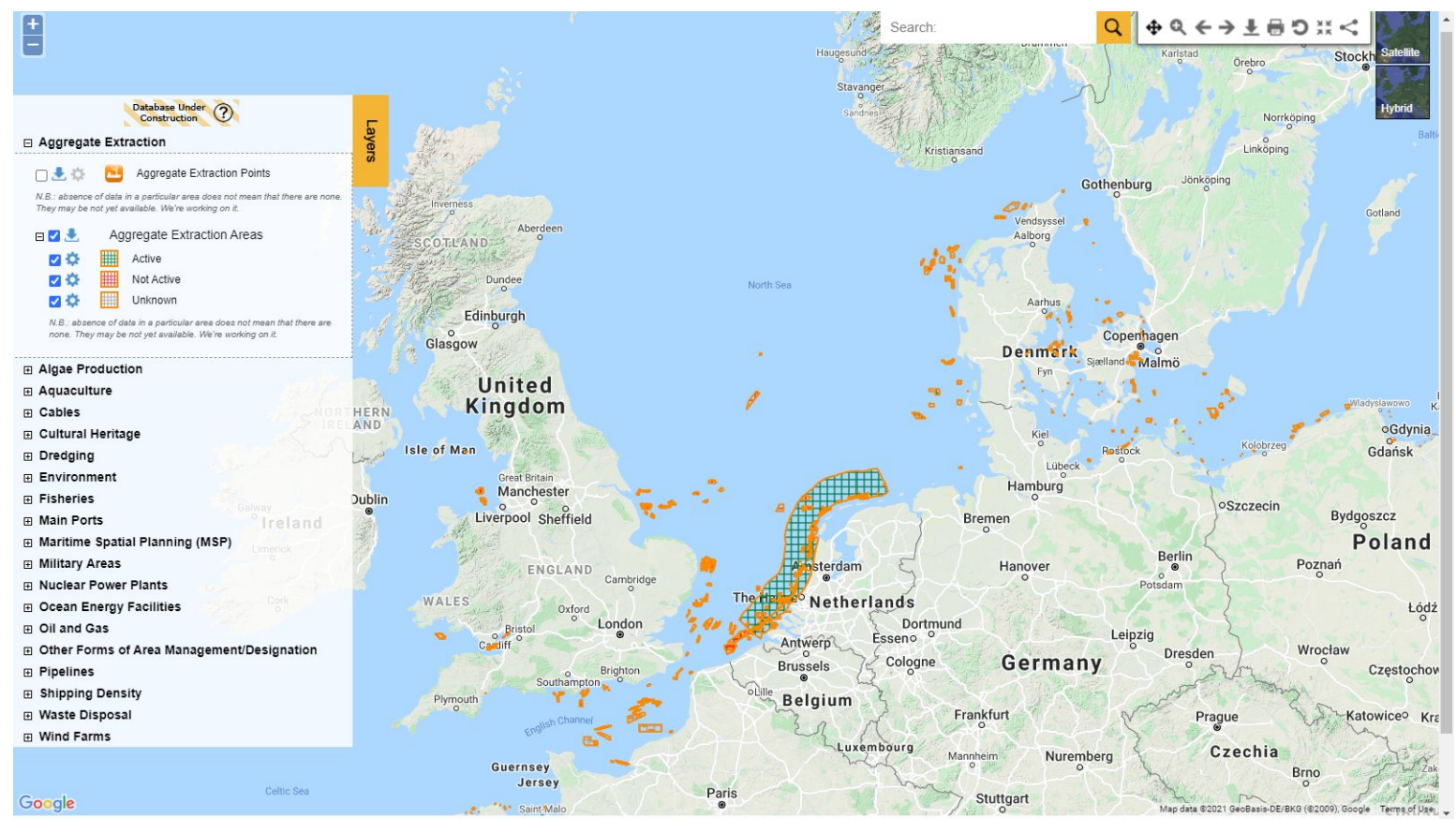




\section{Shipping routes:}

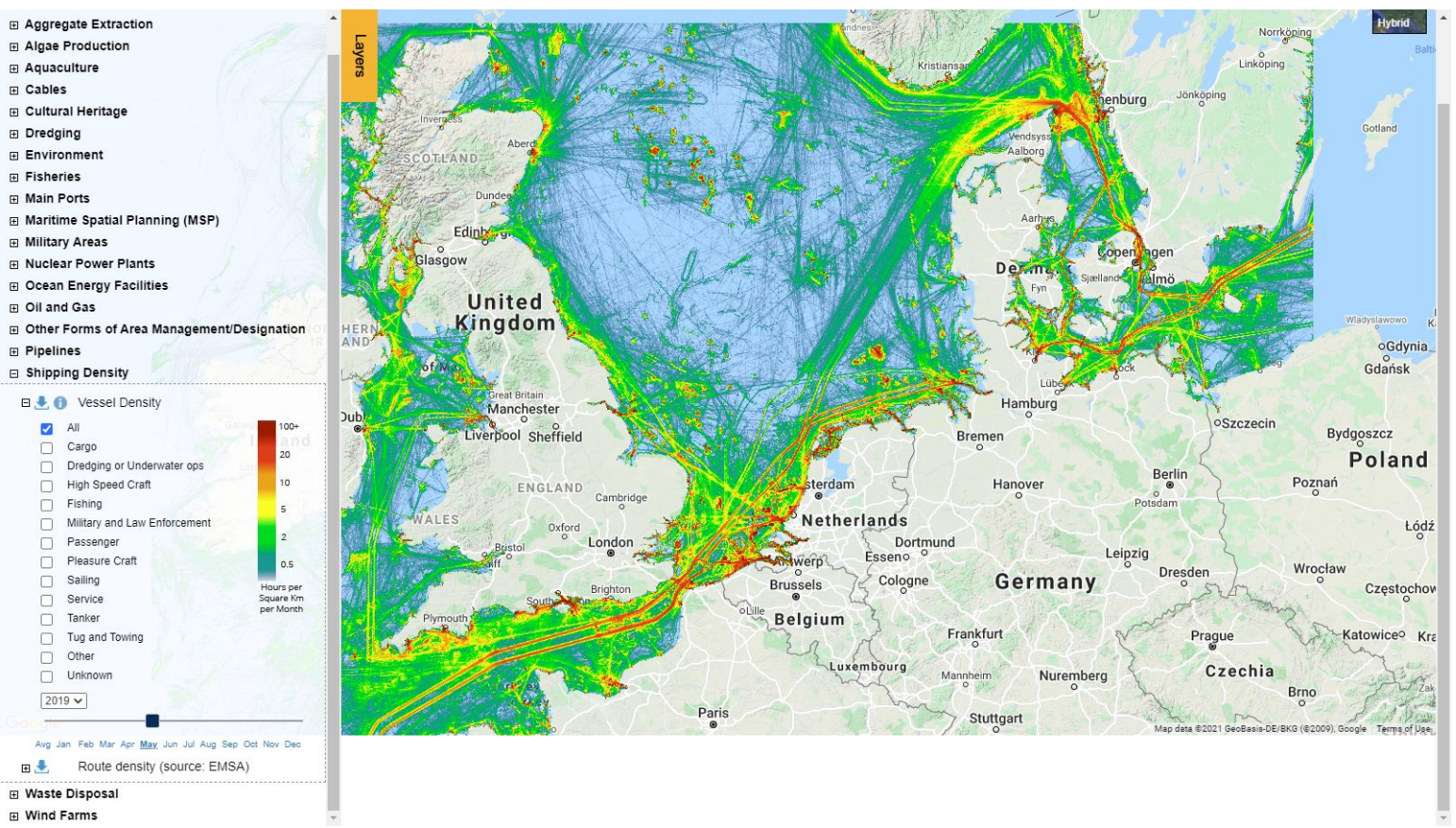




\section{Annex 2 Spatial information and maps for habitats and species in the North Sea}

List of maps available for habitats and species in the North Sea

Access date was 23 March 2021

\begin{tabular}{|c|c|c|c|c|c|}
\hline Habitat / Species group & $\begin{array}{l}\mathrm{M} \\
\mathrm{a} \\
\mathrm{P} \\
\mathrm{s}\end{array}$ & $\begin{array}{l}\text { Sourc } \\
e\end{array}$ & View of maps / URL & $\begin{array}{l}\text { Cover } \\
\text { age }\end{array}$ & Format \\
\hline \multicolumn{6}{|l|}{ A4 (EUNIS level2) } \\
\hline $\begin{array}{l}\text { Circalittoral rock and other hard } \\
\text { substrata }\end{array}$ & $\begin{array}{l}\text { Y } \\
\text { e } \\
\text { s }\end{array}$ & $\begin{array}{l}\text { EMOD } \\
\text { net } \\
\text { Seabe } \\
\text { d } \\
\text { Habita } \\
\text { ts }\end{array}$ & $\begin{array}{l}\text { https://www.emodnet- } \\
\text { seabedhabitats.eu/access-data/launch- } \\
\text { map-viewer/?zoom =4\%C2\%A2er=- } \\
\text { 10.539,53.419\&layerIds=1\&baseLayerId= } \\
\text {-3\&activeFilters = }\end{array}$ & $\begin{array}{l}\mathrm{NL}, \mathrm{BE}, \\
\mathrm{UK}, \\
\mathrm{SE}, \\
\mathrm{DK} \\
\mathrm{DE}, \mathrm{NO}\end{array}$ & $\begin{array}{l}\text { fileGDB / } \\
\text { ShapeFile }\end{array}$ \\
\hline \multicolumn{6}{|l|}{ A5 (EUNIS level2) } \\
\hline Sublittoral sediment & $\begin{array}{l}Y \\
\text { e } \\
\text { s }\end{array}$ & $\begin{array}{l}\text { EMOD } \\
\text { net } \\
\text { Seabe } \\
\text { d } \\
\text { Habita } \\
\text { ts }\end{array}$ & $\begin{array}{l}\text { https://www.emodnet- } \\
\text { seabedhabitats.eu/access-data/launch- } \\
\text { map-viewer/?zoom=4\%C2\%A2er=- } \\
\text { 10.539,53.419\&layerIds=1\&baseLayerId = } \\
\text {-3\&activeFilters }=\end{array}$ & $\begin{array}{l}\mathrm{NL}, \mathrm{BE}, \\
\mathrm{UK}, \\
\mathrm{SE}, \\
\mathrm{DK} \\
\mathrm{DE}, \mathrm{NO}\end{array}$ & $\begin{array}{l}\text { fileGDB / } \\
\text { ShapeFile }\end{array}$ \\
\hline Benthos & $\begin{array}{l}\mathrm{Y} \\
\mathrm{e} \\
\mathrm{s}\end{array}$ & $\begin{array}{l}\text { WMR/ } \\
\text { WindS } \\
\text { peed }\end{array}$ & https://edepot.wur.nl/143467 & $\begin{array}{l}\mathrm{NL}, \mathrm{BE}, \\
\mathrm{UK}, \\
\mathrm{SE}, \\
\mathrm{DK} \\
\mathrm{DE}, \mathrm{NO}\end{array}$ & fileGDB \\
\hline \multicolumn{6}{|l|}{ A7 (EUNIS level2) } \\
\hline Pelagic water column & $\begin{array}{l}\mathrm{N} \\
\mathrm{O}\end{array}$ & $\begin{array}{l}\text { EMOD } \\
\text { net } \\
\text { Seabe } \\
\text { d } \\
\text { Habita } \\
\text { ts }\end{array}$ & $\begin{array}{l}\text { https://www.emodnet- } \\
\text { seabedhabitats.eu/access-data/launch- } \\
\text { map-viewer/?zoom }=4 \% \text { C2\%A2er }=- \\
\text { 10.539,53.419\&layerIds=1\&baseLayerId }= \\
\text {-3\&activeFilters }=\end{array}$ & $\begin{array}{l}\mathrm{NL}, \mathrm{BE} \\
\mathrm{UK}, \\
\mathrm{SE}, \\
\mathrm{DK} \\
\mathrm{DE}, \mathrm{NO}\end{array}$ & $\begin{array}{l}\text { fileGDB / } \\
\text { ShapeFile }\end{array}$ \\
\hline \multicolumn{6}{|l|}{ Birds } \\
\hline Seabirds & $\begin{array}{l}\text { Y } \\
\text { e } \\
\text { s }\end{array}$ & $\begin{array}{l}\text { WMR/ } \\
\text { KEC2 }\end{array}$ & https://edepot.wur.nl/329714 & $\begin{array}{l}\mathrm{NL}, \mathrm{BE}, \\
\mathrm{UK}, \\
\mathrm{SE}, \\
\mathrm{DK} \\
\mathrm{DE}, \mathrm{NO}\end{array}$ & fileGDB \\
\hline \multicolumn{6}{|l|}{ Fish \& Cephalopods } \\
\hline Fish & $\begin{array}{l}\mathrm{Y} \\
\mathrm{e} \\
\mathrm{s}\end{array}$ & $\begin{array}{l}\text { WMR/ } \\
\text { WindS } \\
\text { peed }\end{array}$ & https://edepot.wur.nl/143467 & $\begin{array}{l}\mathrm{NL}, \mathrm{BE}, \\
\mathrm{UK}, \\
\mathrm{SE}, \\
\mathrm{DK} \\
\mathrm{DE}, \mathrm{NO}\end{array}$ & fileGDB \\
\hline \multicolumn{6}{|l|}{ Mammals } \\
\hline $\begin{array}{l}\text { Harbour porpoise, minke whale, } \\
\text { bottlenose dolphin, common } \\
\text { dolphin, fin whale, pilot whale, } \\
\text { striped dolphin, white-beaked } \\
\text { dolphin }\end{array}$ & $\begin{array}{l}\mathrm{Y} \\
\mathrm{e} \\
\mathrm{s}\end{array}$ & $\begin{array}{l}\text { SCANS } \\
3\end{array}$ & $\begin{array}{l}\text { Results | SCANS-III (st-andrews.ac.uk): } \\
\text { https://synergy.st- } \\
\text { andrews.ac.uk/scans3/category/researcho } \\
\text { utput/ } \\
\text { https://synergy.st- } \\
\text { andrews.ac.uk/scans3/files/2017/05/Spec } \\
\text { ies-density-maps.zip }\end{array}$ & $\begin{array}{l}\mathrm{NL}, \mathrm{BE} \\
\mathrm{UK}, \\
\mathrm{SE}, \\
\mathrm{DK} \\
\mathrm{DE}, \mathrm{NO}\end{array}$ & $\begin{array}{l}\text { shapefile+ta } \\
\text { bular data in } \\
\text { report }\end{array}$ \\
\hline $\begin{array}{l}\text { Harbour porpoise, harbour seal, } \\
\text { grey seal, minke whale }\end{array}$ & $\begin{array}{l}\text { Y } \\
\text { e } \\
\text { s }\end{array}$ & $\begin{array}{l}\text { AquaM } \\
\text { aps }\end{array}$ & $\begin{array}{l}\text { AquaMaps Search Page: } \\
\text { https://www.aquamaps.org/ }\end{array}$ & $\begin{array}{l}\mathrm{NL}, \mathrm{BE}, \\
\mathrm{UK}, \\
\mathrm{SE}, \\
\mathrm{DK} \\
\mathrm{DE}, \mathrm{NO}\end{array}$ & $\begin{array}{l}\text { csv-data- } \\
\text { table }+ \\
\text { cSquares } \\
\text { vector grid } \\
\text { (fishnet) }\end{array}$ \\
\hline
\end{tabular}


Maps for habitats and species in the North Sea

In this annex and this report, maps are shown for:

- $\quad$ Seabed habitats

- Benthos

- Birds

- $\quad$ Fish (Fish richness, Fish rareness)

- Marine mammal species (Harbour porpoise, Minke whale, Fin whale, Pilot whale, Bottlenose dolphin, Common dolphin, Striped dolphin, White-beaked dolphin, Harbour seal, Grey seal)

\section{Seabed habitats:}

See Figure 5 in this report.

Birds:

See Figure 6 in this report.

Fish richness:

See Figure 8 in this report. 


\section{Fish rareness:}

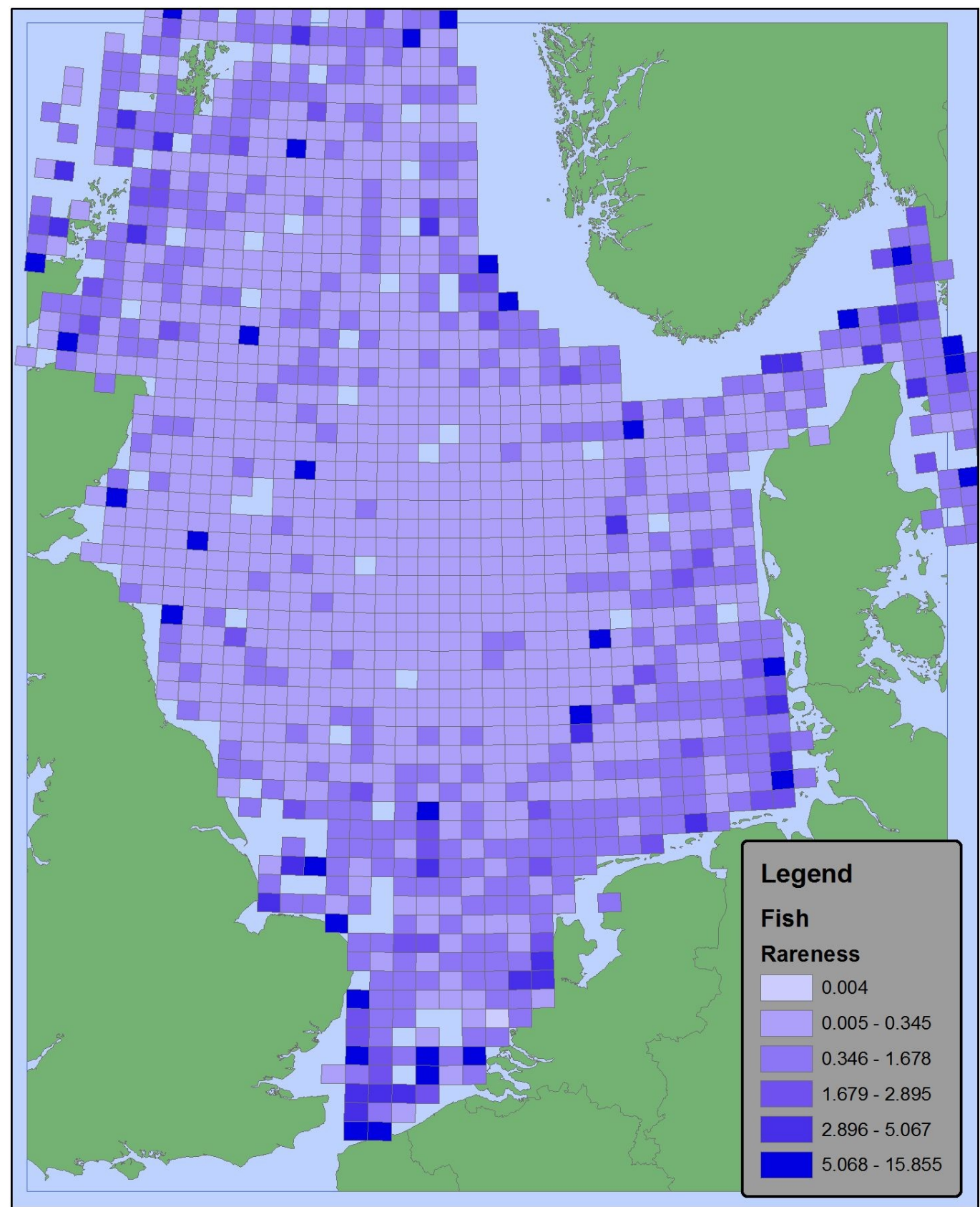

Rareness of the fish community in the North Sea (Van der Wal et al., 2009). 


\section{Benthos:}

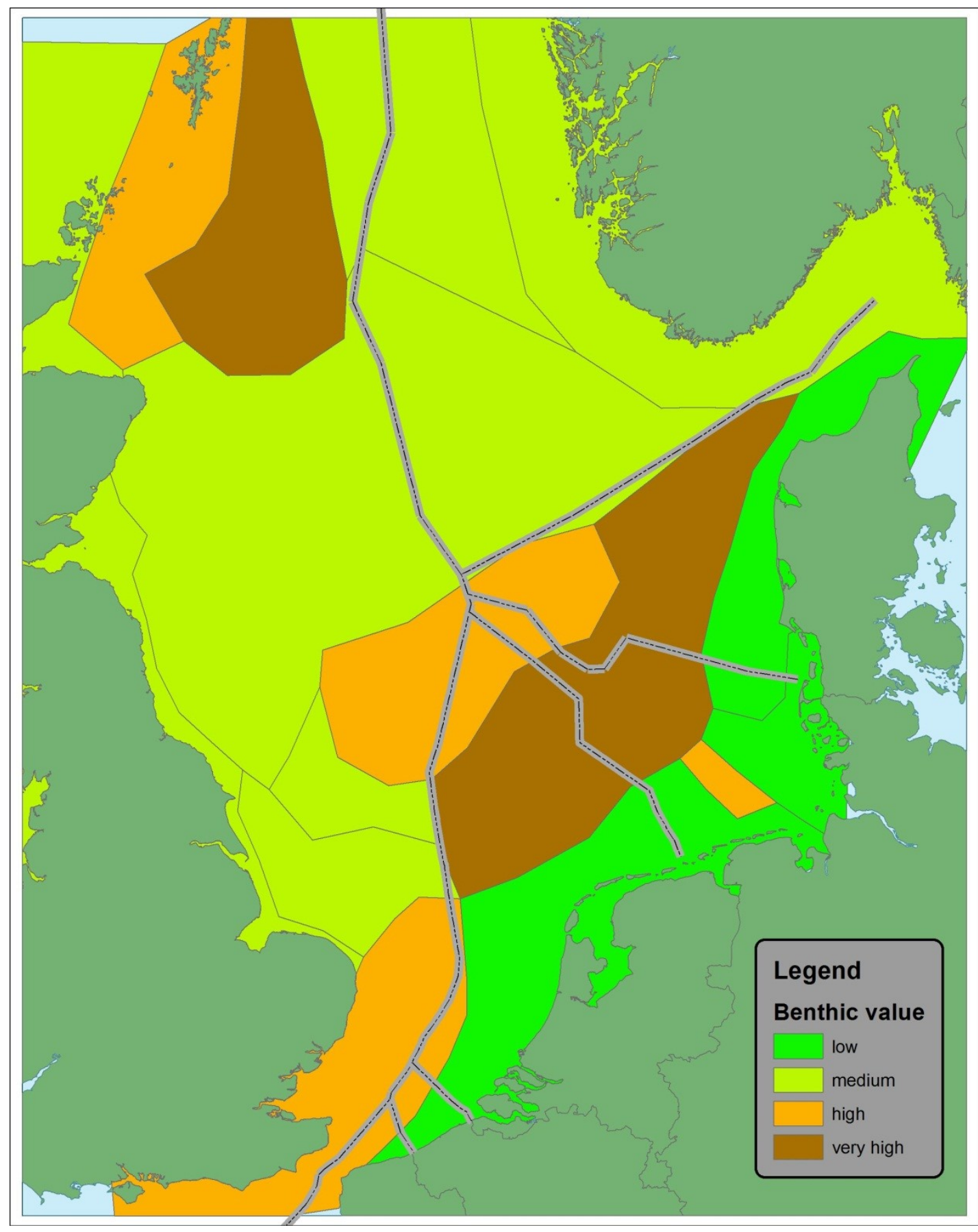

Benthic values in the North Sea (Van der Wal et al., 2009). 


\section{Marine mammal species:}

\section{Harbour porpoise}

See Figure 7 in this report

For 7 other cetacean species, see the next figures.

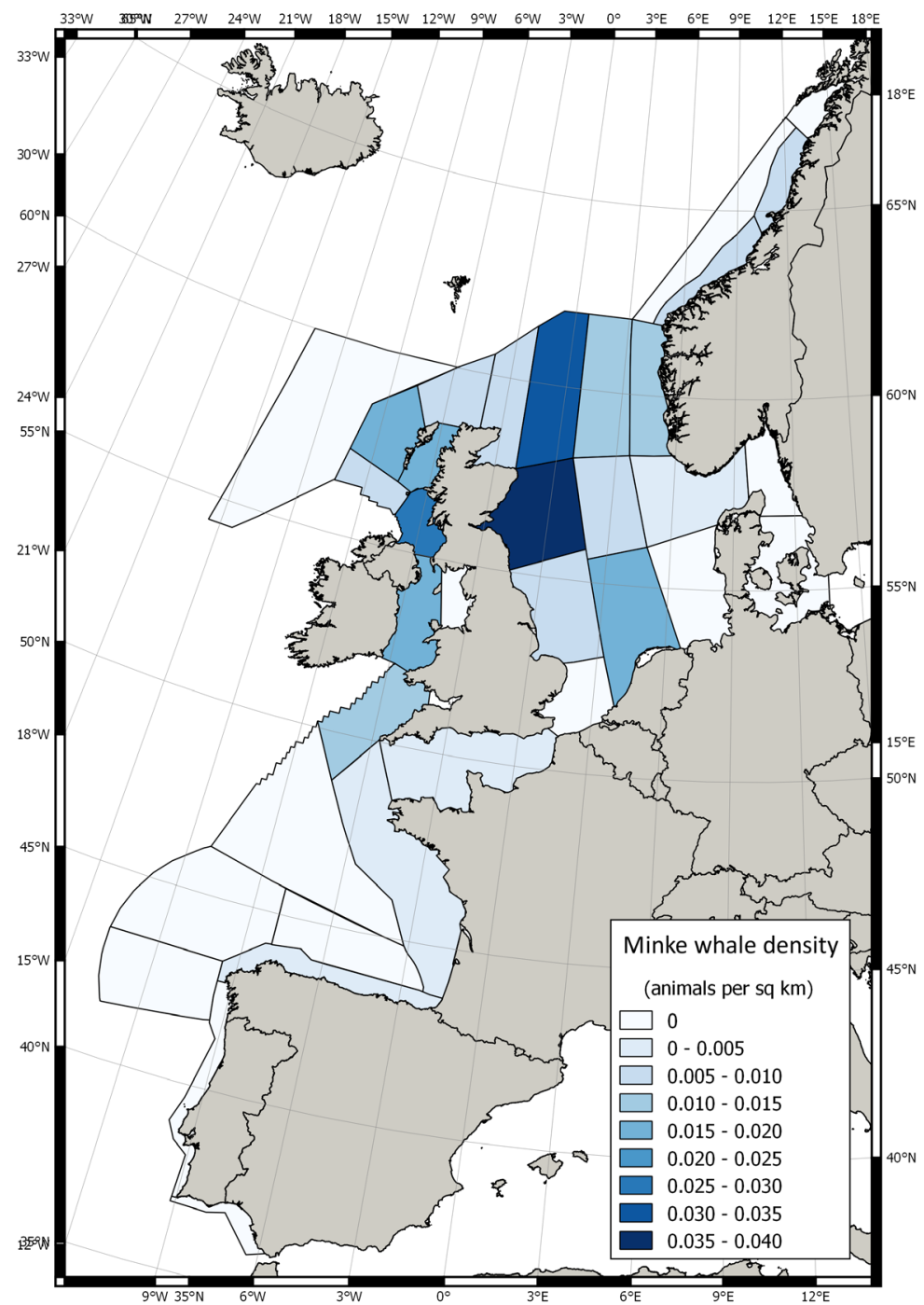

Distribution of minke whale in the North Sea (SCANS-III). 

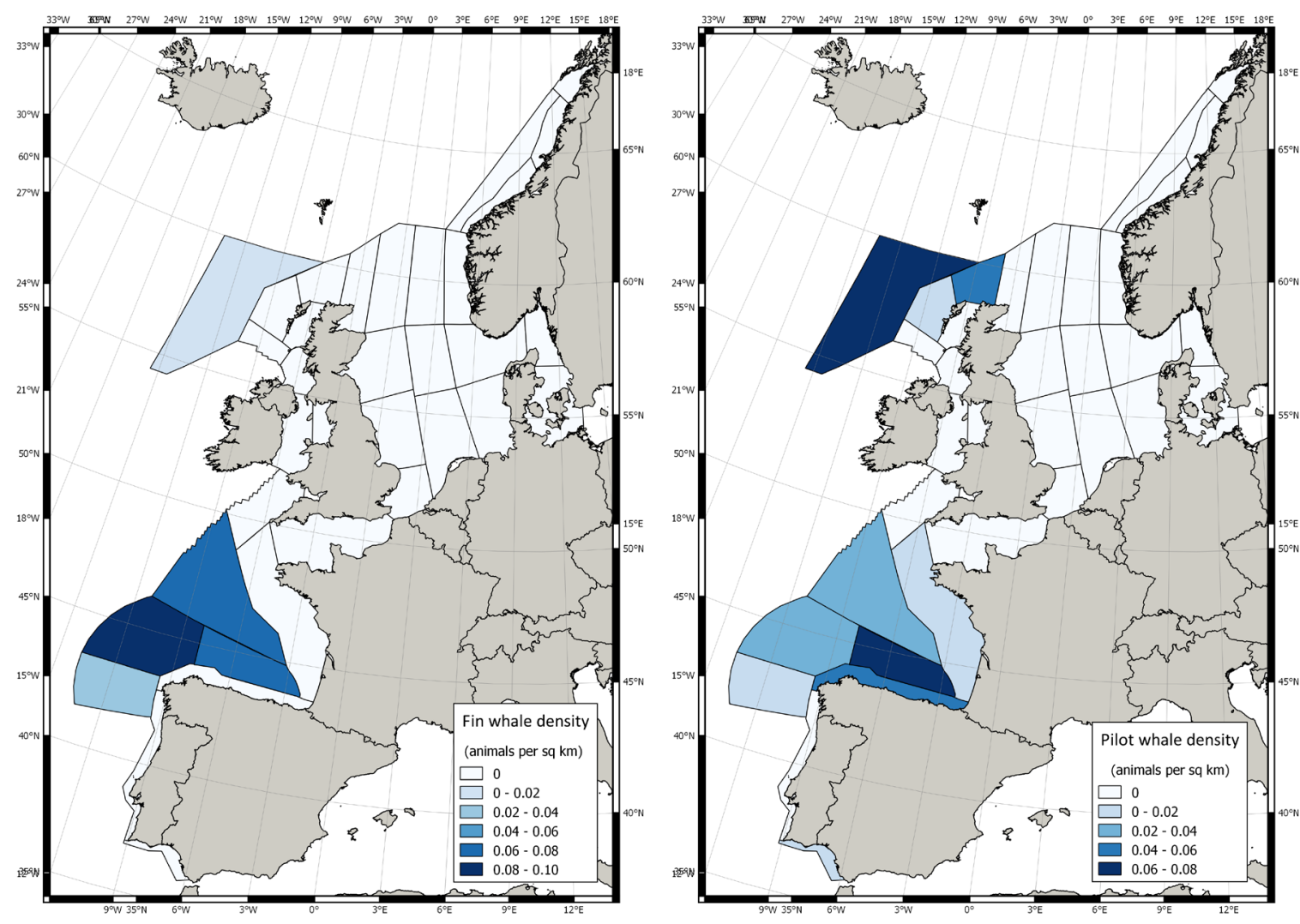

Distribution of Fin whale (left) and Pilot whale (right) in the North Sea (SCANS-III).
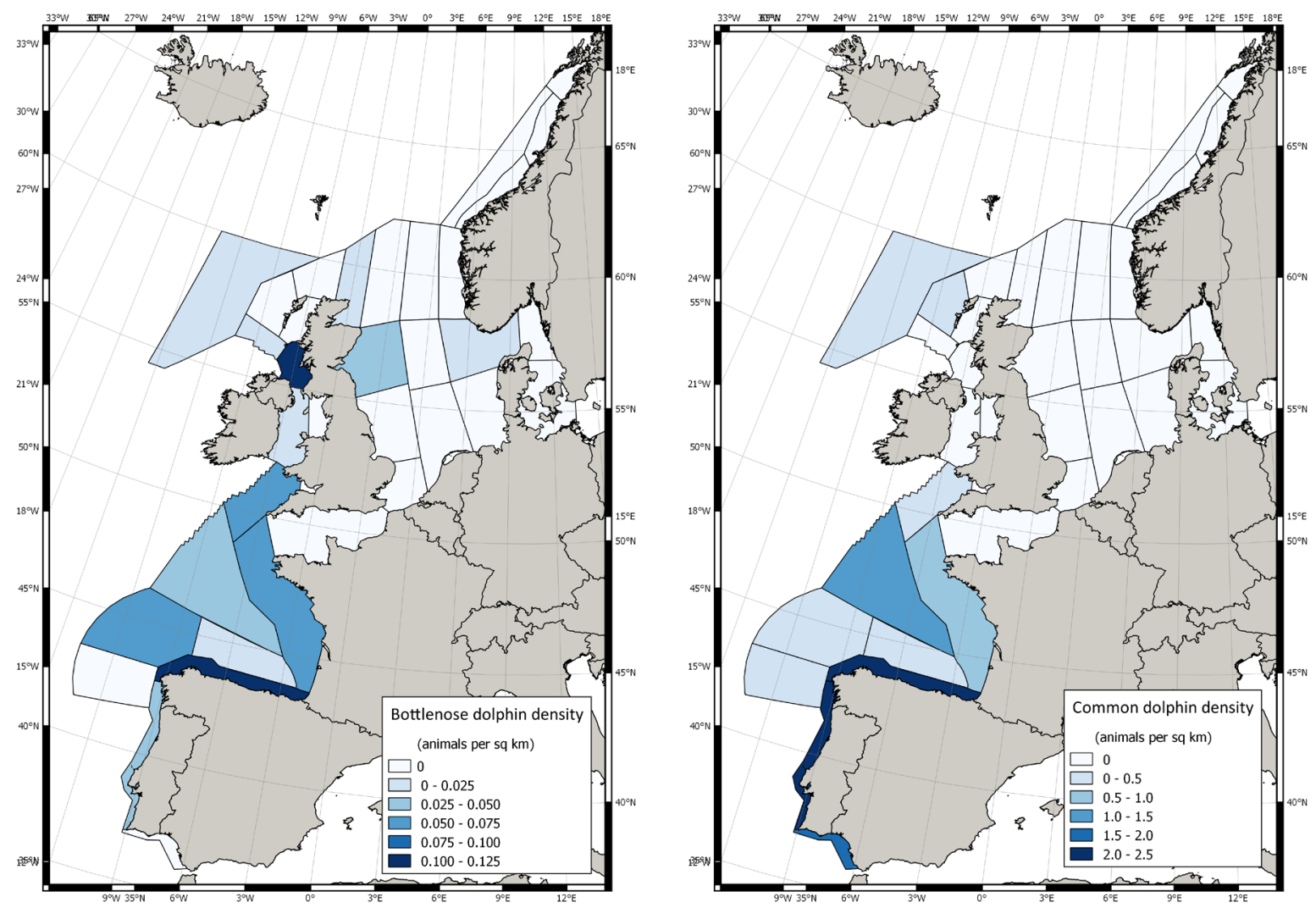

Distribution of Bottlenose dolphin (left) and Common dolphin (right) in the North Sea (SCANS-III). 

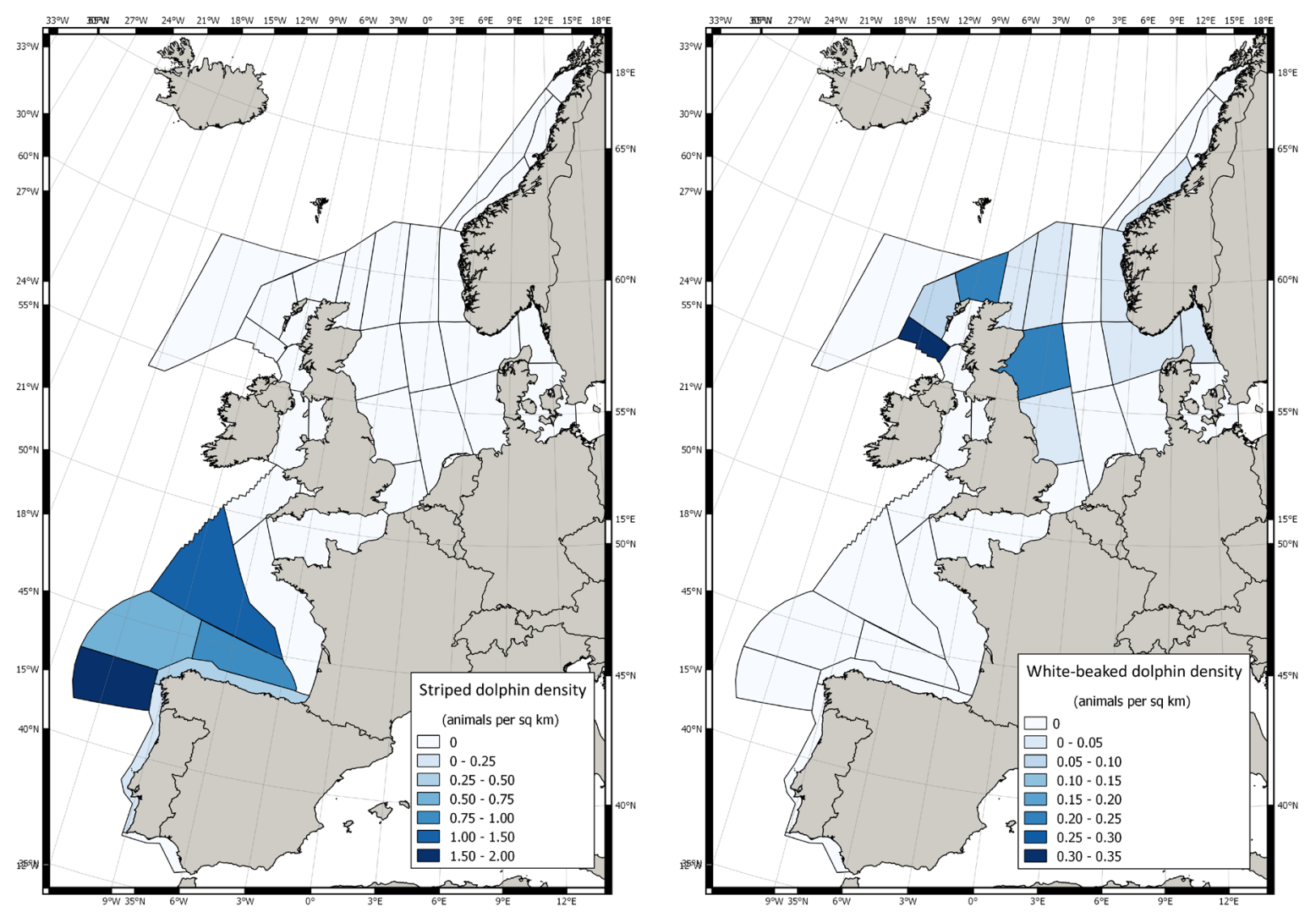

Distribution of Striped dolphin (left) and White-beaked dolphin (right) in the North Sea (SCANS-III). 
For harbour porpoise, minke whale, harbour seal and grey seal, see the next figures:
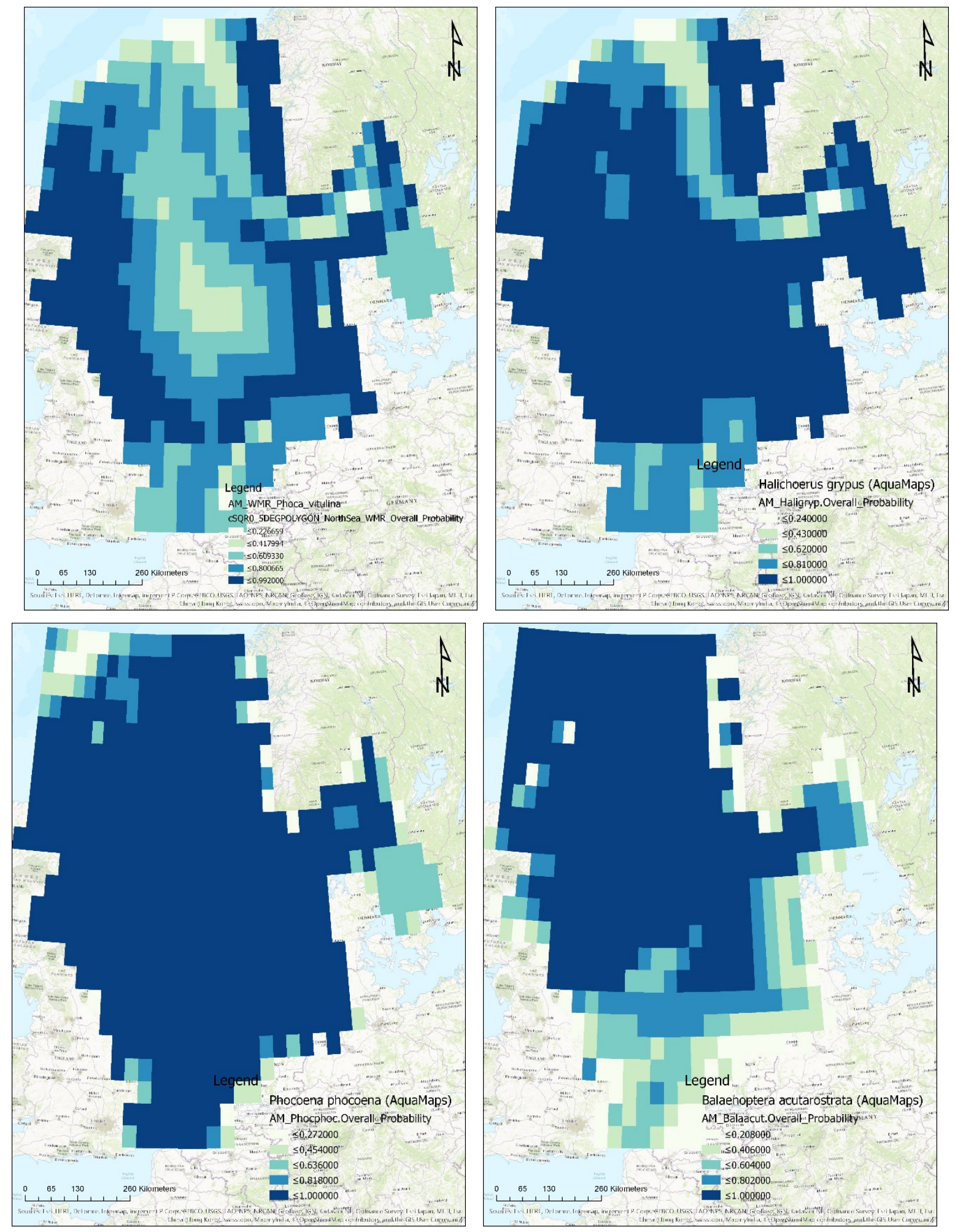

Suitability maps (environmental envelopes) across the Greater North Sea for four sea mammals, based on AquaMaps (AquaMaps.org): Harbour seal (Phoca vitulina); Grey seal (Halichoerus grypus); Harbour porpoise (Phocoena phocoena) and Minke whale (Balaenoptera acutarostrata). 


\section{Annex 3 Impact risk criteria}

Impact risk criteria with their categories (Borgwardt et al., 2019)*

\begin{tabular}{|c|c|c|}
\hline Description & & $\begin{array}{l}\text { Standardized } \\
\text { score }\end{array}$ \\
\hline Spatial extent & Spatial overlap of each activity-pressure combination with an ecosystem component & \\
\hline Exogenous & $\begin{array}{l}\text { The activity occurs outside of the area occupied by the ecosystem component, but one or more of its pressures would reach the ecosystem } \\
\text { component through dispersal }\end{array}$ & 0.01 \\
\hline Site & The activity overlaps with the ecosystem component by up to $5 \%$ of the area occupied by the EC in the case study area & 0.03 \\
\hline Local & The activity overlaps with the ecosystem component by between $\mathbf{5}$ and $\mathbf{5 0 \%}$ of the area occupied by the $\mathrm{EC}$ in the case study area & 0.37 \\
\hline $\begin{array}{l}\text { Widespread } \\
\text { patchy }\end{array}$ & $\begin{array}{l}\text { The activity overlaps with the ecosystem component by between } \mathbf{5 0} \text { and } \mathbf{1 0 0 \%} \text { of the area occupied by the } \mathrm{EC} \text { in the case study area, but the } \\
\text { distribution within that area is patchy }\end{array}$ & 0.67 \\
\hline $\begin{array}{l}\text { Widespread } \\
\text { even }\end{array}$ & $\begin{array}{l}\text { The activity overlaps with the ecosystem component by between } 50 \text { and } \mathbf{1 0 0 \%} \text { of the area occupied by the EC in the case study area, and is } \\
\text { evenly distributed across that area }\end{array}$ & 1 \\
\hline Dispersal & Effect of the dispersal of the pressure on realised area of spatial overlap & \\
\hline None & The pressure does not disperse in the environment & 0.01 \\
\hline Moderate & The pressure disperses, but stays within the local environment & 0.1 \\
\hline High & The pressure disperses widely and can disperse beyond the local environment & 1 \\
\hline Frequency & Temporal overlap of each activity-pressure combination with an ecosystem component & \\
\hline Rare & Occurs approximately 1-2 times in a 5 year period but may (or may not) last for several months when it occurs & 0.01 \\
\hline Occasional & Can occur in most years over a 5 year period, but not more that several times a year & 0.11 \\
\hline Frequent & $\begin{array}{l}\text { (1) occurs in most years over a } 5 \text { year period, and more than several times in each year, or (2) can occur in } \mathbf{1 - 2} \text { years in a } 5 \text { year period but } \\
\text { also in most months of those years }\end{array}$ & 0.33 \\
\hline Very frequent & Occurs in most months of every year, but is not constant where it occurs & 0.72 \\
\hline Continuous & Constant in most or all months of a 5 year period & 1 \\
\hline Persistence & Length of time that is needed that a pressure disappears after activity stops & \\
\hline Low & 0 to $<2 \mathrm{yr}$ & 0.01 \\
\hline Moderate & 2 to $<10 \mathrm{yr}$ & 0.06 \\
\hline High & 10 to $<100 \mathrm{yr}$ & 0.55 \\
\hline Persistent & The pressure never leaves the system or $>100 \mathrm{yr}$ & 1 \\
\hline Severity & Likely sensitivity of an ecosystem component to a pressure where there is an interaction & \\
\hline Low & $\begin{array}{l}\text { An interaction that, irrespective of the frequency and magnitude of the event(s), never causes a noticeable effect for the ecosystem } \\
\text { component of interest in the area of interaction }\end{array}$ & 0.01 \\
\hline Chronic & $\begin{array}{l}\text { An impact that will eventually have severe consequences at the spatial scale of the interaction, if it occurs often enough and/or at high } \\
\text { enough levels }\end{array}$ & 0.1 \\
\hline Acute & A severe impact over a short duration & 1 \\
\hline
\end{tabular}

* Note that the criteria are here scored between 0 and 100 (instead of using the range 0 to 1 ). Furthermore, some criteria scores were adjusted for this case study, i.e. Extent scores: scores were based on the proportion of the ecosystem component distribution area overlapping with the activity-pressure (based on data generated in Chapter 2); Dispersal scores: $N=0, M=5, H=15$; Frequency scores: $R=$ $1, \mathrm{O}=2, \mathrm{~F}=5, \mathrm{VF}=9, \mathrm{C}=12$; Severity scores: Low=1, Chronic=12.5, Acute=90. The criteria 'Resistance' (Knights et al., 2015) was reintroduced with scores: Low $=1$; Medium $=6, \mathrm{High}=55$. In addition, the criteria Pload was introduced, indicating the relative contribution of the activity (\%) to the pressure. 


\section{Annex 4 Knowledge on cause-effect relationships}

This Annex is directly taken from the supplementary material accompanying the article from Dannheim et al. (2020): Benthic effects of offshore renewables: identification of knowledge gaps and urgently needed research. The supplementary material (i.e. Annex 1: Review of current knowledge on the hypothesised cause-effect relationships (hypothesised paths); a literature backbone of 233 publications) is available at https://academic.oup.com/icesjms/article/77/3/1092/5368123\#supplementary-data All references are publicly available in a library at www.mendeley.com/community/benthic-effects-ofoffshore-renewables - access date: 15.01.2019)

\section{Hypothesised paths related to carrying capacity (Dannheim et al., 2020)}

\section{Altered food availability to filter-feeders}

Availability and patchiness of plankton are often attributed to biotic properties such as behavioural aggregation, swimming, grazing and growth (Genin et al., 2005; Birch et al., 2009; Menden-Deuer, 2012). Hydrodynamic characteristics such as turbulent diffusion and horizontal mixing are also important (Stacey et al., 2007; McKiver et al., 2009). Artificial structures and associated epifauna increase turbulence and horizontal/vertical mixing (Floeter et al., 2017), thereby promoting planktonic growth (Marshall, 1967), and food availability to filter-feeding epifauna. For example, increased abundance of phytoplankton and a total of 181 species were identified in an area of artificial reef in Daya Bay, South China (Liao et al., 2013). This ultimately increases productivity at higher trophic levels, increases biomass and promotes biodiversity (Steimle et al., 2002). The formation of artificial reef communities contributes to benthic-pelagic coupling, where epibenthic species on the artificial structure release nutrients and subsequent enrichment promotes primary production (Falcão et al., 2007). The first empirical evidence of increased vertical mixing (reduced stratification during the summer) within a wind farm and subsequent nutrient transport enabling primary production throughout the water column, was demonstrated in the North Sea (Floeter et al., 2017).

\section{Modified currents/ hydrodynamic conditions will determine settlement success and} species occurrences in the surrounding natural substrates

Hydrodynamic properties are part of the physical influencers of natural habitats (Sousa, 1984; Meibner and Sordyl, 2006). The presence of marine renewable energy devices may affect these hydrodynamic conditions (currents, wave activity, vertical mixing) at the local scale (Leonhard et al., 2006; Floeter et al., 2017). This is considered a strong mechanical anthropogenic disturbance (Meibner and Sordyl, 2006; Powilleit et al., 2006). It can affect the local seabed sediment distribution and structure (Gill, 2005; Meibner and Sordyl, 2006). Changes in hydrodynamics and sediment transport can occur locally and regionally as a result of marine renewable energy device foundations (Rivier et al., 2016). Sediment dynamics affect underwater light conditions, which influence availability of nutrients, reproduction and distribution and settlement of benthos (Gill, 2005; Trancoso et al., 2005).

Settlement of benthic larvae can be influenced by local changes in the hydrodynamic environment; hard structures may induce turbulent flow and changes in flow velocity, changing the flux of larvae towards the sediment (Rodriguez et al., 1993). These changes may have measurable effects on the composition of the benthic assemblages close to piles (Coates et al., 2014), but not at a larger scale (Bergman et al., 2015). Any ecological changes related to alteration of flow depend on the sensitivity of benthic species and habitats to the alteration of energy in the environment (Shields et al., 2011). If an organism is unable to resist or evade large hydrodynamic forces, they may be dislodged from the substratum (Gaylord et al., 2001). Some species may disappear (Levinton, 1995) resulting in substrate becoming available for new colonisers (Powilleit et al., 2006). Scour protections, such as large rocks, installed around the foundations limit the sediment transport close to the offshore devices and limit the effect of sediment erosion. Modified hydrodynamics favour fish use of structures on 
generally homogenous sand bottoms as focal points for orientation, shelter from predators, and as a food source (Jessee et al., 1985).

In the immediate vicinity of an offshore gravity based wind turbine in Belgium, changes of the sedimentary characteristics (grain size distributions and organic matter), affected the associated softsediment macrofauna (Coates et al., 2014). The sediments directly around the turbine were classified as medium sands $(250-500 \mu \mathrm{m})$. A finer grain size was observed close to the turbine $(15-50 \mathrm{~m})$ in comparison to stations positioned further away (100-200 m) on the north-west and south-west gradients. Sedimentation changes are linked to the reduction in current speed around the foundation. An enrichment of the soft-sediment macrobenthic assemblage around the foundation was measured with a significant increase in abundance and species richness in close vicinity to the foundation (Coates et al., 2014).

Highly heterogeneous sediments were found up to $5 \mathrm{~m}$ away from a research platform in the German bight (Schröder et al., 2006). The re-suspension of fine, mobile sands away from the foundation and the settlement of coarse, dead shells close by is caused by changes in local current speeds (Hiscock et al., 2002; Schröder et al., 2006).

5 Three-dimensional artificial structures which extend through the entire water column will affect local hydrodynamic conditions such as tidal and wind induced currents

Information on changes in hydrodynamics often relies on models. The output from these often varies according to the specific inclusion of parameters such as hydrodynamic or bathymetric feedback, wind-driven currents, wind waves and tidal currents (Hashemi and Neill, 2014; Neill and Hashemi, 2014; Thiébot et al., 2015). Ultimately, the inclusion of 3D modelling that includes interactions between offshore device wakes and vertical profiles is important for a fuller understanding. Changes in hydrodynamics due to tidal and wind turbines have been shown to differ through vertical and horizontal profiles of the water body (Bryden and Couch, 2006; Floeter et al., 2017). Tidal amplitude is likely to change and a redistribution of currents and strengths around devices and arrays will occur (Walkington and Burrows, 2009). Turbines create wakes that can be several kilometres in length and influence tidal currents and suspended material (Vanhellemont and Ruddick, 2014). Energy extraction from waves will change the spectral frequency of waves and reduce near-shore current velocities (Diaconu and Rusu, 2013; Rusu and Guedes Soares, 2013). The most immediate changes will be in the turbulent wake of the device which should also be considered in a three dimensional state and would be emphasised where devices having moving parts (Kang et al., 2012). The effects can also stretch several kilometres and will vary with the proximity from the shore and local topography. There is evidence for the effects of energy extraction being additive (Walkington and Burrows, 2009; Yates et al., 2013) but also suggestions of linearity (Fairley et al., 2015); this may be very specific to the marine renewable energy device of interest and its locality.

6 Turbidity caused by suspended matter reduces light penetration into the water column thereby reducing the primary production of photosynthetically active phytoplankton Primary production is either nutrient- or light-limited. Suspended particulate matter (SPM) dominates the attenuation of light in turbid waters (Devlin et al., 2008) and may impact primary production by phytoplankton. Negative correlations between turbidity and primary production have been demonstrated especially in estuaries with special attention to the maximum turbidity zone (Jewson and Taylor, 1978; Kromkamp and Peene, 1995; Kocum et al., 2002). Whether the increased levels of turbidity caused by marine renewable energy devices, in this case, wind farms [e.g. up to $\pm 15 \mathrm{mg}$ SPM.I-1 (Baeye and Fettweis, 2015)], which can be in wakes of 30-150 km wide and several $\mathrm{km}$ in length (Vanhellemont and Ruddick, 2014), may also hamper offshore primary production is yet to be investigated within the nutrient- and light-limitation context.

\section{Suspension-feeding fouling organisms extract plankton and suspended matter from the} water column and thereby decrease turbidity

Suspension-feeding fouling organisms extract plankton and suspended matter from the water column (Andre C. Lindegarth M., 1993; Gili and Coma, 1998). In temperate waters, suspension-feeding species are common on artificial structures such as shipwrecks (Leewis and Waardenburg, 1991; Zintzen et al., 2006), oil and gas installations (Van Der Stap et al., 2016) and renewable energy devices (De Mesel et al., 2015). Suspension feeders occur in greater densities on artificial reefs than in soft sediments (Fabi et al., 2002; Wetzel et al., 2014). Removal of suspended matter from the water 
column decreases turbidity, thereby increasing penetration of light (Newell, 2004; Gallardi, 2014). In environments where light is a limiting factor, depth-distribution (Eriksson et al., 2004; Gallardi, 2014) or condition (De Jonge et al., 1993) of benthic primary producers may be affected. Simulations suggest that Mytilus edulis settlement and filter feeding in wind farms in the southern North Sea could change primary productivity up to $8 \%$ within wind farms but could also extend regionally (Slavik et al., 2018). Similar effects can also be seen on phytoplankton (Huisman and Weissing, 1994). Removal of suspended organic matter e.g. by bivalves has consequences at multiple trophic levels. These include direct removal of pelagic primary producers (Meeuwig et al., 1998), recycling of nutrients via biodeposits to support further production by phytoplankton or, if biodeposits are permanently locked into the sediment, pelagic primary production may be reduced (Newell, 2004). Availability of food to higher trophic levels, including zooplankton, fish and mammals may be altered (Gili et al., 1998; Richardson and Schoeman, 2004; Wetzel et al., 2014).

\section{The addition of artificial hard structures will change the morphology and the complexity of benthic habitats. Alters types and amount of habitat}

Marine renewable energy devices provide hard substrata in regions and at depths often dominated by soft bottom habitats. They introduce atypical, and initially unutilised, substrate types in terms of structure and inclination, and often offer a range of depths and environments for marine organisms, including shallow/littoral habitats in otherwise deeper water (Wilhelmsson and Langhamer, 2014). While the structural complexity and the diversity of microhabitats (apart from the depth gradient) generally are lower on offshore device foundations compared to the surrounding sea beds (Wilhelmsson and Malm, 2008), the marine renewable energy devices increase the habitat complexity at the scale of the array areas.

Marine renewable energy devices mainly transform soft-bottom to hard bottom due to the installation of foundations and piles. This impact is the creation of artificial reef that can be considered as positive (Vaissière et al., 2014), but can act as favourable for the introduction of non-native species. Moreover, there is a risk of scouring around the base of the foundations due to local hydrodynamic changes which depends on the current velocities in the zone of implementation of devices; to prevent such scouring boulders are placed around each foundation which increase the reef effect (Vaissière et al., 2014).

\section{A specific hard bottom assemblage (fouling and mobile megafauna) consisting of} primary and secondary producers will colonise the new and complex artificial habitat After construction, a specific hard bottom assemblage (fouling and mobile megafauna) consisting of primary and secondary producers will colonise the new and complex artificial habitat (Wilhelmsson and Malm, 2008; Kerckhof et al., 2010, 2016; Lindeboom et al., 2011; Langhamer, 2012; Krone et al., 2013a; De Mesel et al., 2015; Coolen et al., 2018).

This community follows a clear vertical zonation: The intertidal zone is dominated by barnacles and mussels and the subtidal zone is dominated by amphipods, hydroids and anemones (Andersson and Öhman, 2010; Krone et al., 2013a; Coolen et al., 2018).

In soft sediment environments, hard substrate structures increase the habitat (diversity) available for a wide range of species (Andersson and Öhman, 2010; Langhamer, 2012). This is most notable on the scour protection which often has a higher complexity than the foundations and is a suitable habitat for mobile demersal megafauna species such as lobsters and crabs (Jensen et al., 2000; Langhamer and Wilhelmsson, 2009; Krone et al., 2013b, 2017).

Early succession have been observed in epifauna at wind farms in the North Sea with high turn-over initially followed by only seasonal patterns after 1-1/2 years (De Mesel et al., 2015). From offshore oil platforms it is known that the community changes over time, where initial colonisers (e.g. tubeworms and hydroids) are replaced by secondary colonisers such as anemones after 2-4 years which stay dominant up to 11 years after construction (Whomersley and Picken, 2003). Recent evidence suggest than epibenthos and fish assemblages will stabilise within $<6$ years (De Backer and Hostens, 2017).

20 Changes in the current conditions/altered hydrodynamics resuspend fine inorganic and organic sediment fractions in the water column and cause scour effects

Marine renewable energy devices significantly modify near-surface suspended particulate matter (SPM) concentration in the form of turbid wakes, extending up to several km downstream as shown for wind turbines (Vanhellemont and Ruddick, 2014). SPM plumes were generated at the foundations 
and concentrations reached up to five times that of the background concentration in offshore Belgian waters (Baeye and Fettweis, 2015). These authors suggested that the epifaunal communities at the foundations play a key role as the source of the SPM: "the organisms filter and trap SPM from the water column, resulting in an accumulation of SPM at the base of the foundations. When tidal currents exceed a critical velocity, fine particles in the near-bed fluff layer are resuspended and transported downstream in the wake of the foundations". Consequently the resuspended material consists of both an inorganic sediment component and an organic component derived from the biodeposition of pseudo-faeces from the epifaunal communities.

29 Sediment disturbance such as dredging and cable laying during the construction phase will resuspend formerly deposited organic matter from the sediment

During the construction of marine renewable energy devices, sediment disturbance due to trenching and cable laying will create resuspension of sediments. The effects can to some extent be compared to those resulting from dredging and trawling (Wainright and Hopkinson, 1997; OSPAR Commission, 2012). Organic matter, nutrients and possible pollutants will be released from the sediments into the water column. Due to improved mixing with oxygen, the remineralisation rate will be increased. Recovery of this process is in the order of hours to days. Most of the sediments and organic matter will be transported over a short distance and deposited again. The effects will be local and temporal due to the construction of the marine renewable energy devices; after construction, based on dredging studies the seabed community will most likely recover within months to a few years, depending on the local conditions (Boyd et al., 2004; Coates et al., 2015). 


\title{
Annex 5 Introduction to maritime spatial planning (MSP) and the ecosystem based approach (EBA)
}

\begin{abstract}
Maritime spatial planning
- Involve stakeholders;

- Develop cross-border cooperation;

- Apply an ecosystem-based approach;

- Use the best available data and share information;

- Take into account land-sea interaction;

- Promote the co-existence of activities; and

- Review the plans at least every 10 years.
\end{abstract}

MSP is a relatively new, however rapidly growing research field (Chalastani et al., 2021). Managing pressures at sea and competition between maritime sectors requires spatial planning to account for pressures from individual sectors and their cumulative impacts, taking into account of the vulnerability and importance of marine ecosystems and the services they deliver. Therefore, the EU adopted the Directive 2014/89/EU of the European parliament and of the council of 23 July 2014 establishing a framework for maritime spatial planning, or so-called MSP Directive. The directive aims in particular at: (a) reducing conflicts between sectors and create synergies between activities; (b) encouraging investment - by creating predictability, transparency and clearer rules in the management and sharing of marine space; (c) protecting marine ecosystems ; and (d) increasing cross-border cooperation between EU countries to support cost-effective development projects and initiatives including for the effective protection of marine ecosystems. Member States requires that maritime spatial plans (MSP) are established by 2021, and implemented thereafter. Minimum requirements for Member States (cf. in particular Articles 4-7, 10-12 of the Directive) include (Friess and Grémaud-Colombier, 2019):

MSP is widely seen as a tool enabling effective implementation of ecosystem-based marine management by considering and responding to our increasing understanding of the complex socioecological inter-relationships with the sea (Langlet and Westholm, 2019; Kidd et al., 2020). Worldwide, MSP is put forward as a key mechanism for implementing Agenda 2030 (including environmental, economic and social values), which aims to achieve integrated and ecosystem-based management of the marine environment, in the pursuit of sustainable development of the ocean and seas (Kidd et al., 2020). The Roadmap on International MSP (DG Mare-IOC-UNESCO, 2017) sets out a clear forward looking and global perspective towards 2030. All the actions integrate the perspective that MSP should be a means for implementing the Agenda 2030 and should demonstrate how maritime spatial plans deliver on economic, social and environmental values in that context (Friess and Grémaud-Colombier, 2019).

\section{Ecosystem-based approach}

In the period from the EU Green Paper (2006) to the MSP Directive Proposal (2013), most national and European MSP initiatives seemed to follow a MSP approach focused in delivering blue growth. Adjusting policy decisions to properly preserve ecosystems and the services they provide therefore became a challenge (Frazão Santos et al., 2014). However, the ecosystem-based approach (EBA) is enshrined in both Directives of the European Union's (EU) Integrated Maritime Policy, the Marine Strategy Framework Directive (MSFD) and the Directive on MSP (Zaucha and Gee, 2019). Since then, the EBA (and related concepts such as ecosystem-based management (EBM) and ecosystem approach (EA)) is increasingly being applied in MSP (Kirkfeldt, 2019). The three concepts (EBA, EBM and EA) are in many cases used interchangeably or without distinction by MSP researchers and practitioners (Kirkfeldt, 2019). Looking at principles, no significant distinction are found between the three concepts but there are differences in the objectives of the concepts (Figure 23). EBA includes objectives of impact management and good environmental status, the latter being connected to EBA through the MSFD and as a key objective of the MSFD (Kirkfeldt, 2019). The MSFD is also consistent with the recognition that ecosystem conservation underpins other pillars of sustainable development and thus provides a suitable framework for ecosystem-based MSP (Qiu and Jones, 2013). 


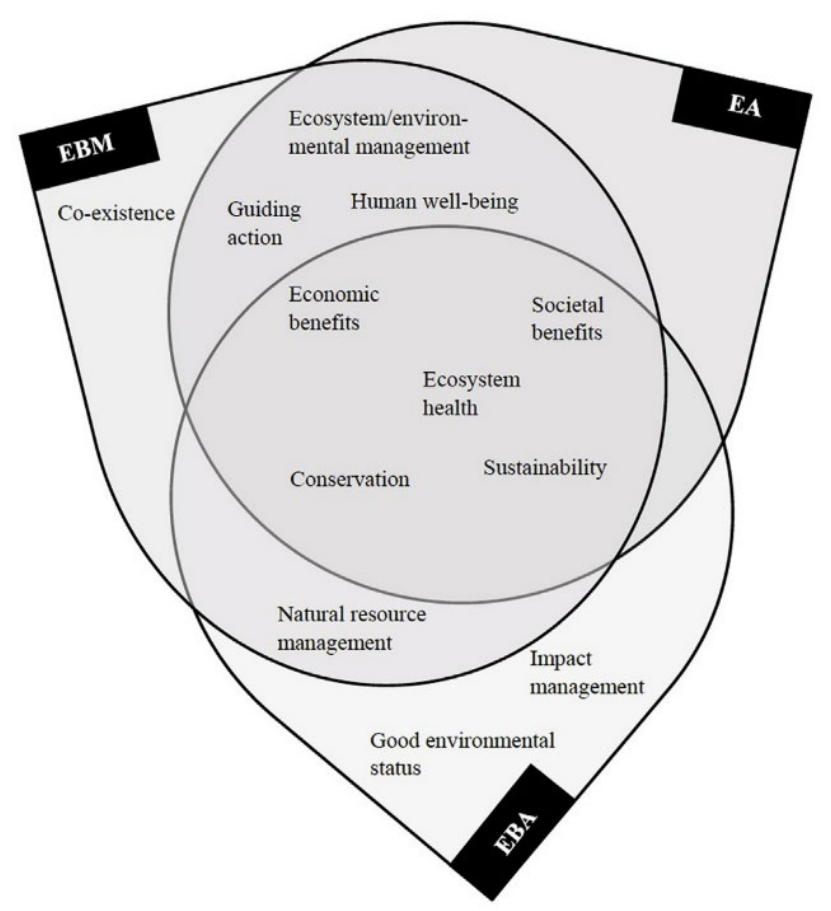

Figure 20 Objectives of ecosystem-based management (EBM), ecosystem-based approach (EBA) and ecosystem approach (EA) (Kirkfeldt, 2019).

In a Workshop on the Ecosystem Approach (Lilongwe, Malawi, 26-28 January 1998), whose report was presented at the Fourth Meeting of the Conference of the Parties to the Convention on Biological Diversity (Bratislava, Slovakia, 4-15 May 1998, UNEP/CBD/ COP/4/Inf.9), twelve

principles/characteristics (often called the Malawi Principles) of the ecosystem approach to biodiversity management were identified (Garcia, 2003):

1. Management objectives are a matter of societal choice.

2. Management should be decentralized to the lowest appropriate level.

3. Ecosystem managers should consider the effects of their activities on adjacent and other ecosystems.

4. Recognizing potential gains from management there is a need to understand the ecosystem in an economic context, considering e.g. mitigating market distortions, aligning incentives to promote sustainable use, and internalizing costs and benefits.

5. A key feature of the ecosystem approach includes conservation of ecosystem structure and functioning.

6. Ecosystems must be managed within the limits to their functioning.

7. The ecosystem approach should be undertaken at the appropriate scale.

8. Recognizing the varying temporal scales and lag effects which characterize ecosystem processes, objectives for ecosystem management should be set for the long term.

9. Management must recognize that change is inevitable.

10. The ecosystem approach should seek the appropriate balance between conservation and use of biodiversity.

11. The ecosystem approach should consider all forms of relevant information, including scientific and indigenous and local knowledge, innovations and practices.

12. The ecosystem approach should involve all relevant sectors of society and scientific disciplines.

The Malawi Principles has become an important reference point in discussions about ecosystem management and are used within the EBA to MSP, e.g. by the HELCON/VASAB Guideline (Langlet and Westholm, 2019). The HELCON/VASAB Guideline is presented as 'a first step towards a common understanding on how the ecosystem-based approach can be applied in drawing up a spatial plan for a sea area in accordance with spatial planning legislation in force in the Baltic Sea countries.' This guideline has been used together with other sources identified by a literature study covering over 200 source documents within the recent international study on Integrating an Ecosystem-based Approach into Maritime Spatial Planning. This study developed a practical approach, which is described in section 4.3 of this report. 
Wageningen Marine Research

T +31 (0)31748 7000

E: marine-research@wur.nl www.wur.eu/marine-research

Visitors' address

- Ankerpark 27, 1781 AG Den Helder

- Korringaweg 7, 4401 NT Yerseke

- Haringkade 1, 1976 CP IJmuiden
With knowledge, independent scientific research and advice, Wageningen Marine Research substantially contributes to more sustainable and more careful management, use and protection of natural riches in marine, coastal and freshwater areas.
Wageningen Marine Research is part of Wageningen University \& Research. Wageningen University \& Research is the collaboration between Wageningen University and the Wageningen Research Foundation and its mission is: 'To explore the potential for improving the quality of life' 